Cristiano Minotti

\title{
Estimador Fuzzy de Velocidade Para Motores de Indução Trifásicos Usando Abordagem Sensorless
}

\author{
Dissertação apresentada à Escola de \\ Engenharia de São Carlos da \\ Universidade de São Paulo, sendo \\ parte dos requisitos para obtenção do \\ título de Mestre em Engenharia \\ Elétrica.
}

Área de Concentração: Sistemas Dinâmicos

Orientador: Prof. Dr. Ivan Nunes da Silva

São Carlos 

"Dedico este trabalho aos meus pais e ao meu filho, Cássio". 



\section{Agradecimentos}

Gostaria neste item de expressar todo apreço àqueles que ao longo desta jornada tornaram este trabalho possível, bem como fazê-lo melhor.

À Deus, pelo dom maravilhoso da vida e por ter me permitido esta realização.

Aos meus pais, que desde a mais tenra idade, direcionaram-me no caminho do estudo e aqui, um dos frutos mais notáveis desta conduta.

Sem dúvida, ao Prof. Dr. Ivan Nunes da Silva, por ter acreditado e me acolhido prontamente quando cheguei à EESC, e na circunstância, após infindáveis e ainda presentes dificuldades particulares.

Aos amigos do LAIPS - Laboratório de Automação Inteligente de Processos e Sistemas, especialmente ao Prof. Dr. Alessandro Goedtel, que fez inúmeras e valorosas sugestões, ao Eng. Msc. Sérgio Ferreira da Silva, pelas inúmeras contribuições na etapa de interfaceamento Matlab $^{\circledR}-$ Simulink $^{\circledR}$ e ao Eng. Msc. Marcelo Suetake, por contribuições diversas que aqui compõem este trabalho como um todo e a todos outros que acompanharam esta jornada: Eng. Dr. Antonio Vanderlei Ortega, Eng. Msc. Danilo Hernani Spatti, Eng. Msc. Fernando Ranieri, Eng. Ricardo Augusto de Souza Fernandes, Eng. Msc. Rodrigo Antonio Faccioli, se não por adendos acadêmicos, mas pelas palavras sábias em momentos difíceis.

À minha namorada Ximene, que esteve comigo ao longo de toda esta jornada, apoiando e incentivando sempre.

À CAPES - Coordenação de Aperfeiçoamento de Pessoal de Nível Superior, pelo auxílio financeiro concedido em grande parte do período de realização deste 
trabalho, sem o qual o mesmo não seria possível, bem como no auxílio das publicações que são frutos deste trabalho.

À FAPESP - Fundação de Amparo a Pesquisa do estado de São Paulo, nos processos $n^{\circ}$. 06/5693-3 e $n^{\circ}$. 03/11353-0, que foram o fomento do projeto que inspirou o presente trabalho. 
"Caiam mil ao seu lado e dez mil à sua direita, a você, nada atingirá"

Salmos 91,7 



\section{Resumo}

MINOTTI, C. (2008). Estimador Fuzzy de Velocidade Para Motores de Indução Trifásicos Usando Abordagem Sensorless. Dissertação (Mestrado) - Escola de Engenharia de São Carlos, Universidade de São Paulo, 2008.

O uso da tecnologia sensorless é uma tendência crescente para acionamentos industriais aplicados em máquinas elétricas. A estimação dos parâmetros elétricos e mecânicos envolvidos com o controle da máquina elétrica são utilizados freqüentemente para se evitar medir todas as variáveis envolvidas no processo. A redução de custos em acionamentos industriais, além do incremento da robustez do sistema, são algumas das vantagens do uso de técnicas sensorless. Este trabalho propõe o uso de lógica fuzzy para estimar a velocidade de rotação de motores de indução trifásicos. Estão presentes resultados de simulações computacionais e comparação com outras técnicas inteligentes para validação da abordagem apresentada.

Palavras chave: Motor de indução trifásico, sistemas fuzzy, estimadores de velocidade sensorless, sistema de inferência fuzzy. 



\section{Abstract}

MINOTTI, C. (2008). Speed Fuzzy Estimator for Three-Phase Induction Motors Using Sensorless Approach. Dissertation (Master's Degree) - Escola de Engenharia de São Carlos, Universidade de São Paulo, 2008.

The use of sensorless technologies is an increasing tendency on industrial drives for electrical machines. The estimation of electrical and mechanical parameters involved with the electric machine control is used very frequently in order to avoid measurement of all variables from this process. The cost reduction may also be considered in industrial drives, besides the increasing robustness of the system, as advantages of the use of sensorless technologies. This work proposes the use of fuzzy logic to estimate the speed in three-phase induction motors. Simulation results are presented to validate the proposed approach and comparative analyses with other intelligent techniques are also outlined.

Keywords: Three-phase induction motor, fuzzy systems, sensorless technique, intelligent systems. 



\section{Lista de Siglas e Abreviaturas}

$\begin{array}{ll}\text { ANFIS } & \text { Adaptive Neuro-Fuzzy Inference System } \\ \text { CA } & \text { Corrente Alternada } \\ \text { DC } & \text { Direct Current } \\ \text { DTC } & \text { Direct Torque Control } \\ \text { DSP } & \text { Digital Signal Processor } \\ \text { EPE } & \text { Empresa de Pesquisa Energética } \\ \text { FEM } & \text { Força Eletromotriz } \\ \text { FMM } & \text { Força Magneto-Motriz } \\ \text { GUI } & \text { Ghaphical User Interface } \\ \text { LN } & \text { Lógica Nebulosa } \\ \text { LPF } & \text { Low-Pass Filter } \\ \text { MI } & \text { Motor de Indução } \\ \text { MIT } & \text { Motor de Indução Trifásico } \\ \text { PMSM } & \text { Permanent Magnet Synchronous Motor } \\ \text { RMS } & \text { Root Mean Square } \\ \text { RNA } & \text { Reurais Artificiais } \\ & \text { Modes }\end{array}$





\section{Lista de Figuras}

Figura 2.1 - Atração/repulsão de condutores elétricos em função do sentido da corrente transportada.

Figura 2.2 - Solenóide e linhas de campo magnético.

Figura 2.3 - Condutor transportando corrente imerso em um campo magnético......14

Figura 2.4 - Condutor elétrico movendo-se ao longo de um campo magnético........16

Figura 2.5 - Correntes circulantes no estator 20

Figura 2.6 - Diagramação da produção de um campo magnético girante constante sob velocidade síncrona.

Figura 2.7 - Princípio de funcionamento do Ml.

Figura 2.8 - Vista espacial da conseqüência da aplicação da transformação

$\alpha \beta 0$. 30

Figura 2.9 - Transformação de coordenadas. 32

Figura 2.10 - Principais tipos de cargas presentes no ambiente industrial.

Figura 3.1 - Representação comparativa de um conjunto convencional e um conjunto fuzzy.......

Figura 3.2 - Função de pertinência gaussiana

Figura 3.3 - Esquematização gráfica de um sistema fuzzy genérico.

Figura 3.4 - Esquematização gráfica da inferência TS.

Figura 3.5 - Exemplo de estrutura em camadas da arquitetura ANFIS com três

entradas.

Figura 4.1 - Visão geral do sistema estimador de velocidade fuzzy.

Figura 4.2 - Funções de pertinência para a variável tensão (V). 65

Figura 4.3 - Funções de pertinência para a variável corrente (A). 
xvi

Figura 4.4 - Esquematização gráfica da estratégia de obtenção de estimação de velocidade com uso de lógica fuzzy. 68

Figura 5.1 - Resposta do estimador de velocidade fuzzy diante de uma situação de carga quadrática, com alimentação de 203V

Figura 5.2 - Resposta do estimador de velocidade fuzzy diante de uma situação de carga quadrática, com alimentação de 220V.

Figura 5.3 - Resposta do estimador de velocidade fuzzy diante de uma situação de carga quadrática, com alimentação de $242 \mathrm{~V}$. 73

Figura 5.4 - Resposta do estimador de velocidade fuzzy diante de uma situação de carga linear, com alimentação de 200V. 75

Figura 5.5 - Resposta do estimador de velocidade fuzzy diante de situação de carga linear, com alimentação de 220V.

Figura 5.6 - Resposta do estimador de velocidade fuzzy diante de uma situação de carga linear, com alimentação de 240V.

Figura 5.7 - Resposta do estimador de velocidade fuzzy diante de uma situação de carga inversa, com alimentação de 203V.

Figura 5.8 - Resposta do estimador de velocidade fuzzy diante de uma situação de carga inversa, com alimentação de 220V. 80

Figura 5.9 - Resposta do estimador de velocidade fuzzy diante de uma situação de carga inversa, com alimentação de $242 \mathrm{~V}$.

Figura 5.10 - Resposta do estimador de velocidade fuzzy diante de uma situação de carga constante com alimentação de $207 \mathrm{~V}$ e torque de carga abaixo do nominal 
Figura 5.11 - Resposta do estimador de velocidade fuzzy diante de uma situação de carga constante com alimentação de $220 \mathrm{~V}$ e torque nominal.

Figura 5.12 - Resposta do estimador de velocidade fuzzy diante de uma situação de carga constante com alimentação de $239 \mathrm{~V}$ e torque de carga abaixo do nominal.

Figura 5.13 - Resposta do estimador de velocidade fuzzy diante da imposição de um degrau de torque de carga. .86

Figura B.1 - GUI do ANFIS no ambiente MatLab ${ }^{\circledR}$ .99

Figura B.2 - Estrutura da arquitetura do ANFIS para o estimador de velocidade fuzzy 100

Figura B.3 - Tela do ANFIS durante uma simulação de carga inversa. 102 



\section{Lista de Tabelas}

Tabela 4.1 - Parâmetros do MIT usado para simulações. 62

Tabela 4.2 - Equacionamento das cargas presentes no ambiente industrial. .63

Tabela 5.1 - Resultados do estimador fuzzy em forma tabular, englobando todas as cargas abordadas. 



\section{SUMÁRIO}

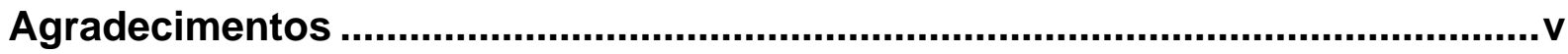

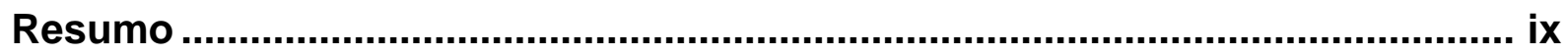

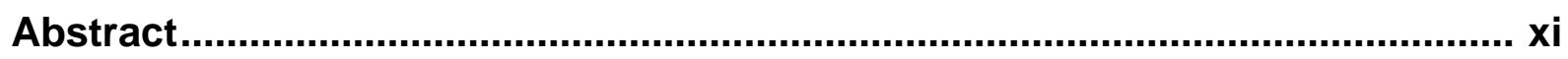

Lista de Siglas e Abreviaturas ................................................................ xiii

Lista de Figuras............................................................................................... XV

Lista de Tabelas ...........................................................................................

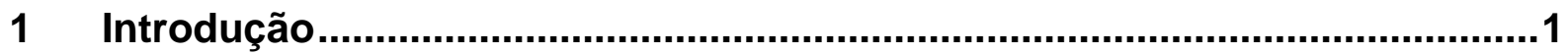

1.1 Motivação e Relevância do Trabalho ......................................................

1.2 Proposta e Justificativa da Dissertação.............................................. 4

1.3 Aplicações de Sistemas Inteligentes em Estimadores para Motores

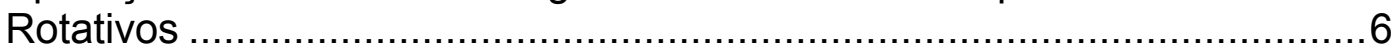

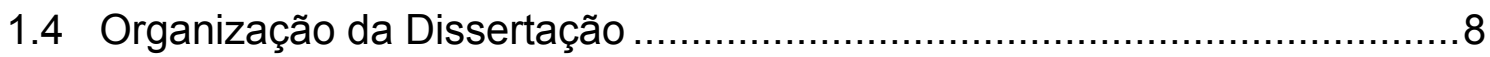

2 Motor de Indução Trifásico e Aspectos Característicos.............................11

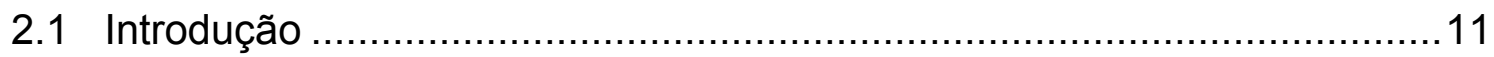

2.2 Princípio de Funcionamento do MIT .............................................. 11

2.2.1 A conversão eletromecânica de energia ..................................11

2.2.2 Máquinas de indução ou assíncronas trifásicas ..........................16

2.2.3 O princípio do motor de indução..............................................22

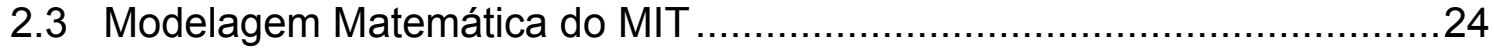

2.3.1 Estudo da transformação $\alpha \beta 0$............................................ 29

2.3.2 Estudo da transformação qd0......................................... 30

2.4 Classificação dos Principais Tipos de Cargas Acopladas ao Motor de

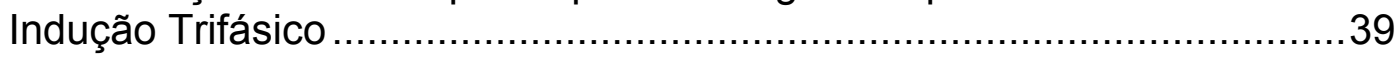

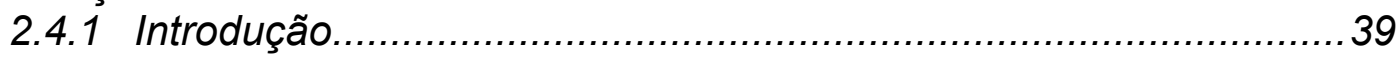

2.4.2 Carga quadrática ............................................................ 39

2.4.3 Carga linear ....................................................................... 40

2.4.4 Carga inversa ................................................................... 40

2.4.5 Carga constante ............................................................. 41

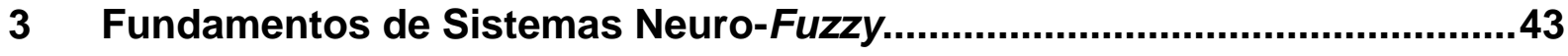

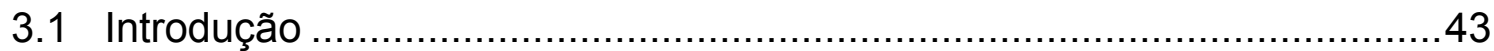

3.1.1 Os conjuntos fuzzy ......................................................... 44

3.1.2 Funções de pertinência fuzzy .......................................... 47

3.1.3 Composição estrutural de sistemas fuzzy .............................48 
3.2 Sistemas de Inferência Fuzzy Paramétricos ........................................ 49

3.3 Aspectos de Sintonização de Parâmetros em Sistemas de Inferência

Fuzzy Paramétricos .................................................................. 52

3.3.1 Introdução .................................................................. 52

3.3.2 Funcionamento do ANFIS..................................................... 54

4 Metodologia Proposta Para Estimação de Velocidade Usando

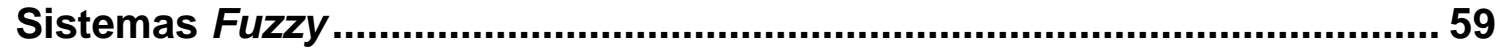

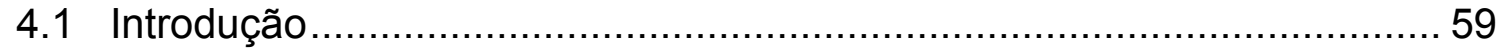

4.1.1 Características do estimador fuzzy .........................................6 60

4.2 Descrição da Estratégia de Obtenção das Curvas de Velocidade............. 60

4.2.1 Parâmetros de referência de simulação do MIT ........................... 61

4.3 Estrutura do Sistema Fuzzy Para Estimação de Velocidade no MIT ......... 63

4.3.1 Esquematização do processo de estimação de velocidade

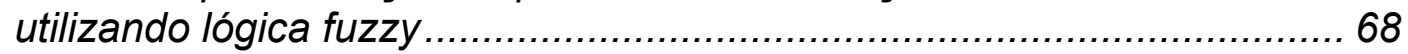

5 Resultados da Aplicação do Sistema Fuzzy para Estimação de

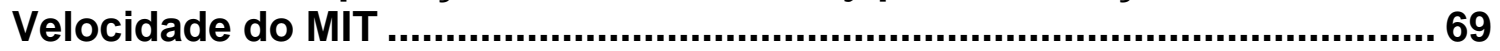

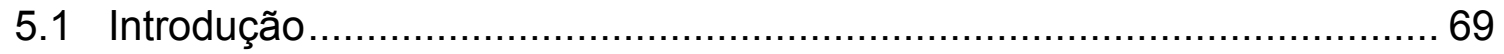

5.2 Resultados em Formato Gráfico ……………................................ 70

5.2.1 Estimação de velocidade considerando carga quadrática .............. 70

5.2.2 Estimação de velocidade considerando carga linear ...................... 74

5.2.3 Estimação de velocidade considerando carga inversa ................... 77

5.2.4 Estimação de velocidade considerando carga constante .............. 81

5.2.5 Estimação de velocidade para um degrau de carga ...................... 85

5.3 Resultados em Formato Tabular ........................................................ 86

6 Conclusões Gerais e Trabalhos Futuros ............................................... 89

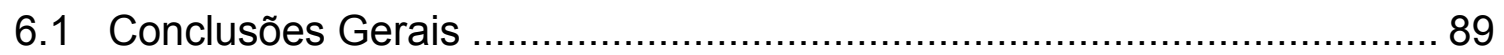

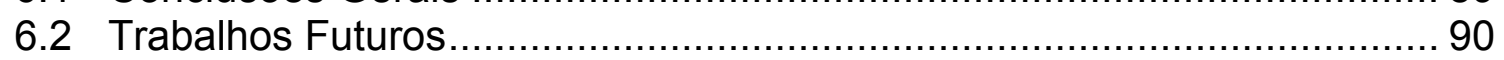

6.3 Publicações Relativas ao Trabalho..................................................... 91

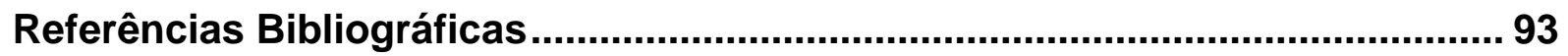

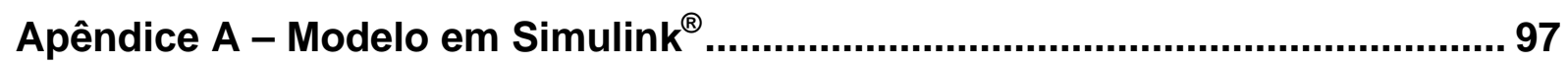

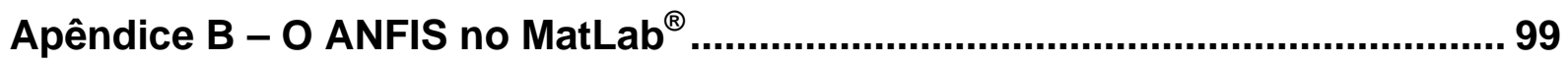




\section{Introdução}

\subsection{Motivação e Relevância do Trabalho}

O Motor de Indução Trifásico (MIT) tem amplo uso no setor industrial mundial. Devido ao fato de serem de construção simples, robustos e terem alta confiabilidade, são altamente empregados no setor produtivo. Estima-se que, no Brasil, os motores elétricos instalados nas plantas industriais são responsáveis por $49 \%$ do total destinado ao setor fabril (SOARES et al., 2000) e, mais atualmente, está num patamar de 50\%, segundo estudos da Empresa de Pesquisa Energética (Empresa de Pesquisa Energética, 2007). Nos EUA, estima-se que mais de 66\% da energia gerada é consumida por sistemas de acionamentos de máquinas elétricas (LU et al., 2006).

Porém, o MIT é extremamente dispendioso em termos energéticos quando mal-dimensionado para uma dada aplicação. Em média, nos EUA, motores em plantas industriais operam em $60 \%$ de sua capacidade por terem sido sobredimensionados para a aplicação em que estão sendo empregados (LU et al., 2006).

Em alguns casos, o procedimento de escolha de um motor baseia-se na experiência prévia do projetista, seguida de uma rotina de verificação. Se o motor escolhido, quando ligado ao processo, apresentar medidas de corrente acima da nominal e velocidade abaixo da nominal admissível, fica claro que a escolha deste motor tornou-se imprópria (GOEDTEL, 2003). Quando corretamente dimensionado, o motor trabalha em velocidade de operação próxima da velocidade síncrona do campo girante considerando seu número de par de pólos, incluindo o fator de escorregamento nominal. 
Partindo-se de sua análise matemática, é possível demonstrar que o MIT, trabalhando fora de sua faixa nominal, apresenta baixo fator de potência e queda de rendimento (BOSE, 1987), sendo extremamente dispendioso e provocando redução da sua vida útil (DIAS \& LOBOSCO, 1988),

Assim, conclui-se que a medida de velocidade da máquina é imprescindível para o seu dimensionamento adequado. Mesmo que as pesquisas avancem na concepção de um MIT de maior rendimento, de nada adiantará se este não for devidamente dimensionado para a aplicação em que fará o acionamento.

Por outro lado, em servo-sistemas, faz-se necessário conhecer esta informação para que a malha de controle seja adequadamente fechada (VAS, 1998), sendo a mesma fundamental para a concepção destes dispositivos, pois a realimentação da informação de velocidade faz com que o sistema de controle possa atuar devidamente. A estimativa de velocidade e torque aplicado no eixo de um Motor de Indução (MI) é imprescindível para desenvolvimento de técnicas adequadas que propiciem o controle, tanto em regime transitório como permanente (VAS, 1999).

Em técnicas como DTC (Direct Torque Control) e VC (Vetorial Control), utilizadas em sistemas de controle de alto desempenho, o uso de técnicas sensorless são bastante presentes. São encontradas principalmente em aplicações como acionamentos vetoriais e esquemas DTC (VAS, 1998).

Em estimadores sensorless, com o uso de sistemas inteligentes, as principais técnicas são abordagens usando redes neurais artificiais (RNA) e lógica nebulosa (LN), (GOEDTEL, 2007; VAS, 1998).

A forma convencional de medida de velocidade é feita diretamente no eixo da máquina através de encoders ópticos, resolvers eletromagnéticos, ou por 
tacogeradores DC brushless. Porém, o uso destes tipos de dispositivos eletromecânicos apresentam algumas limitações em sua aplicação, como o aumento do custo global do servo-sistema, redução da robustez mecânica e queda da imunidade a ruídos eletromagnéticos, requerendo atenção especial em ambientes hostis (VAS, 1998).

O uso da tecnologia sensorless é uma tendência crescente no controle do MIT. Os métodos de controle convencionais, como medida direta de torque e de velocidade da máquina, têm várias desvantagens, além do custo envolvido (GOEDTEL, 2006). Além disso, é uma forma de captura de dados não invasiva, vantagem "sine qua non" quando isto se faz necessário em equipamentos que usam o MIT e são lacrados pelos seus fabricantes, sendo que a violação do mesmo custa em perda de garantia (LU et al., 2006).

Especialmente em métodos com uso de encoders, o valor de velocidade é dado pela taxa de deslocamento angular por unidade de tempo. Tal deslocamento é obtido pela contagem do número de pulsos gerados pelo encoder. Este método tem desvantagens acentuadas em regimes de baixa rotação da máquina, pois a freqüência de contagem de pulsos cai, bem como a de amostragem, resultando em queda de desempenho e instabilidades no sistema (OHMAE et al., 1982).

Métodos convencionais de estimação de velocidade (GOEDTEL, 2006) são baseados em resolução de sistemas de equações do motor. É possível calcular, a partir de valores de tensão e corrente, a velocidade usando o conjunto de equações diferenciais do motor. Outros parâmetros a considerar são indutâncias e resistências, e os parâmetros mecânicos da máquina. As desvantagens deste método são: 
i) valores de indutâncias e resistências dos componentes da máquina estão indisponíveis na placa da mesma;

ii) necessidade de resolução de sistemas de equações diferenciais;

iii) a maioria dos sistemas são não-lineares e;

iv) requerem um custo computacional elevado.

Entretanto, conforme Goedtel (2007), não há consenso sobre um método genérico para estimação de velocidade visando atender às diversas necessidades para sistemas a laço aberto ou controle realimentado; quais sejam: i) regime permanente ou regime transitório, ii) alimentação senoidal ou não-senoidal, iii) variações paramétricas observadas ao longo de sua operação devido à temperatura, iv) variações paramétricas observadas ao longo de sua operação em regime transitório, v) variações de carga, vi) variação de tensão de alimentação, e vii) esforço computacional envolvido nesta estimativa.

\subsection{Proposta e Justificativa da Dissertação}

O presente trabalho tem a proposta de conceber um sistema estimador de velocidade sensorless com o uso de lógica fuzzy, sem outra estratégia qualquer (exceto em seu treinamento, onde se aplicam técnicas neuro-fuzzy), com abrangência desde sua partida até o regime permanente, considerando os principais tipos de cargas utilizados na indústria (DIAS \& LOBOSCO, 1988), tendo ainda simplicidade e baixo custo como principais vertentes. As potencialidades de um sistema fuzzy foram exploradas totalmente, em todos os aspetos (por questão de organização, estes detalhes serão explorados adequadamente no capítulo 
pertinente). Com a leitura de variáveis elétricas primárias, sendo estas a tensão e a corrente que alimentam o motor, a estimação de velocidade é então realizada.

Porém, para que o estimador seja aplicado em um ambiente industrial satisfatoriamente, conforme proposto, este deve ter a capacidade de lidar com as variações de tensão inerentes a este ambiente. Assim, conforme a norma NBR 7094 (2003), esta pode variar em um intervalo de $\pm 10 \%$. Deste modo, a faixa abordada pelo dispositivo está compreendida entre 198 a 242V RMS. Esta consideração é importante, pois o torque entregue à carga pelo motor tem uma relação quadrática com a tensão de alimentação (BOSE, 1987).

O sistema proposto neste trabalho é definido por um único bloco que engloba tanto a estimação de velocidade do motor em regime permanente como transitório, quer o motor esteja adequadamente dimensionado ou não. Assim, a proposta tem o caráter diferenciado no que tange ao aspecto de implementação do estimador, simplificando a estimativa de velocidade.

Outro fator a considerar é que os modelos desenvolvidos para sistemas dinâmicos, de complexidade considerável, são usualmente deficientes no que tange à modelagem de processos não-lineares, os quais são usualmente aproximados para sistemas lineares, sendo que para isto, desconsidera-se uma série de efeitos, chamando-os de "desprezíveis". Para a área de máquinas elétricas, estas idéias estão voltadas à desconsideração de saturação magnética, variações paramétricas em função da temperatura de operação do motor e efeito pelicular, sendo que o modelo linear então trata apenas do fluxo magnético e das perdas ôhmicas (resistivas). Neste sentido, a abordagem com sistemas fuzzy vem a contemplar uma lacuna importante, pois a habilidade deste em trabalhar com não-linearidades é uma 
de suas principais características, contornando este tipo de problema com eficiência e elegância.

\subsection{Aplicações de Sistemas Inteligentes em Estimadores para}

\section{Motores Rotativos}

A idéia de se usar um sistema fuzzy nos moldes propostos neste trabalho tem sua singularidade quando se analisa o estado da arte neste nicho de pesquisa.

As características de um sistema fuzzy o tornam uma poderosa ferramenta para aplicação na área de máquinas, principalmente pelo fato de tratar com facilidade não-linearidades e dispensar modelamentos matemáticos.

O escopo de aplicação de lógica fuzzy na estimativa de velocidade em motores de indução ainda é pequeno. Seu grande nicho tem sido a aplicação em controle para máquinas elétricas girantes em geral, inclusive no MIT. Deste modo, serão abordados trabalhos em seqüência de maior proximidade, em ordem decrescente com o escopo da presente dissertação.

Em comparação com outros trabalhos de mesmo nicho de pesquisa, cita-se o trabalho sobre estimador de velocidade sensorless, para uso no MI, utilizando-se de lógica fuzzy. López et al. (2002) abordam um sistema estimador de velocidade sensorless fuzzy que está dividido em duas partes: um sistema fuzzy dedicado à estimação de regime transitório e outro dedicado a regime permanente. Porém, para que o estimador venha a funcionar adequadamente, é necessário que haja um

seletor adequado para regime permanente e transitório. Além disso, quando a estimação se encontra em uma lacuna de indecisão do sistema, é proposto pelos 
autores a inclusão de um sistema que responda em termos de uma média ponderada entre os estimadores. Nisto, agregam-se outras estratégias, tais como técnicas de processamento de sinais, filtros adaptativos, onde, apesar de bons resultados obtidos pelos autores, a complexidade do sistema e o esforço computacional para implementação deste aparato elevam o custo. Em López et al. (2006), o trabalho anterior recebe avanços. Agora é usado um sistema fuzzy adaptativo que atua como filtro (para baixas rotações), onde que a freqüência de corte é feita de forma otimizada, e um segundo sistema fuzzy adaptativo responde pela média ponderada entre os estimadores de regime transitório e de regime permanente. Como CPU de implementação, é utilizado um DSP TMS320C32 Texas Instruments em conjunto com um computador PC. Na proposta e conclusão, é explicitado o intuito de um aparato de médio desempenho com baixo custo computacional. Porém, com o uso de um DSP e um PC simultaneamente para esta finalidade, o baixo custo computacional é uma afirmação discutível, principalmente tendo em vista a quantidade de implementações concebidas pelos autores.

Em Goedtel (2007) encontra-se um sistema estimador de velocidade sensorless com o uso de RNAs para esta finalidade. O autor trabalha com uma nova idéia para melhorar o sistema estimador, que é a bi-validação cruzada, ou seja, utilização de dados de simulação no treinamento e experimentais nos testes de generalização, para incremento do desempenho do sistema. Deste modo, consegue aprimorar a precisão do sistema estimador implementado, comprovado através de resultados apresentados.

No trabalho de Yusivar et al. (1999) os autores utilizam um sistema fuzzy para estimação de velocidade, tendo como entrada do mesmo um encoder de baixa resolução. Há uma preocupação no trabalho em fazer com que o estimador tenha 
bom desempenho em baixas velocidades, em torno de 25 rpm. Deste modo, há associado ao sistema estimador um filtro passa-baixas (LPF - Low-Pass Filter), que tem a finalidade de eliminar interferências provenientes da planta. Assim, o sistema, com a presença deste LPF, tem em sua resposta de estimação de velocidade overshoots provenientes do agregamento deste LPF. Mesmo descartando-o, o efeito não é eliminado totalmente, mas minimizado. Outro fator a comentar sobre este trabalho é de que o mesmo não se destina a aplicar com o MI, mas sim com um motor síncrono de imã permanente (PMSM - Permanent Magnet Synchronous Motor), utilizando para sua implementação um DSP (Digital Signal Processor) TMS320C32 (Texas Instruments), de $50 \mathrm{MHz}$, sendo que este fator diverge da proposta aqui apresentada, ou seja, de simplicidade na implementação.

Para estimadores de torque de carga, em Silva (2007) encontra-se um sistema de identificação sensorless com esta finalidade para o MIT baseado em sistemas fuzzy. O estimador também é, tal como deste trabalho, modelado com base nos principais tipos de carga encontrados na indústria (DIAS \& LOBOSCO, 1988).

Em Goedtel (2003), o autor concebe um estimador sensorless para o torque de carga aplicado no MIT que tem como base as RNAs, com o refinamento de que na modelagem matemática são considerados a saturação magnética e o efeito pelicular. As premissas são as mesmas do citado anteriormente.

\subsection{Organização da Dissertação}

Esta dissertação está organizada como se segue:

No Capítulo 2 são apresentados aspectos teóricos sobre o motor de indução trifásico, tais como seu princípio de funcionamento, sua modelagem matemática e 
também das cargas que estão acopladas ao mesmo visando composição de dados de simulação.

No Capítulo 3 são apresentados os principais aspectos relacionados aos sistemas de inferência fuzzy, bem como sua composição estrutural, sintonização de parâmetros.

No Capítulo 4 é apresentado o desenvolvimento de uma estrutura de estimação de velocidade em motores de indução trifásicos usando lógica fuzzy e as respectivas estratégias abordadas para esta finalidade.

No Capítulo 5 são apresentados os resultados obtidos pela aplicação do estimador de velocidade desenvolvido naquelas cargas descritas no Capítulo 2, além do degrau de carga. Avaliações de desempenho são efetuadas para validar a proposta apresentada.

No Capítulo 6 são tecidas as considerações finais, as conclusões relativas ao estimador de velocidade proposto, as publicações realizadas e propostas de trabalhos futuros que estão então previstos. 


\section{Motor de Indução Trifásico e Aspectos}

\section{Característicos}

\subsection{Introdução}

O MIT é, sem dúvida, uma das máquinas elétricas de característica mais notável. De construção extremamente simples, em especial o de gaiola de esquilo, a singularidade de sua concepção tange exatamente no aspecto da simplicidade construtiva em função do aproveitamento do princípio da indução eletromagnética. Em virtude disto, tem-se baixo custo, robustez e, portanto, alta empregabilidade.

Neste capítulo será feita uma explanação sobre o funcionamento do MIT, os princípios físicos que norteiam seu funcionamento e o equacionamento matemático sobre esta máquina elétrica, a qual é foco de aplicação do estimador de velocidade abordado.

\subsection{Princípio de Funcionamento do MIT}

\subsubsection{A conversão eletromecânica de energia}

Toda corrente elétrica que percorre um condutor elétrico está associada a um campo magnético e vice-versa. Deste modo, os dispositivos conversores de energia elétrica em mecânica utilizam-se de arranjos diversos de condutores para a produção de forças e torques, conforme o tipo de dispositivo. 
Quando dois condutores estão colocados em regiões próximas, as forças são determinadas pela intensidade e sentido da corrente. O princípio da indução eletromagnética, descoberto pelo físico e químico inglês Michael Faraday, em 1831, deu início à possibilidade de concepção da conversão eletromecânica de energia e das máquinas elétricas (motores e geradores), bem como outros baseados no mesmo princípio (KOSOV, 1998).

A Figura 2.1 mostra dois arranjos de condutores transportando correntes elétricas. O sentido do campo magnético produzido por cada corrente pode ser obtido pela "regra da mão direita", onde o polegar representa o sentido da corrente e os demais dedos indicam o sentido do campo magnético.
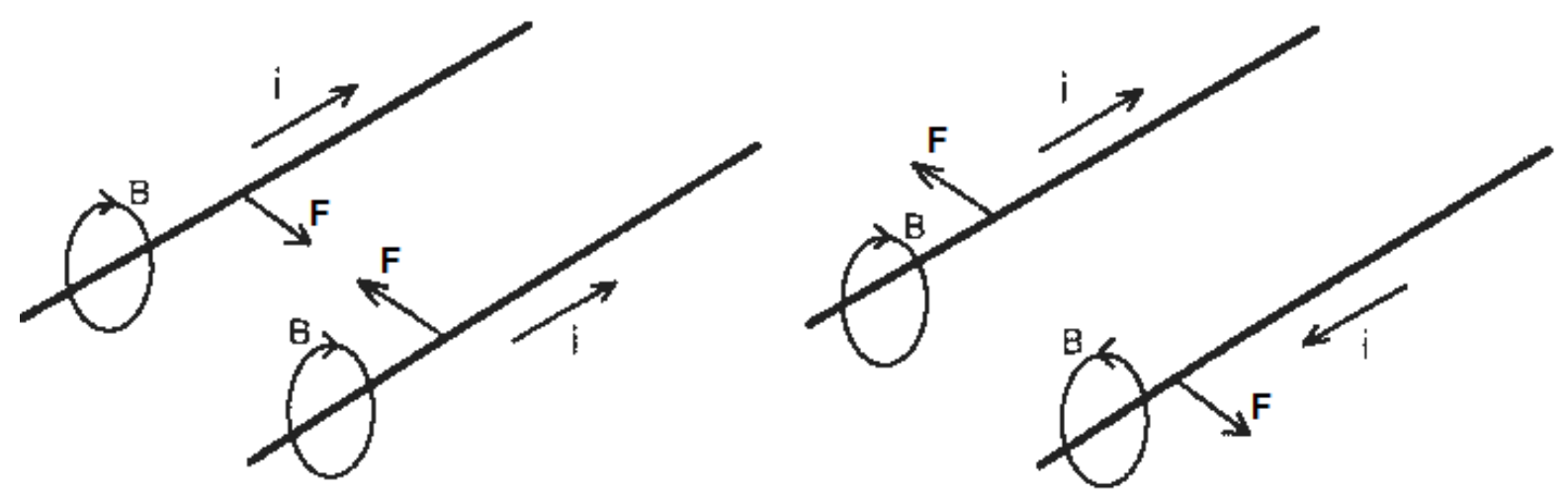

Figura 2.1 - Atração/repulsão de condutores elétricos em função do sentido da corrente transportada.

Porém, no arranjo mostrado, o campo fica espalhado ao longo do comprimento do condutor elétrico. Para contornar esta situação e concentrá-lo convenientemente, enrola-se o condutor elétrico, formando-se então um solenóide. Neste, com o bobinamento do condutor elétrico e a conseqüente aglutinação do campo em torno de um núcleo magnético, a distribuição de campo magnético toma a 
forma semelhante à de um imã permanente (CREPPE, 1999), conforme mostrado na Figura 2.2.

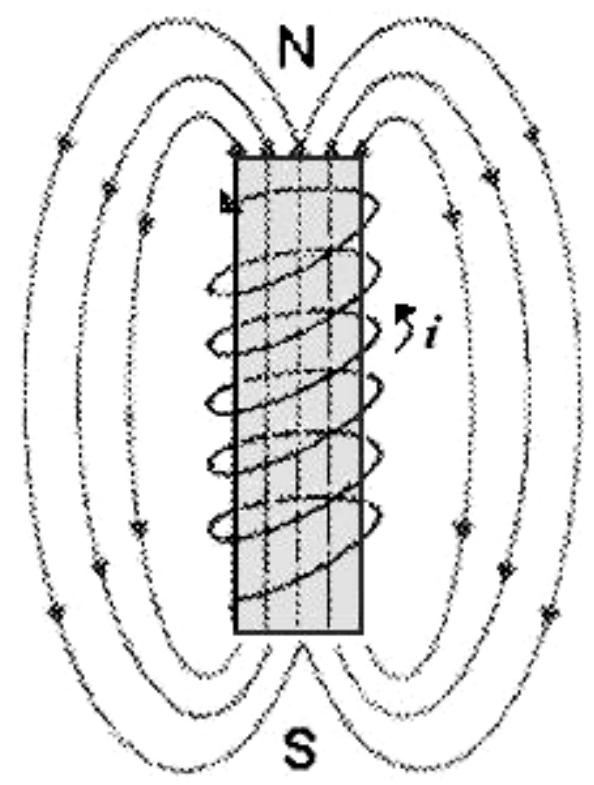

Figura 2.2 - Solenóide e linhas de campo magnético.

Ao contrário, se um condutor elétrico de comprimento $L$, conduzindo uma corrente $I$ for colocado dentro de um campo magnético de densidade $\vec{B}$, ortogonalmente às linhas de campo, este sofrerá a ação de uma força, conforme mostrado na Figura 2.3. O módulo da força é dado pelo produto mostrado na Equação (2.1) e o sentido da força é dado pela regra da mão esquerda (recebe o fluxo magnético pela palma da mão com o indicador mostrando o sentido da corrente elétrica, o polegar mostrará o sentido da força). Caso exista um ângulo diferente de $90^{\circ}$ entre a corrente e o campo, a força será afetada pelo seno deste ângulo $\alpha$.

$$
\vec{F}=\vec{B} . I . L . \operatorname{sen}(\alpha)
$$




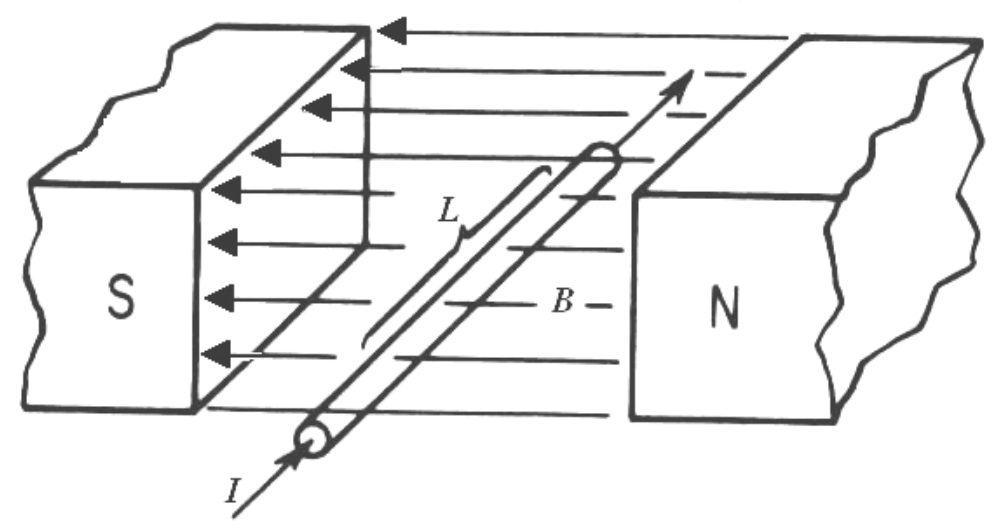

Figura 2.3 - Condutor transportando corrente imerso em um campo magnético.

Em 1820, o físico dinamarquês Christian Hans Öersted descobriu que toda a corrente elétrica está associada a um campo magnético; assim, é possível produzir um campo magnético através de uma corrente elétrica (CREPPE, 1999). O caminho inverso foi constatado pelas pesquisas de Faraday que, em 1831, mostrou que o movimento relativo entre um condutor e um campo magnético pode produzir uma diferença de potencial (força eletromotriz - FEM) no condutor. Se o condutor fizer parte de um circuito elétrico fechado, haverá então circulação de corrente no mesmo.

As pesquisas de Faraday, complementadas por Heinrich Lenz em 1833, determinaram os sentidos das FEM e das correntes induzidas, com o seguinte postulado: "Em todos os casos de indução eletromagnética, uma FEM induzida fará com que a corrente circule em um circuito fechado, num sentido tal que seu efeito magnético se oponha à variação que a produziu". Finalmente, James Clerk Maxwell (CREPPE, 1999) estabeleceu a forma quantitativa da lei da indução magnética, que é dada pela Equação (2.2):

$$
e=-\frac{d \theta}{d t}=-\frac{d(N \lambda)}{d t}=-N \frac{d \lambda}{d t}
$$


sendo:

e é a tensão induzida em Volts;

$\theta$ é o fluxo magnético em Webers;

$\lambda$ é o fluxo magnético concatenado em Webers;

$N$ é o número de espiras do indutor em questão.

Com a análise da Equação (2.2), onde o sinal negativo indica a oposição à variação, verifica-se que uma bobina com $N$ espiras colocada sob a ação de um campo que varia com o tempo sofre indução de uma tensão em seus terminais, sendo uma referência do fenômeno de força motriz variacional. O transformador é o exemplo clássico de dispositivo que usufrui deste fenômeno para seu funcionamento.

Os fluxos variantes no tempo, ou FEM variacional, produzidos por uma alimentação também variante no tempo (corrente alternada) no enrolamento primário, induzem tensões no enrolamento secundário que serão proporcionais ao fluxo magnético e ao número de espiras do enrolamento. O único acoplamento entre os enrolamentos primário e secundário é magnético.

Já uma FEM mocional é definida como sendo a tensão induzida em condutores em movimento em relação a um campo magnético estacionário ou viceversa. A Figura 2.4 mostra um condutor de comprimento $L$, movimentando-se com velocidade $V$ através de um campo magnético de densidade $\vec{B}$, cortando as linhas de fluxo. 


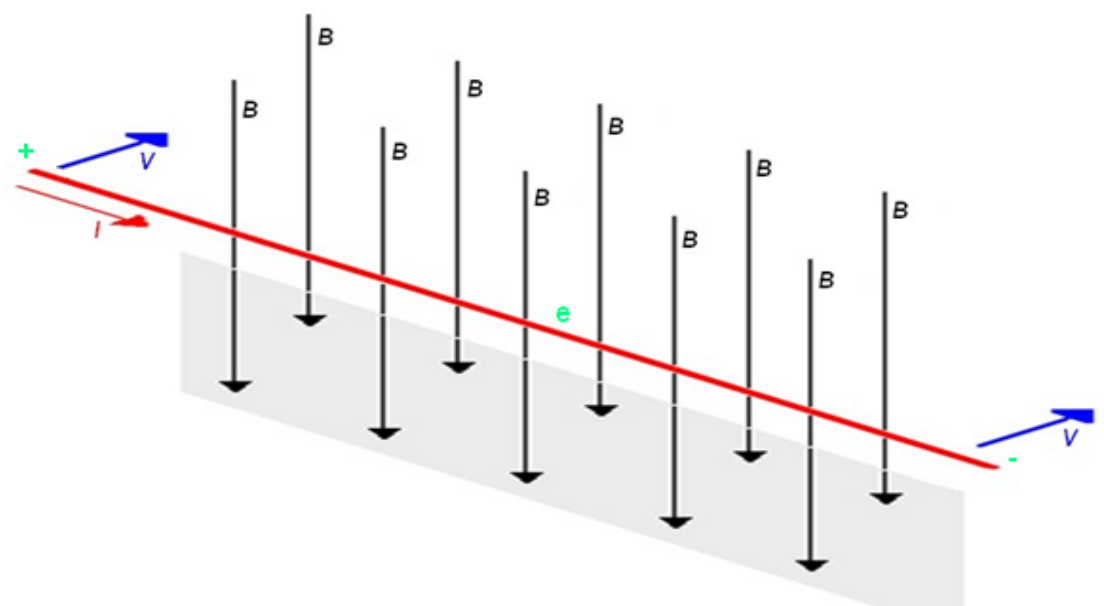

Figura 2.4 - Condutor elétrico movendo-se ao longo de um campo magnético.

Se a velocidade, o campo e o condutor são ortogonais entre si, o módulo da tensão induzida será o produto dado pela Equação (2.3).

$$
e=B . L . V
$$

O sentido da tensão é dado pela regra da mão direita (com o fluxo magnético entrando pela palma da mão e o polegar apontando no sentido da velocidade, então os demais dedos estarão indicando a extremidade positiva da tensão induzida).

\subsubsection{Máquinas de indução ou assíncronas trifásicas}

A enorme maioria dos $\mathrm{Ml}$ são rotativos, basicamente com um estator e um rotor, ambos lisos (CREPPE, 1999). Em consonância com este fato, os mesmos possuem um entreferro uniforme (SEN, 1989). O estator é um cilindro, onde são 
montados os enrolamentos de campo, imbricados em chapas metálicas (lâminas), que compõe a estrutura formadora do campo em torno do rotor.

A parte do motor que não gira, é estática (o estator) e engloba a parte que sofre rotação (o rotor) e o acoplamento entre estas partes é completamente isento de qualquer interação mecânica, considerando-se o chamado Ml de "gaiola de esquilo". A interação é apenas eletromagnética, sendo o fato singular salientado na introdução deste capítulo. Já em outros tipos de motores, como o síncrono e o de corrente contínua, utilizam-se escovas.

Existem motores de indução com rotor bobinado (ou enrolado) e são chamados comumente de motores de anéis (ONG, 1997), mas o mais comum, pelos motivos já expostos, é o de gaiola de esquilo.

O núcleo magnético do estator é composto por lâminas de aço empilhadas sistematicamente, espaçadas uniformemente na circunferência interna do cilindro estatórico, de modo a acomodar apropriadamente os enrolamentos das três fases. Para máquinas de $60 \mathrm{~Hz}$, a laminação tem espessura média em torno de $0,5 \mathrm{~mm}$ (ONG, 1997).

O rotor consiste de um cilindro laminado com núcleo de ferro com ranhuras uniformemente espaçadas, de modo a acomodar apropriadamente o bobinamento de rotor, considerando o caso de rotor bobinado. Para motores com rotor em gaiola de esquilo, este é composto de barras axiais de alumínio que são soldadas em anéis terminais contíguos em ambas as extremidades destas. Daí a procedência do nome, em comparação com o dispositivo entretecedor presente em gaiola de roedores, mais especificamente esquilos. Salienta-se que esta nomenclatura é mundial, presente em toda bibliografia pertinente. 
No MI, a corrente alternada é fornecida ao enrolamento do estator diretamente e, por conseqüência, ao enrolamento do rotor por indução eletromagnética, no caso do MIT tipo gaiola de esquilo. As correntes polifásicas equilibradas do estator e do rotor criam ondas de força magneto motriz - FMM, tendo componentes estatóricas e rotóricas de amplitude constante, girando no entreferro à velocidade síncrona e, portanto, estacionárias uma em relação à outra, independentemente da velocidade mecânica do rotor. A interação entre a onda de fluxo e a onda de FMM do rotor dá origem ao torque. Todas as condições são preenchidas para a produção de um valor de torque de regime permanente em todas as velocidades diferentes da velocidade síncrona (FITZGERALD, 1975).

Os bobinamentos são constituídos de bobinas interconectadas compostas de condutores de cobre ou alumínio. Os eixos dos enrolamentos de estator para uma máquina de $P$ pólos são espaçados por um fator $\{(2 / P)(2 \pi / 3)\}$ radianos, cada qual ocupando um mesmo número de ranhuras. Os terminais elétricos das três fases do estator podem estar conectados em delta ou estrela, conforme a tensão de alimentação da rede e de projeto da máquina (ONG, 1997).

Tendo em vista que as máquinas de indução são alimentadas, normalmente, apenas através do estator, pode-se, à primeira vista, considerá-las como máquinas de excitação única. Porém, como são induzidas correntes alternadas de freqüência variável no seu rotor, estas são na realidade máquinas de dupla excitação do ponto de vista magnético, embora possuam apenas uma alimentação externa (GONZAGA \& AMÊNDOLA, 2003; KOSOV, 1998).

Para que o motor de indução funcione, em seu estator, conforme mencionado, o bobinamento está estrategicamente disposto no intuito de conceber o chamado campo girante. Assim, este campo, girando à velocidade síncrona $n_{s}$, pode 
ser produzido por qualquer grupo polifásico de bobinas deslocados no espaço da armadura, desde que as correntes que circulem através delas também sejam defasadas no tempo (GONZAGA \& AMÊNDOLA; 2003, KOSOV, 1998). Então, a velocidade síncrona é expressa por:

$$
n_{s}=\frac{120 . f}{p}[\mathrm{rpm}]=\frac{2 \pi f}{p / 2}[\mathrm{rad} / \mathrm{s}]
$$

sendo:

$n_{s}$ é a velocidade síncrona em rpm ou rad/s;

f é a freqüência das correntes de alimentação em Hz; p é o número de pólos.

Todas as máquinas de indução trifásicas, portanto, a fim de produzirem um campo magnético de amplitude constante que gire à velocidade síncrona, necessitam de três bobinas individuais e idênticas, deslocadas no estator de $120^{\circ}$ elétricos e pelas quais circulem correntes, de mesmas amplitudes, defasadas também de $120^{\circ}$ elétricos no tempo. Na Figura 2.5 e Figura 2.6 está esquematizado graficamente o entendimento do campo girante. 


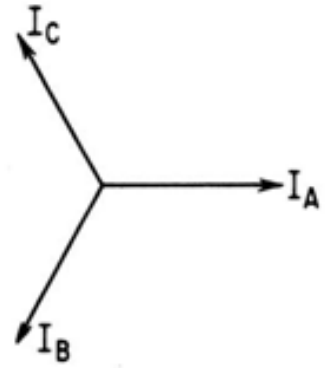

(a) Correntes defasadas de $120^{\circ}$ num enrolamento de armadura $3 \phi$.

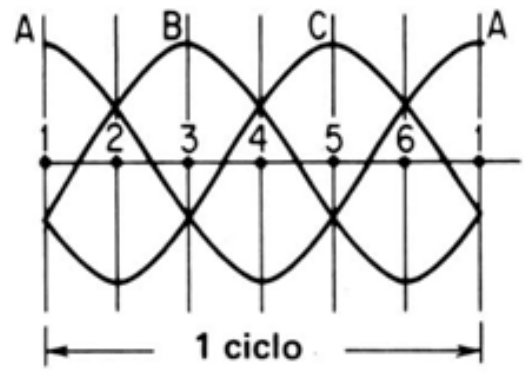

(b) Relações entre correntes de fasadas de $120^{\circ}$ no tempo.

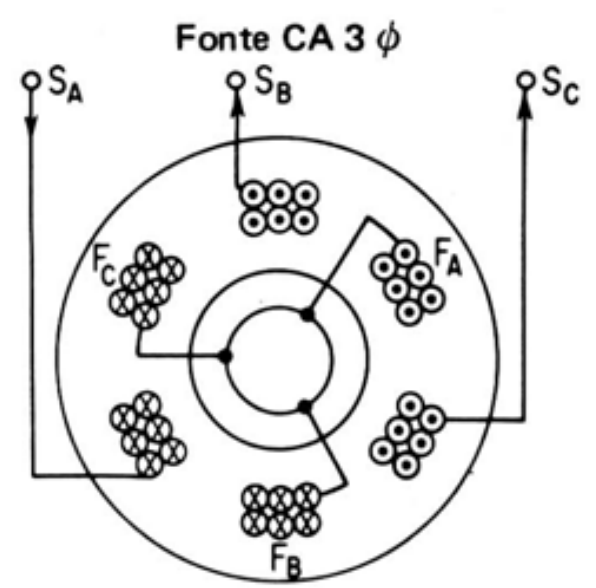

(c) Relações entre enrolamentos defasados de $120^{\circ}$ no espaço.

Figura 2.5 - Correntes circulantes no estator.

Na Figura 2.5(a) tem-se o diagrama fasorial das correntes que circulam no estator de uma máquina trifásica na seqüência $A B C$ e na Figura 2.5(b) tem-se a relação gráfica e as variações senoidais de cada corrente. A Figura 2.5(c) mostra o deslocamento espacial de um enrolamento trifásico de dois pólos (concentrado). Verifica-se que os inícios das bobinas são indicados por $S_{A}, S_{B}$ e $S_{C}$, por onde são alimentados e os términos por $F_{A}, F_{B}$ e $F_{C}$, que estão curto-circuitados, pois se trata de uma ligação tipo estrela. Assume-se que quando uma tensão positiva é aplicada ao enrolamento, a corrente entra por $S$ e sai por $F$ e quando é aplicada uma tensão negativa a corrente entra por $F$ e sai por $S$.

Na Figura 2.6 é então diagramado o resultado da aplicação das correntes mostradas na Figura 2.5. 


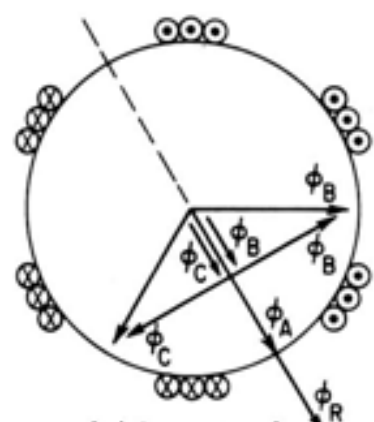

(a) Instante 1.

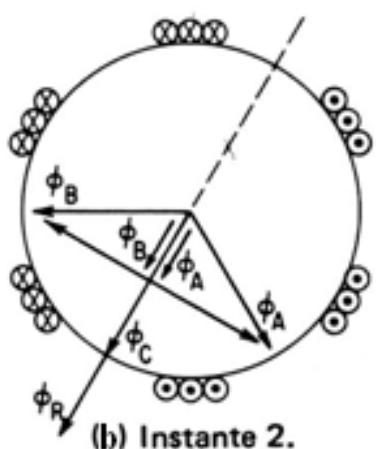

(b) Instante 2.

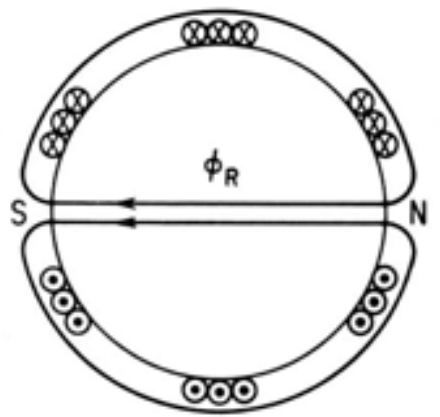

(c) Instante 3.

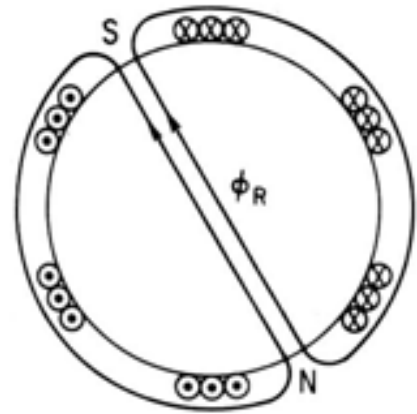

(d) Instante 4.

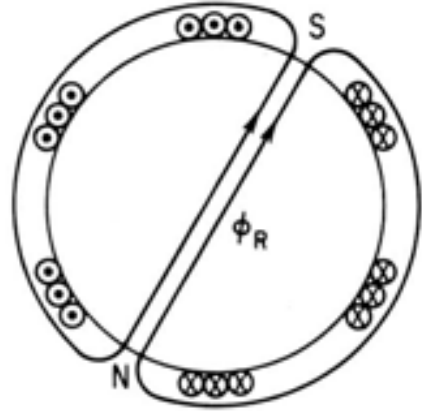

(e) Instante 5.

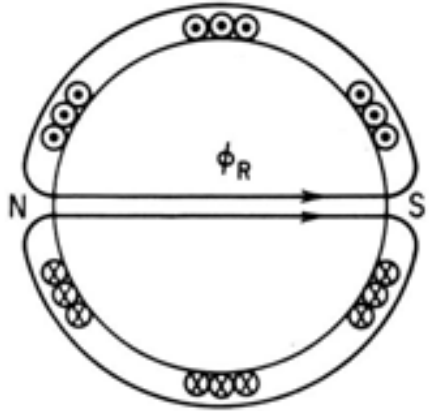

(f) Instante 6.

Figura 2.6 - Diagramação da produção de um campo magnético girante constante sob velocidade síncrona.

Com o ante exposto, é possível então iniciar a análise:

- No instante 1, indicado nas Figura 2.5(b) e Figura 2.6(a), a tensão é positiva e máxima, aplicada no enrolamento "A" e tensões negativas são aplicadas aos enrolamentos "B" e "C". Como conseqüência, a corrente $I_{A}$ entra por $S_{A}$ e sai por $F_{A}$, obtendo-se, através da regra da mão direita o fluxo $\phi_{A}$; a corrente $I_{B}$ entra por $F_{B}$ e sai por $S_{B}$, obtendo-se $\phi_{B} ; I_{C}$ entra por $F_{C}$ e sai por $S_{C}$, obtendo-se $\phi_{C}$. A direção e o sentido dos fluxos são indicados na figura e a soma vetorial dos três resulta no fluxo $\phi_{R}$.

- No instante 2, indicado nas Figura 2.5(b) e Figura 2.6(b), é aplicada a tensão negativa máxima no enrolamento " $C$ " e positiva nos enrolamentos "A" e " $B$ ". Analisando-se da mesma maneira que no instante 1 , constata-se que o fluxo 
girou $60^{\circ} \mathrm{e}$ isto se repete para todos os outros instantes, sendo que em um lado a corrente entra e no outro a corrente sai. Analogamente, é representado cada instante, da Figura 2.6(c) até a Figura 2.6(f) e a seqüência de fases na Figura 2.5(b).

Constatam-se, então, os seguintes fatos:

- Um único campo magnético girante constante é produzido por um enrolamento qualquer localizado no estator;

- O deslocamento no espaço do campo magnético girante corresponde exatamente ao deslocamento tempo-fásico da freqüência da fonte;

- Se duas fases da alimentação forem trocadas, ter-se-á a inversão da seqüência de fases e, obviamente, a reversão do sentido de rotação do motor;

- Nos demais instantes, a análise é semelhante, considerando-se o sentido das correntes.

\subsubsection{O princípio do motor de indução}

O princípio do motor de indução pode ser ilustrado pelo dispositivo ilustrado na Figura 2.7. Consiste de um ímã permanente, suspenso por um fio, que é posto a girar acima de um disco de cobre ou alumínio pivotado em um mancal de apoio sobre uma placa de ferro (GONZAGA \& AMÊNDOLA, 2003; KOSOV, 1998). 


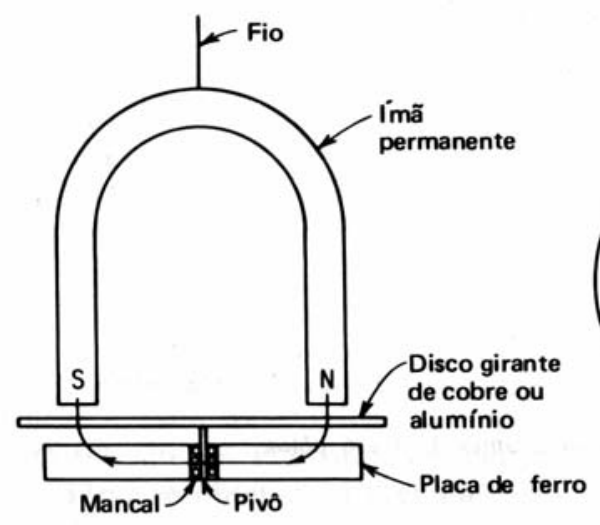

(a) Vista anterior.

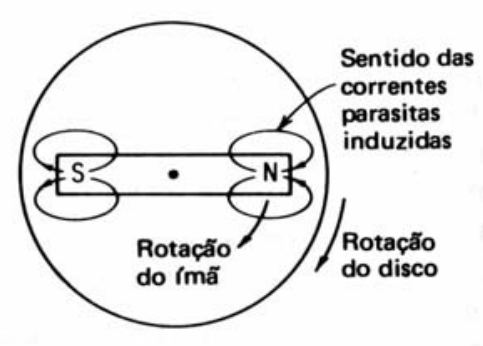

(b) Vista superior.

Figura 2.7 - Princípio de funcionamento do MI.

Conforme o ímã gira, o disco o acompanha, independentemente do sentido de rotação do ímã. Com o movimento relativo entre o campo magnético do ímã e o disco condutor, induzem-se, então, correntes no disco. Pela Lei de Lenz, estas correntes induzidas produzem um campo que se opõe à força, ou seja, ao movimento que produziu as correntes induzidas.

Como ilustrado na Figura 2.7(b), as correntes induzidas tendem a gerar um pólo-Sul sob o pólo-Norte do ímã e um pólo-Norte sob o pólo-Sul do ímã. Enquanto o ímã continua o seu movimento, novas linhas de fluxo são concatenadas pelo disco; as correntes continuam sendo induzidas e os pólos no disco continuarão a existir, logo, o disco continuará a girar. No entanto, o disco sempre girará a uma velocidade menor que o ímã. Caso a velocidade do disco seja igual à do ímã, as linhas de fluxo não serão mais concatenadas, as correntes não serão mais induzidas e os pólos induzidos no disco desapareceriam, fazendo com que o torque $e$, conseqüentemente, a velocidade extinguissem.

No motor de indução, nem a ação motora e nem a ação geradora poderão ocorrer à velocidade síncrona. Por isso, as máquinas de indução são classificadas 
como assíncronas, considerando os motivos anteriormente descritos (GONZAGA \& AMÊNDOLA, 2003; KOSOV, 1998).

Assim, o disco deve "escorregar" em velocidade a fim de que se produza torque. Isto resulta em uma diferença de velocidade denominado escorregamento, que é expressa como uma percentagem da velocidade síncrona conforme dada na equação seguinte:

$$
s=\frac{n_{s}-n_{r}}{n_{s}}
$$

sendo que:

$s$ é o escorregamento;

$n_{s}$ é a velocidade síncrona em rpm ou em rad/s;

$n_{r}$ é velocidade do rotor em rpm ou em $\mathrm{rad} / \mathrm{s}$.

Nesta equação, o escorregamento será nulo quando a velocidade de rotor for igual à velocidade síncrona. Nesta circunstância, não haverá indução no rotor, conforme já justificado.

\subsection{Modelagem Matemática do MIT}

Para esta tarefa, adotar-se-ão as seguintes convenções iniciais, a saber: o modelamento a seguir não leva em conta efeitos de saturação magnética do núcleo, efeito pelicular (skin) e outros, tais como correntes parasitas (Foucault). Além disso, há outros importantes aspectos a considerar para desenvolvimento deste modelamento (BARBI, 1985), a saber:

- Os bobinamentos das fases de estator têm a mesma composição; 
- Os bobinamentos das fases de rotor têm a mesma composição;

- Os ângulos elétricos entre os enrolamentos são iguais, tanto no estatórico quanto rotórico, e valem $120^{\circ}$ ou $2 \pi / 3$ radianos elétricos;

- O entreferro é considerado constante, sem ranhuras no mesmo;

- A distribuição da densidade de fluxo magnético no entreferro é radial e senoidal; sem perdas magnéticas quaisquer, a máquina será considerada bipolar.

E, como conseqüência destas aproximações, tem-se um circuito magnético linear, permitindo a aplicação do princípio de superposição, assim, o fluxo total é a soma do fluxo estatórico e rotórico; ou seja:

$$
\phi_{\text {total }}=\sum_{i=1}^{3} \phi_{R i}+\sum_{i=1}^{3} \phi_{S i}
$$

sendo:

$\phi_{R i}$ é o fluxo produzido pelo enrolamento $i$ do rotor e;

$\phi_{S i}$ é o fluxo produzido pelo enrolamento $i$ do estator.

As indutâncias próprias de todos os enrolamentos serão constantes, ou seja, não existirá o torque de relutância.

Como as bobinas das fases do estator são iguais, então as suas indutâncias próprias serão iguais e as resistências também. Assim: $L_{S_{1}}=L_{S_{2}}=L_{S_{3}}=L_{s}$ e $=R_{S_{1}}=$ $R_{S_{2}}=R_{S_{3}}=R_{S}$. Analogamente, para o rotor: $L_{R_{1}}=L_{R_{2}}=L_{R_{3}}=L_{R}$ e $R_{R_{1}}=R_{R_{2}}=$ $R_{R_{3}}=R_{R}$ 
Como as defasagens das bobinas também são iguais, as indutâncias mútuas entre bobinas de mesmo enrolamento também serão iguais, tanto no estator quanto no rotor. Assim: $M_{S_{12}}=M_{S_{23}}=M_{S_{13}}=M_{S}$ e $M_{R_{12}}=M_{R_{23}}=M_{R_{13}}=M_{R}$.

As indutâncias mútuas entre as fases dos enrolamentos estatóricos e rotóricos são funções senoidais do deslocamento angular $\theta$ e terão mesmo valor máximo $M_{S R}$.

Assim, pode-se iniciar de fato a modelagem em si com as equações de tensão estatóricas e rotóricas do MIT.

As equações de tensão estatóricas são escritas da seguinte maneira:

$$
v_{j s}=i_{j s} r_{s}+\frac{d \theta_{j s}}{d t}
$$

Analogamente, escrevem-se as equações de tensão rotóricas:

$$
v_{j r}=i_{j r} r_{r}+\frac{d \theta_{j r}}{d t}
$$

sendo que:

j é a representação de uma das três fases quaisquer, ou seja, $A, B$ ou $C$;

$r$ é a resistência do enrolamento em questão, dado em Ohms;

$v$ é a tensão estatórica ou rotórica, dada em Volts;

$\theta$ é o fluxo magnético para qualquer uma das fases, dado em Webers;

i é a corrente elétrica, dada em Ampères, para cada fase. 
27

Dispondo-se das equações de tensões, pode-se então desenvolver as equações de fluxo concatenado estatórico e rotórico, denotadas em formato matricial, de modo a compactar o equacionamento:

$$
\left[\begin{array}{l}
\lambda_{s}^{j} \\
\lambda_{r}^{j}
\end{array}\right]=\left[\begin{array}{cc}
L_{s s}^{j} & L_{s r}^{j} \\
L_{r s}^{j} & L_{r r}^{j}
\end{array}\right] \cdot\left[\begin{array}{l}
i_{s}^{j} \\
i_{r}^{j}
\end{array}\right]
$$

sendo:

$\lambda_{s}^{j}=\left[\begin{array}{lll}\lambda_{a s} & \lambda_{b s} & \lambda_{c s}\end{array}\right]^{T}$ é o fluxo concatenado estatórico por fase;

$\lambda_{r}^{j}=\left[\begin{array}{lll}\lambda_{a r} & \lambda_{b r} & \lambda_{c r}\end{array}\right]^{T}$ é o fluxo concatenado rotórico por fase;

$i_{s}^{j}=\left[\begin{array}{lll}i_{a s} & i_{b s} & i_{c s}\end{array}\right]^{T}$ é o vetor corrente de estator por fase;

$i_{r}^{j}=\left[\begin{array}{lll}i_{a r} & i_{b r} & i_{c r}\end{array}\right]^{T}$ é o vetor corrente de rotor por fase.

As submatrizes de indutâncias estator-estator e rotor-rotor (indutâncias próprias) e estator-rotor (indutância mútua) são apresentadas respectivamente a seguir. Para esta última, salienta-se a dependência do ângulo de rotor.

$$
\begin{gathered}
L_{s s}^{j}=\left[\begin{array}{ccc}
L_{l s}+L_{s m} & L_{s m} & L_{s m} \\
L_{s m} & L_{l s}+L_{s m} & L_{s m} \\
L_{s m} & L_{s m} & L_{l s}+L_{s m}
\end{array}\right] \\
L_{r r}^{j}=\left[\begin{array}{ccc}
L_{l r}+L_{r m} & L_{r m} & L_{r m} \\
L_{r m} & L_{l r}+L_{r m} & L_{r m} \\
L_{r m} & L_{r m} & L_{l r}+L_{r m}
\end{array}\right]
\end{gathered}
$$




$$
L_{s r}^{j}=\left[L_{r s}^{j}\right]^{t}=L_{s r}=\left[\begin{array}{ccc}
\cos \theta_{r} & \cos \left(\theta_{r}+\frac{2 \pi}{3}\right) & \cos \left(\theta_{r}-\frac{2 \pi}{3}\right) \\
\cos \left(\theta_{r}-\frac{2 \pi}{3}\right) & \cos \theta_{r} & \cos \left(\theta_{r}+\frac{2 \pi}{3}\right) \\
\cos \left(\theta_{r}+\frac{2 \pi}{3}\right) & \cos \left(\theta_{r}-\frac{2 \pi}{3}\right) & \cos \theta_{r}
\end{array}\right]
$$

sendo:

$L_{s s}$ é a indutância de dispersão estatórica [H];

$L_{\text {rr }}$ é a indutância de dispersão rotórica $[\mathrm{H}]$;

$L_{s s}$ é a indutância própria estatórica $[\mathrm{H}]$;

$L_{r r}$ é a indutância própria rotórica $[\mathrm{H}]$;

$L_{s m}$ é a indutância mútua estatórica $[\mathrm{H}]$;

$L_{r m}$ é a indutância mútua rotórica $[\mathrm{H}]$;

$L_{s r}$ é a indutância mútua rotórica / estatórica;

$N_{s}$ e $N_{r}$ é o número de espiras dos enrolamentos rotórico e estatórico, respectivamente.

Desprezando-se as perdas de entreferro e magnéticas, expressam-se estas indutâncias em termos de número de espiras dos enrolamentos estatórico e rotórico, $N_{s}$ e $N_{r}$, e da permeância $P_{g}$ do entreferro, com o uso das seguintes relações:

$$
\begin{gathered}
L_{s s}=N_{s}^{2} P_{g} \\
L_{s m}=N_{s}^{2} P_{g} \cos \left(\frac{2 \pi}{3}\right) \\
L_{s r}=N_{S} N_{r} P_{g}
\end{gathered}
$$




$$
\begin{gathered}
L_{r r}=N_{r}^{2} P_{g} \\
L_{r m}=N_{r}^{2} P_{g} \cos \left(\frac{2 \pi}{3}\right)
\end{gathered}
$$

Do exposto, nota-se que uma máquina idealizada é descrita por seis equações diferenciais de $1^{\mathrm{a}}$ ordem, uma para cada fase do enrolamento estatórico e rotórico. Estas equações diferenciais são acopladas uma à outra através das indutâncias mútuas existentes entre os enrolamentos, particularmente nos termos de acoplamento estator-rotor, que são função da posição rotórica; assim, quando o rotor gira, estes termos que acoplam as equações variam em função do tempo (ONG, 1997).

Transformações matemáticas como qd0 ou $\alpha \beta 0$ podem facilitar a resolução para resposta transitória pela transformação do modelo acima exposto de equações diferenciais com coeficientes variáveis no tempo em equações diferenciais com coeficientes constantes.

Estas transformações têm a finalidade de estabelecer modelos mais simples a partir do modelo original para estudo do comportamento da máquina (BARBI, 1995).

\subsubsection{Estudo da transformação $\alpha \beta 0$}

O primeiro passo a ser dado na obtenção de modelos mais adequados para a análise da máquina de indução e simplificá-los é a transformação $\alpha \beta 0$. 
Fisicamente, esta transforma a máquina simétrica trifásica em uma máquina simétrica bifásica, de mesma potência mecânica, torque, velocidade e número de pólos. Assim, é conhecida também como transformação trifásica-bifásica (BARBI, 1985).

Como conseqüência, o MIT será visto como sendo constituído apenas por duas bobinas fictícias defasadas espacialmente de $90^{\circ}$, nos enrolamentos estatórico e rotórico $(C A D, 2000)$ ao invés do sistema original, de 3 eixos defasados de $120^{\circ}$ entre si.
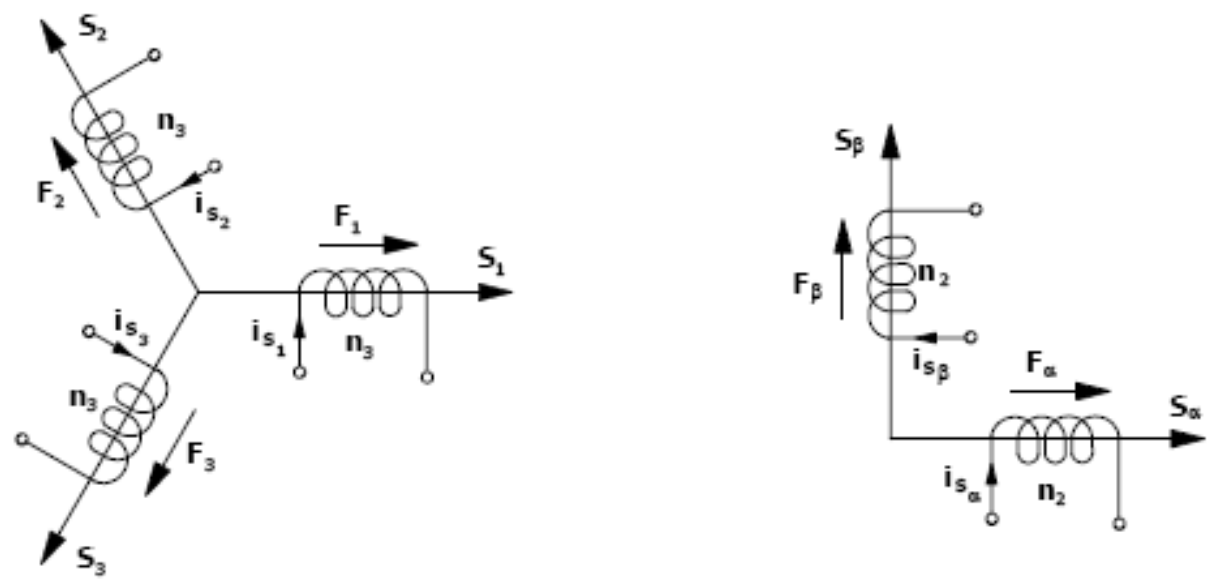

Figura 2.8 - Vista espacial da conseqüência da aplicação da transformação $\alpha \beta 0$.

Aqui, porém, a transformação $\alpha \beta 0$ será apenas visualizada como passo para a transformação qd0. Esta sim é a base da máquina simulada para a obtenção dos resultados para o estimador de velocidade.

\subsubsection{Estudo da transformação qdo}

A transformada de Park $(q d 0)$ transforma a máquina bifásica com enrolamentos estatóricos fixos e enrolamentos rotóricos girantes em enrolamentos 
estatóricos fixos e rotóricos pseudo-estacionários. As correntes dos enrolamentos fixos terão freqüências diferentes das correntes de enrolamentos girantes. O sistema de coordenadas qd0 é tradicionalmente escolhido em virtude da sua conveniência para a representação de outros elementos (ONG, 1997). Assim, para se analisar o MIT, utilizam-se os referenciais síncrono e estacionário. Deste modo, para análise de transitórios, é melhor o referencial fixo; já para regime permanente o referencial síncrono tem melhores atributos (ONG, 1997).

O sistema de coordenadas arbitrárias é formado pelo eixo $q$ (quadratura) e $d$ (direto) e zero. Aqui, salienta-se a inclusão da componente de seqüência zero, importante para a análise de sistemas assimétricos ou desbalanceados. Matematicamente, a componente de seqüência zero vem de uma condição da inversão da matriz de transformação.

Estabelecendo uma variável que faça a correspondência biunívoca entre os sistemas de coordenadas abc e qd0 (GOEDTEL, 2003, ONG, 1997), tem-se:

$$
f_{d q 0}=K^{-1} f_{a b c}
$$

sendo $K$ a relação entre as variáveis de ambos os sistemas de coordenadas.

A seguir, a Figura 2.9 representa a ação de transformação (ONG, 1997), onde $a_{s}, b_{s}$ e $c_{s}$ são os eixos de coordenadas com referencial estatórico e $a_{r}, b_{r}$ e $c_{r}$ são os eixos de coordenadas com referencial rotórico. 


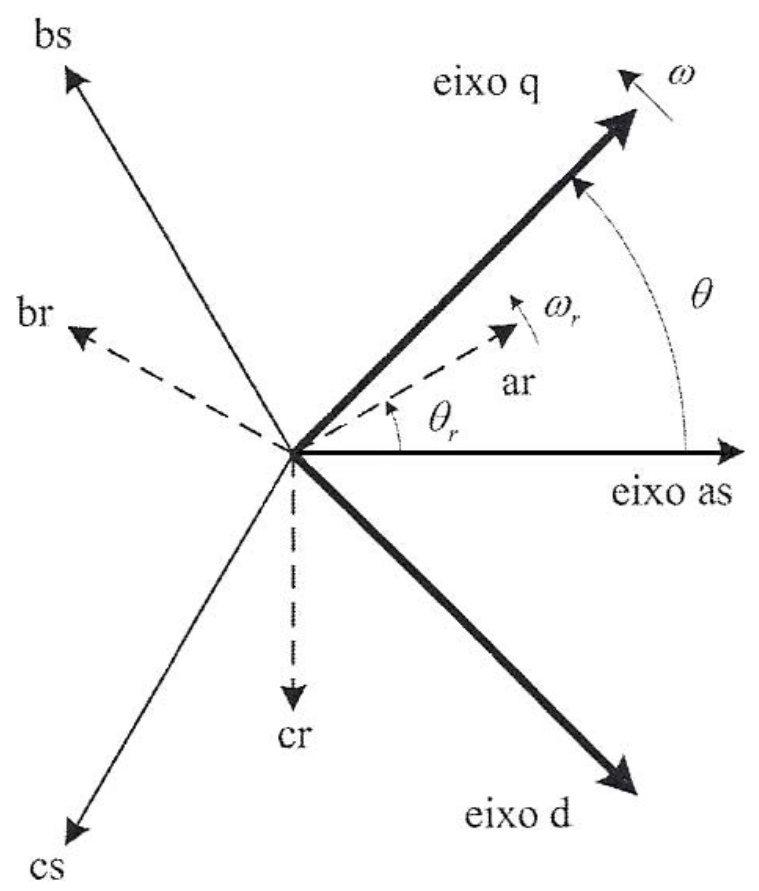

Figura 2.9 - Transformação de coordenadas.

De posse da correspondência biunívoca dos sistemas de coordenadas, podese proceder à transformação abc-qd0, conforme abaixo expresso:

$$
\left[\begin{array}{c}
f_{q} \\
f_{d} \\
f_{0}
\end{array}\right]=\left[T_{q d 0}(\theta)\right] \cdot\left[\begin{array}{c}
f_{a} \\
f_{b} \\
f_{c}
\end{array}\right]
$$

sendo que $f$ é o índice que pode representar as grandezas de tensão, corrente ou fluxo eletromagnético de cada fase.

A matriz de transformação $\left[T_{q d 0}(\theta)\right]$ é denotada por: 


$$
\left[T_{q d 0}(\theta)\right]=\frac{2}{3}\left[\begin{array}{ccc}
\cos \theta & \cos \left(\theta-\frac{2 \pi}{3}\right) & \cos \left(\theta+\frac{2 \pi}{3}\right) \\
\operatorname{sen} \theta & \operatorname{sen}\left(\theta-\frac{2 \pi}{3}\right) & \operatorname{sen}\left(\theta+\frac{2 \pi}{3}\right) \\
\frac{1}{2} & \frac{1}{2} & \frac{1}{2}
\end{array}\right]
$$

E a sua respectiva inversa é dada por:

$$
\left[T_{q d 0}(\theta)\right]^{-1}=\left[\begin{array}{ccc}
\cos \theta & \operatorname{sen} \theta & 1 \\
\cos \left(\theta-\frac{2 \pi}{3}\right) & \operatorname{sen}\left(\theta-\frac{2 \pi}{3}\right) & 1 \\
\cos \left(\theta+\frac{2 \pi}{3}\right) & \operatorname{sen}\left(\theta+\frac{2 \pi}{3}\right) & 1
\end{array}\right]
$$

As equações de tensão no sistema de coordenadas qd0, em notação matricial, para a tensão de enrolamento estatórico no sistema de coordenadas abc expressam-se por:

$$
V_{s}^{j}=i_{S}^{j} \cdot r_{S}^{j}+\frac{\mathrm{d} \lambda_{s}^{j}}{\mathrm{dt}}
$$

sendo $j$ uma das fases $a, b$ ou $c$.

Aplicando-se a matriz de transformação $K^{-1}=\left[T_{q d 0}(\theta)\right]$ em (2.22), encontrase a equação de tensão, agora no sistema de coordenadas qd0:

$$
V_{S}^{q d 0}=K^{-1} \cdot \frac{d(K)}{d t} \cdot \lambda_{S}^{q d 0}+K^{-1} \cdot r_{S}^{j} \cdot K \cdot I_{S}^{q d 0}
$$


De posse do valor da derivada de $\left\{T_{q d 0}(\theta)^{-1} \cdot \lambda_{s}^{q d 0}\right\}$, em relação a variável $t$, na Equação (2.23), encontra-se:

$$
V_{s}^{q d 0}=\omega\left[\begin{array}{ccc}
0 & 1 & 0 \\
-1 & 0 & 0 \\
0 & 0 & 0
\end{array}\right] \lambda_{s}^{q d 0}+\frac{d\left(\lambda_{s}^{q d 0}\right)}{d t}+r_{s}^{q d 0} i_{s}^{q d 0}
$$

sendo que $\omega \mathrm{e} r_{S}^{q d 0}$ são definidos por:

$$
\omega=\frac{d \theta}{d t}
$$

e

$$
r_{S}^{q d 0}=r_{s}\left[\begin{array}{ccc}
0 & 1 & 0 \\
-1 & 0 & 0 \\
0 & 0 & 0
\end{array}\right]
$$

Finalmente, o procedimento para obtenção da equação da tensão rotórica para o sistema de coordenadas qd0 é semelhante, sendo apresentada a seguir:

$$
V_{r}^{q d 0}=\left(\omega-\omega_{r}\right)\left[\begin{array}{ccc}
0 & 1 & 0 \\
-1 & 0 & 0 \\
0 & 0 & 0
\end{array}\right] \lambda_{r}^{q d 0}+\frac{d\left(\lambda_{r}^{q d 0}\right)}{d t}+r_{r}^{q d 0} i_{r}^{q d 0}
$$


As equações de fluxo do estator expressas em coordenadas qd0 são obtidas pela aplicação da matriz de transformação $\left[T_{q d 0}(\theta)\right]$ na equação de fluxo concatenado (2.9), da seguinte maneira:

$$
\lambda_{s}^{q d 0}=\left[T_{q d 0}(\theta)\right] \cdot\left(L_{s s}^{j} i_{s}^{j}+L_{s r}^{j} i_{r}^{j}\right)
$$

Desta forma, as equações de fluxo estatórico e rotórico tornam-se:

$$
\begin{gathered}
\lambda_{s}^{q d 0}=K^{-1} L_{s s}^{j} K i_{s}^{q d 0}+K^{-1} L_{s s}^{j} T_{q d 0}\left(\theta-\theta_{r}\right)^{-1} i_{r}^{q d 0} \\
\lambda_{r}^{q d 0}=G L_{r s}^{j} K i_{s}^{q d 0}+G L_{r r}^{j} G^{-1} i_{r}^{q d 0}
\end{gathered}
$$

sendo que o operador $G$ é dado por $T_{q d 0}\left(\theta-\theta_{r}\right)$.

A equação de torque no sistema de coordenadas qdo é proveniente do equacionamento desenvolvido até o momento para o MIT e levando-se em conta a transmissão de potência instantânea nos seis enrolamentos (ONG, 1997).

Em termos de coordenadas abc, é dada pela Equação (2.31):

$$
p_{i n}=v_{j s} \cdot i_{j s}+v_{j r}^{\prime} i_{j r}^{\prime}
$$

Para o sistema de coordenadas qd0, tem-se a soma de potências instantâneas com as componentes estatóricas e rotóricas, em $q$ e $d$. Além disso, há a componente homopolar (seqüência zero), como segue: 


$$
p_{i n}=\frac{3}{2}\left(v_{q s} \cdot i_{q s}+v_{d s} \cdot i_{d s}+2 v_{0 s} \cdot i_{0 s}+v_{q r}^{\prime} i_{q r}^{\prime}+v_{d r}^{\prime} i_{d r}^{\prime}+2 v_{0 r}^{\prime} i_{0 r}^{\prime}\right)
$$

Através das Equações (2.24) e (2.27) e a apropriada manipulação algébrica, são obtidos os termos: $i^{2} r$, ip $\lambda$ e $\varpi \lambda i$. O primeiro é alusivo às perdas no cobre (ôhmicas), já o segundo termo é relativo à taxa de energia trocada na forma de campo magnético entre os enrolamentos e o terceiro termo é relativo à energia convertida em trabalho mecânico. Assim, o torque eletromecânico desenvolvido pelo motor é obtido pela soma dos termos $\varpi \lambda i$ dividido pela velocidade mecânica, ou seja:

$$
T_{e m}=\frac{3}{2} \frac{P}{2 \omega_{r}}\left[\omega\left(\lambda_{d s} i_{q s}-\lambda_{q s} i_{d s}\right)+\left(\omega-\omega_{r}\right)\left(\lambda_{d r}^{\prime} i_{q r}^{\prime}-\lambda_{q r}^{\prime} i_{d r}^{\prime}\right)\right]
$$

A Equação (2.33) também pode ser escrita, de forma resumida, conforme segue:

$$
T_{e m}=\frac{3}{2} \frac{P}{2}\left(\lambda_{q r}^{\prime} i_{d r}^{\prime}-\lambda_{d r}^{\prime} i_{q r}^{\prime}\right)
$$

sendo que o termo $T_{e m}$ representa o torque eletromagnético desenvolvido pelo motor, $P$ é o número de pólos do motor de indução e as variáveis $\lambda_{q r}^{\prime}, \lambda_{d r}^{\prime}, i_{q r}^{\prime}$ e $i_{d r}^{\prime}$ são as grandezas de rotor referenciadas no estator e definidas por:

$$
\lambda_{q r}^{\prime}=\frac{N_{s}}{N_{r}} \lambda_{q r}
$$




$$
\begin{aligned}
& \lambda_{d r}^{\prime}=\frac{N_{s}}{N_{r}} \lambda_{d r} \\
& i_{d r}^{\prime}=\frac{N_{s}}{N_{r}} i_{d r} \\
& i_{q r}^{\prime}=\frac{N_{s}}{N_{r}} i_{q r}
\end{aligned}
$$

Enfim, é mais conveniente que o sistema de equações esteja expresso em termos das variáveis de $\psi$ (fluxo concatenado por segundo) e de $x$ (reatâncias), no lugar de $\lambda$ (fluxo magnético) e $L$ (indutâncias) (ONG, 1997). Este relacionamento é dado através de $\omega_{b}$ (freqüência angular), da seguinte maneira:

$$
\begin{gathered}
\psi=\omega_{b} \cdot \lambda \\
x=\omega_{b} \cdot L \\
\omega_{b}=2 \pi \cdot f_{r}
\end{gathered}
$$

sendo $f_{r}$ a freqüência relativa rotórica/estatórica $(\mathrm{Hz})$.

De posse dos elementos acima expostos, é possível se escrever as equações do MIT em termos de $\psi$ e $x$, conforme podem ser vistas na seqüência: 
Estatórico: $\quad V_{s}^{q d 0}=\frac{\omega}{\omega_{b}}\left[\begin{array}{ccc}0 & 1 & 0 \\ -1 & 0 & 0 \\ 0 & 0 & 0\end{array}\right] \psi_{s}^{q d 0}+\omega_{b}^{-1} \cdot \frac{d\left(\psi_{s}^{q d 0}\right)}{d t}+r_{s}^{q d 0} \cdot i_{s}^{q d 0}$

Rotórico: $\quad V_{r}^{q d 0}=\frac{\left(\omega-\omega_{r}\right)}{\omega_{b}}\left[\begin{array}{ccc}0 & 1 & 0 \\ -1 & 0 & 0 \\ 0 & 0 & 0\end{array}\right] \psi_{r}^{q d 0}+\omega_{b}^{-1} \cdot \frac{d\left(\psi_{r}^{q d 0}\right)}{d t}+r_{r}^{q d 0} \cdot i_{r}^{q d 0}$

Em forma de sistema de equações, com todos os elementos, tem-se:

$$
\left[\begin{array}{l}
\psi_{q s} \\
\psi_{d s} \\
\psi_{0 s} \\
\psi_{q r}^{\prime} \\
\psi_{d r}^{\prime} \\
\psi_{0 r}^{\prime}
\end{array}\right]=\left[\begin{array}{cccccc}
x_{l s}+x_{m} & 0 & 0 & x_{m} & 0 & 0 \\
0 & x_{l s}+x_{m} & 0 & 0 & x_{m} & 0 \\
0 & 0 & x_{l s} & 0 & 0 & 0 \\
x_{m} & 0 & 0 & x_{l r}^{\prime}+x_{m} & 0 & 0 \\
0 & x_{m} & 0 & 0 & x_{l r}^{\prime}+x_{m} & 0 \\
0 & 0 & 0 & 0 & 0 & x_{l r}^{\prime}
\end{array}\right]\left[\begin{array}{c}
i_{q s} \\
i_{d s} \\
i_{0 s} \\
i_{q r}^{\prime} \\
i_{d r}^{\prime} \\
i_{0 r}^{\prime}
\end{array}\right]
$$

sendo o termo $x_{l r}^{\prime}$ dado por:

$$
x_{l r}^{\prime}=\omega_{b}\left(\frac{N_{s}}{N_{r}}\right)^{2} L_{l r}
$$

Finalmente, para o torque, com o mesmo raciocínio, obtém-se:

$$
T_{\text {em }}=\frac{3}{2} \frac{P}{2 \omega_{r}}\left[\frac{\omega}{\omega_{b}}\left(\psi_{d s} i_{q s}-\psi_{q s} i_{q s}\right)+\frac{\omega-\omega_{r}}{\omega_{b}}\left(\psi_{d r}^{\prime} i_{q r}^{\prime}-\psi_{q r}^{\prime} i_{d r}^{\prime}\right)\right]
$$




\subsection{Classificação dos Principais Tipos de Cargas Acopladas ao Motor de Indução Trifásico}

\subsubsection{Introdução}

A análise de desempenho do estimador fuzzy de velocidade será realizada com base nos principais tipos de cargas que são mais freqüentemente encontrados em ambientes industriais (DIAS \& LOBOSCO, 1988), os quais consistem em: quadrática, linear, constante e inversa. Uma breve descrição de cada carga será explanada nos itens subseqüentes.

Cita-se, também, além destas (DIAS \& LOBOSCO, 1988), as cargas que não solicitam torque (cargas volante), que tem a finalidade de estabilizar transitórios de carga pulsantes e torques não-uniforme, sendo que, nesta última, não há função matemática que a modele fidedignamente.

\subsubsection{Carga quadrática}

A carga quadrática caracteriza-se por um torque resistente que varia com o quadrado da rotação. Suas principais aplicações são encontradas em ventiladores, misturadores, centrífugas, bombas centrífugas, exaustores e compressores (DIAS \& LOBOSCO, 1988). Matematicamente, esta pode ser representada pela seguinte equação: 


$$
T(\omega)=a \cdot \omega^{2}+K
$$

sendo que a e $K$ estão relacionados à concavidade da parábola e ao torque inicial de partida, respectivamente. A Figura 2.10(a) representa uma curva de carga quadrática.

\subsubsection{Carga linear}

A carga linear consiste de um torque resistente que apresenta uma variação linear com relação à rotação do eixo do motor. Este tipo de carga encontra-se em aplicações como moinho de rolos, bombas de pistão, plainas e serras para madeira (DIAS \& LOBOSCO, 1988). A carga linear pode ser representada pela seguinte expressão:

$$
T(\omega)=a \cdot \omega+K
$$

sendo que a e $K$ estão relacionadas à inclinação e ao torque de carga inicial, respectivamente. A Figura 2.10(b) ilustra uma curva de carga linear.

\subsubsection{Carga inversa}

Este tipo de carga comporta-se de forma inversa com a velocidade de rotação do motor, ou seja, seu valor diminui com o incremento de velocidade. As 
principais aplicações concentram-se em fresadoras e mandriladoras (DIAS \& LOBOSCO, 1988). A carga inversa pode ser determinada pela seguinte expressão:

$$
T(\omega)=a \cdot e^{-b \cdot \omega}+K
$$

sendo que a está relacionado com o valor inicial do torque e $K$ se refere ao valor mínimo do torque de carga. A Figura 2.10(c) ilustra o torque de carga inverso.

\subsubsection{Carga constante}

A carga constante caracteriza-se pela baixa ou nenhuma variação de torque resistente exigido do motor, permanecendo seu valor praticamente constante com o aumento de velocidade. As aplicações típicas deste tipo de carga residem em guinchos, guindastes e correias transportadoras (DIAS \& LOBOSCO, 1988). A carga constante pode ser representada pela seguinte expressão:

$$
T(\omega)=K
$$

sendo que $K$ representa o valor do torque de carga. A Figura 2.10(d) ilustra uma curva de carga constante. 

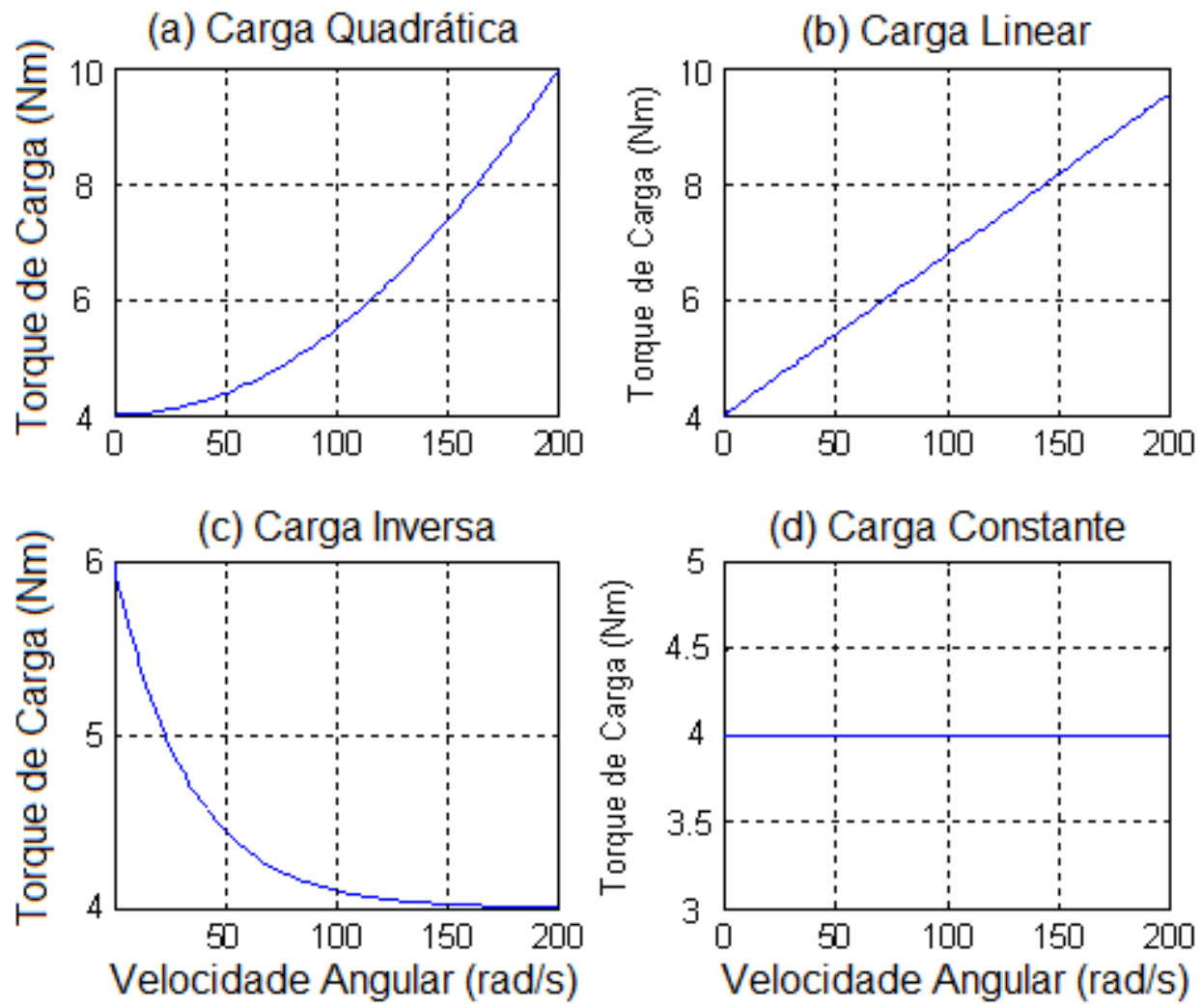

Figura 2.10 - Principais tipos de cargas presentes no ambiente industrial. 


\section{Fundamentos de Sistemas Neuro-Fuzzy}

\subsection{Introdução}

Os sistemas fuzzy (nebulosos) consistem em aproximar o processo de decisão computacional da decisão humana. Isto é feito de modo que um sistema não se resuma apenas a um "sim" ou um "não", mas também decisões abstratas do tipo "próximo de", "em torno de", "muito alto", etc.

Os conceitos de lógica fuzzy e a teoria dos conjuntos fuzzy podem ser utilizados para se traduzir, em termos lingüísticos, informações imprecisas definidas por conjuntos de regras lingüísticas.

Os sistemas fuzzy têm as seguintes características principais:

- expressam imprecisões e incertezas;

- são sistemas baseados em regras;

- o raciocínio é executado de forma aproximada;

- têm a capacidade de aproximar sistemas não lineares complexos;

- dispensam modelos matemáticos dos processos;

- $\quad$ sistemas lineares e não lineares são tratados igualmente.

O marco inicial da história da lógica nebulosa está relacionado à publicação de trabalhos do pesquisador do Azerbaijão, naturalizado norte-americano, Lotfi A. Zadeh, em 1965, mais precisamente à publicação do artigo denominado Fuzzy Sets (ZADEH, 1965). Neste trabalho, propôs-se uma forma para expressar e operar matematicamente conceitos subjetivos, permitindo o tratamento de problemas que envolvem conceitos abstratos e subjetivos, aproximando-se da forma com que os seres humanos tratam a maioria dos problemas do mundo real. Em Fuzzy Sets, 
foram concentradas todas as idéias de que existem elementos no universo que não estão classificados como verdade ou falsidade absoluta na elaboração do conceito de conjuntos nebulosos. Além disso, neste trabalho foi estabelecido o "princípio da incompatibilidade", versando que "à medida que a complexidade de um sistema aumenta, diminui a habilidade humana em se fazer afirmações precisas e significativas sobre o comportamento do sistema, até um limite no qual precisão e significado (ou relevância) tornam-se características mutuamente exclusivas". Este princípio estabelece que "quanto mais próximo alguém examinar um problema do mundo real, mais nebulosa será a solução para este problema".

Em Fuzzy Sets é dito que a definição de conjuntos nebulosos decorre da observação da própria natureza, onde mais freqüentemente encontram-se classes de objetos em que o conceito de pertinência não é bem definido. Ao contrário do que acontece na teoria clássica de conjuntos matemáticos, o mundo físico real possui diversos exemplos onde o conceito de pertinência é indefinido.

Em 1973, Zadeh publicou outro trabalho (ZADEH, 1973), onde trata o enfoque lingüístico para o processamento de problemas complexos e propõe a "computação com palavras", fazendo uma relação entre a linguagem e a inteligência humana com o uso da matemática e postulando que "os elementos-chave no pensamento humano não são números, mas rótulos lingüísticos que representam conjuntos nebulosos".

\subsubsection{Os conjuntos fuzzy}

O que distinguiu a teoria de Zadeh em relação aos outros matemáticos que o antecederam no estudo de conjuntos, tais como Jonh Venn e Georg Ferdinand 
Ludwig Philip Kantor, foi estabelecer uma graduação (escala) para a associação de conceitos vagos com valores numéricos intermediários entre o zero e o um, ou seja, o conceito de grau de pertinência. Sendo mais próximo de 1 , maior é o grau de pertinência do elemento ao conjunto e, mais próximo de 0 , menor é o grau de pertinência do elemento ao conjunto (KLIR, 1995). Define-se, matematicamente, função de pertinência da seguinte forma:

$$
\mu_{A}(x): x \rightarrow[0,1] ; x \in X
$$

sendo que $\mu(x)$ retorna o grau de pertinência de $x$, pertencente ao universo de discurso $X$, em relação ao conjunto fuzzy $A$.

Pode-se, por meio da Figura 3.1, comparar o conceito de um conjunto fuzzy com um conjunto tradicional. Ambos são alusivos à temperatura ambiente, porém, no conjunto fuzzy é possível notar o quanto um conceito pode ter de inter-relação com o outro.
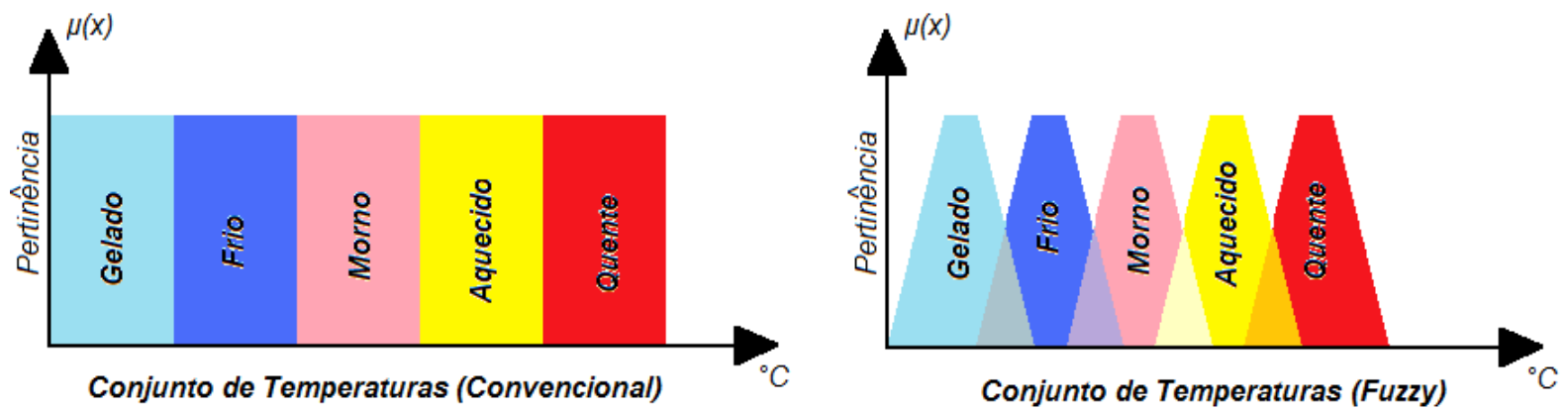

Figura 3.1 - Representação comparativa de um conjunto convencional e um conjunto fuzzy. 
Comparando-se ambos, nota-se que no conjunto fuzzy de temperaturas, o conceito de gelado e frio é relacionado, já no conjunto tradicional (crisp), cada conceito é absolutamente isolado.

A veracidade de uma assertiva não é mais, então, verdadeiro ou falso, mas o grau de veracidade da assertiva é dado pelo valor de seu grau de pertinência, que se confunde com a própria assertiva. O conectivo de negação é expresso pelo complemento do conjunto nebuloso que expressa a assertiva (PEDRYCZ, 1993).

A lógica fuzzy, desde que se esteja utilizando os operadores T-Norm e SNorm, para intersecção e união, respectivamente, obedece aos mesmos operadores da teoria de conjuntos de Kantor e as Leis de Morgan:

- Complementaridade:

$$
\overline{(A \cap B)}=\bar{A} \cup \bar{B} \text { e } \overline{(A \cup B)}=\bar{A} \cap \bar{B}
$$

- Associatividade:

$$
(A \cap B) \cap C=A \cap(B \cap C) \text { e }(A \cup B) \cup C=A \cup(B \cup C)
$$

- Comutatividade:

$$
A \cap B=B \cap A \text { e } A \cup B=B \cup A
$$

- Distributividade:

$$
A \cap(B \cup C)=(A \cap B) \cup(B \cap C) \text { e } A \cup(B \cap C)=(A \cup B) \cap(B \cup C)
$$

Assim sendo, estas propriedades permitem que se possam inter-relacionar os conjuntos fuzzy. 


\subsubsection{Funções de pertinência fuzzy}

Funções de pertinência são ferramentas matemáticas para indicar como estão distribuídos os graus de pertinência em um conjunto fuzzy (TSOUKALAS \& UHRIG, 1997).

Os tipos mais usuais de funções de pertinência são as triangulares, trapezoidais, gaussianas e sigmóides. A modelagem e/ou escolha de uma função de pertinência é um dos itens mais delicados da concepção de um sistema fuzzy, pois esta idéia está diretamente vinculada a como o sistema fuzzy representa a planta a ser modelada.

Para o presente trabalho é aplicada a função gaussiana, que será devidamente justificada no capítulo dedicado à modelagem do sistema. Esta é definida matematicamente da seguinte forma:

$$
\mu_{A}(x)=e^{-K(x-m)^{2}}, \operatorname{com} K>1
$$

sendo que $m$ é o centro da gaussiana e $K$ é o valor da constante que define a excentricidade desta. Na Figura 3.2 encontra-se a representação gráfica da função de pertinência gaussiana.

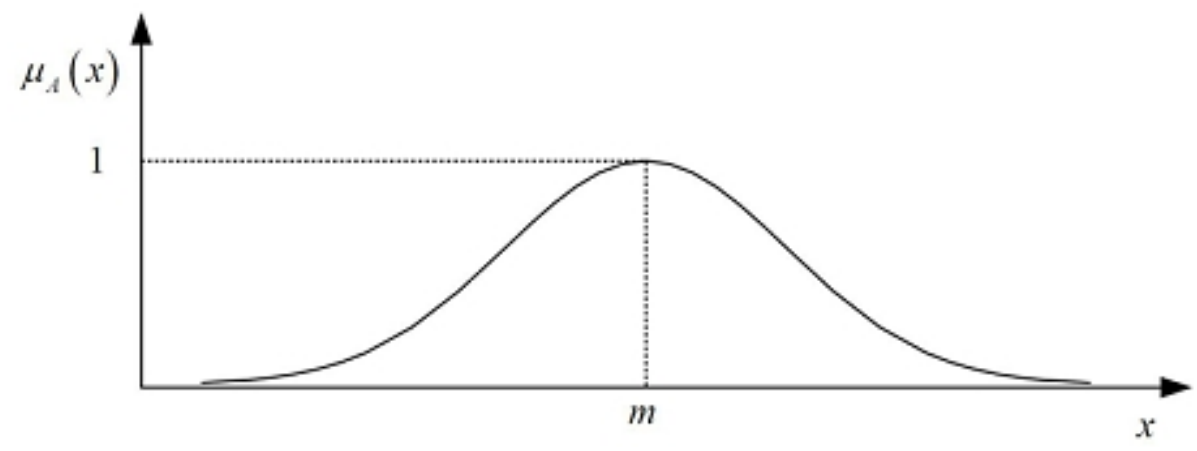

Figura 3.2 - Função de pertinência gaussiana. 


\subsubsection{Composição estrutural de sistemas fuzzy}

Um sistema fuzzy, assim como em outro sistema convencional qualquer, pode ser tratado, para fins de entendimento, como um fluxo de informações que são adquiridas pelo sistema, processadas e então, finalmente, apresentadas na saída.

Esquematicamente, este sistema pode ser descrito conforme a Figura 3.3.

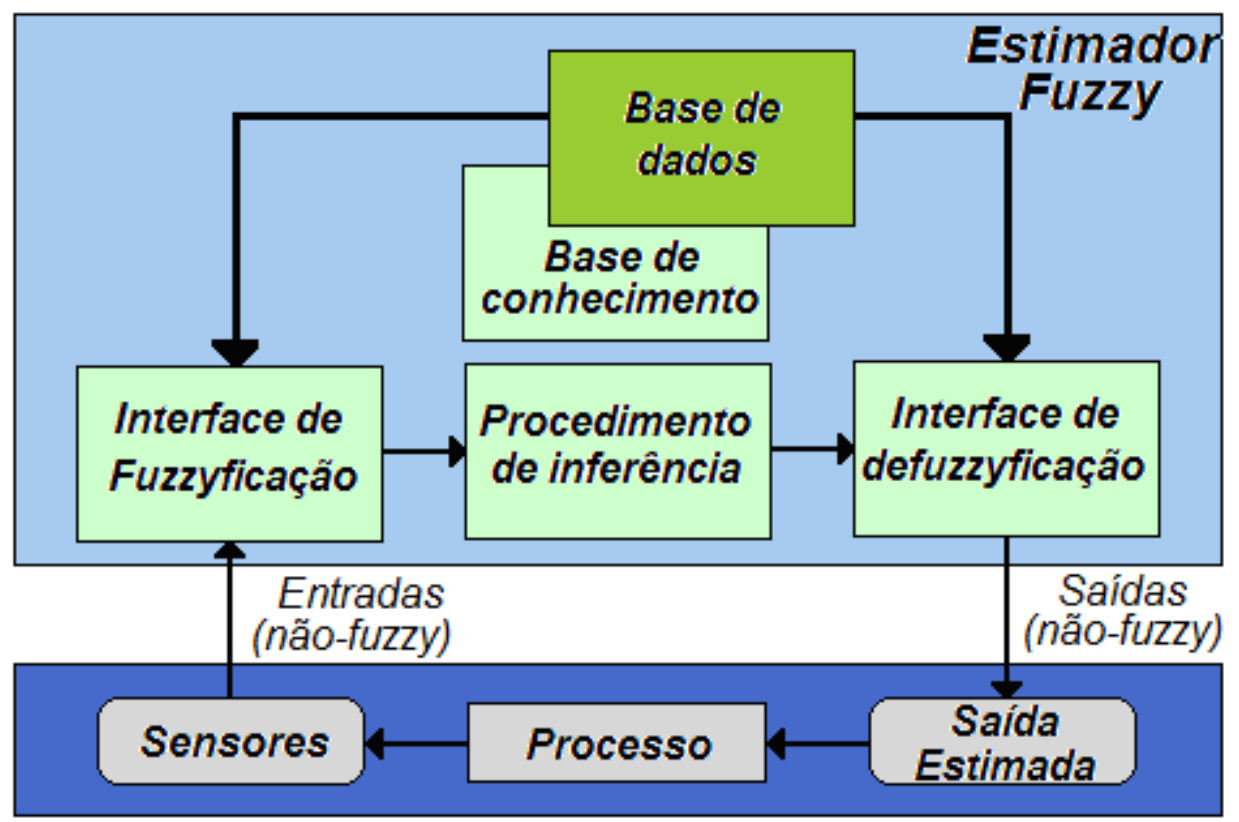

Figura 3.3 - Esquematização gráfica de um sistema fuzzy genérico.

A seguir, serão descritos sucintamente os blocos do sistema:

- Interface de fuzzyficação: toma os valores das variáveis de entrada (precisos), faz o escalamento para condicionar os valores a universos de discursos apropriados, transformando valores em conjuntos fuzzy, de modo que possam se tornar instâncias de variáveis lingüísticas.

- Base de conhecimento: Consiste em uma base de regras, caracterizando a estratégia de estimação e controle, bem como suas metas. 
- Base de dados: Armazena definições necessárias sobre discretizações dos universos de discursos, definições das funções de pertinência, etc.

- $\quad$ Procedimento de inferência: Processa os dados fuzzy de entrada, junto com as regras, de modo a inferir as ações de saída fuzzy, aplicando o operador de implicação fuzzy e as respectivas regras, ou seja, ocorrem as operações com os conjuntos fuzzy.

As regras são baseadas geralmente no conhecimento especialista do sistema, ou seja, sua composição é baseada em informações provenientes de conhecedores do funcionamento do processo a ser aplicado o sistema fuzzy. O sistema fuzzy só terá um desempenho a contento se estas regras representarem fidedignamente o sistema a ser analisado.

Além das regras fornecidas por especialistas, é possível também se obtê-las a partir de um conjunto de dados de entrada-saída do sistema analisado. Deste modo, este conjunto é detentor do comportamento do sistema.

Particularmente, é o que acontece neste trabalho em virtude de seu escopo.

- Interface de defuzzyficação: transforma as ações de saída fuzzy inferidas em ações/respostas não fuzzy, ou seja, valores precisos. Em seguida, efetua-se o escalamento, de modo a compatibilizar os valores normalizados vindos do passo anterior com os valores dos universos de discurso reais das variáveis.

\subsection{Sistemas de Inferência Fuzzy Paramétricos}

Inseridos no conceito de inferência fuzzy, há diversos tipos de processos de implicação, que é o modo como serão geradas saídas fuzzy a partir de entradas 
fuzzy. Há vários operadores de implicação, como Mamdani, Larsen e Zadeh (TSOUKALAS \& UHRIG, 1997). Porém, todos estes não são paramétricos, ou seja, são definidos por regras lingüísticas, cujos antecedentes e conseqüentes são especificados por conjuntos fuzzy.

Entretanto, há sistemas fuzzy denominados paramétricos, cujos conseqüentes das regras são funções polinomiais. Nestes sistemas, diferentemente dos anteriormente citados, além de se resultar em regiões geométricas para definir os conseqüentes das regras, como no processo de inferência por Mamdani, é necessário também que haja a disponibilidade de uma coleção de dados de entrada e de saída provenientes da planta analisada, para ajuste de seus parâmetros. Este modelo de inferência é conhecido por Takagi-Sugeno (modelo TS) (TSOUKALAS \& UHRIG, 1997), e suas regras podem ser descritas genericamente da seguinte forma:

$$
\text { Se (x é } \left.A_{1}\right) E\left(y \text { é } B_{1}\right) \text {, então } Z_{i}=f_{i}(x, y)
$$

sendo $Z_{i}$ funções polinomiais. Assim, para funções lineares de $Z_{i}$, escreve-se:

$$
Z_{i}=f_{i}(x, y)=\alpha_{i} \cdot x+\beta_{i} \cdot y+\gamma_{i}
$$

sendo que os parâmetros $\alpha_{i}, \beta_{i}$ e $\gamma_{i}$ são as incógnitas (coeficientes de regressão) do aproximador linear $Z_{i}$. Os coeficientes de regressão envolvendo $Z_{i}$ são obtidos a partir de simulações realizadas sobre o processo. Quando se tratar do polinômio de ordem zero (constante), o processo é chamado de Takagi-Sugeno de ordem zero ou processo de inferência de Tsukamoto (GOMIDE, 2007). 
Finalmente, para o cálculo do valor de saída final $Z$ (defuzzificado), tem-se, a partir das regras oportunamente ativadas $R_{i}$ e $R_{j}$ (Figura 3.4), a seguinte expressão:

$$
Z=\frac{m_{i} f_{i}(x, y)+m_{j} f_{j}(x, y)}{m_{i}+m_{j}}
$$

sendo que $m_{i}$ e $m_{j}$ são os coeficientes de ponderação.

A Figura 3.3 mostra esquematicamente como é composto este tipo de inferência (GOMIDE, 2007).
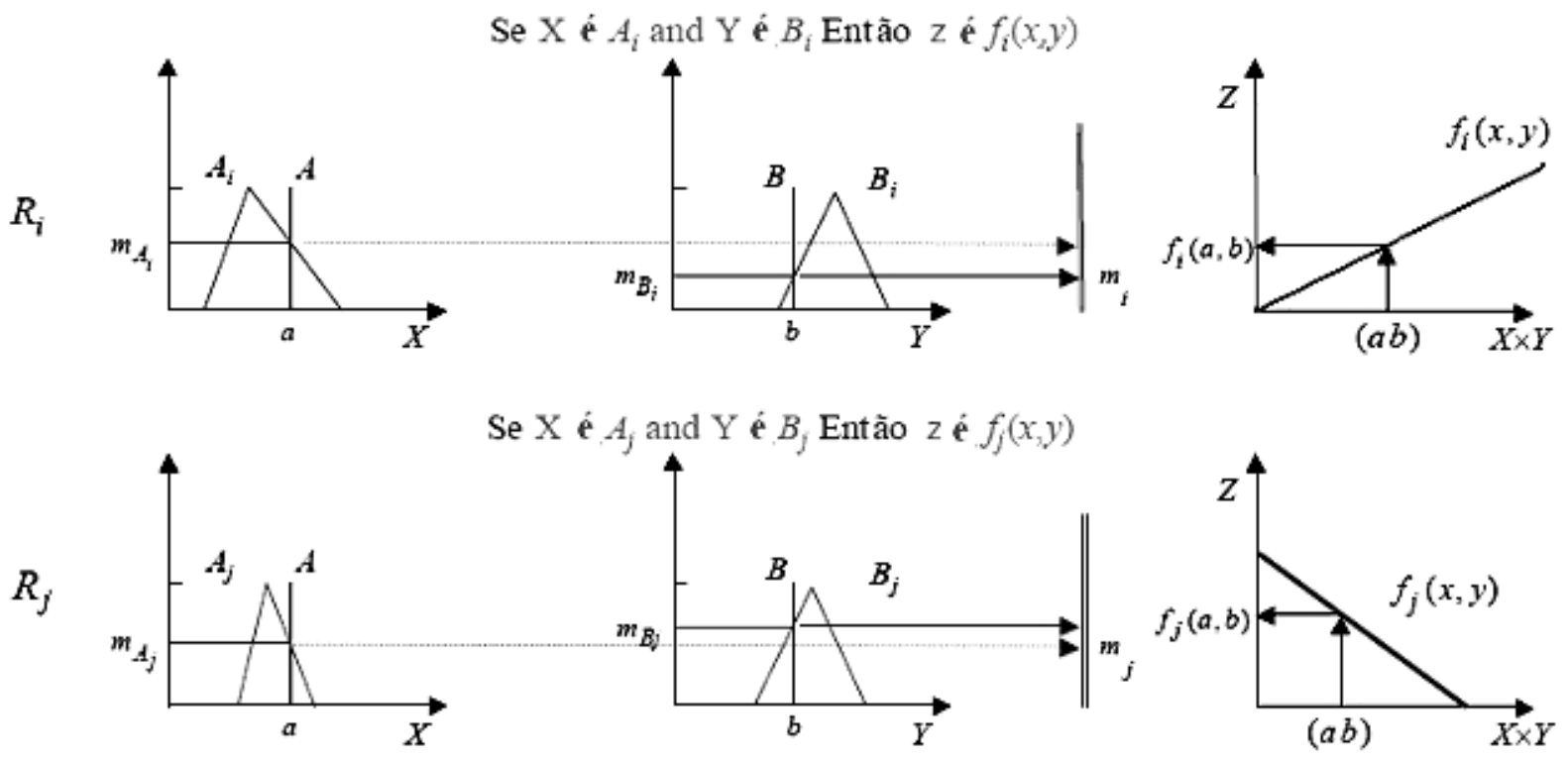

Figura 3.4 - Esquematização gráfica da inferência TS.

Aqui, foram abordados aspectos sucintos sobre a fundamentação de sistemas fuzzy. Na literatura sobre fuzzy, há detalhamento de como é feito este processo (PEDRICZ, 1993; TSOUKALAS \& UHRIG, 1997). Serão tratados agora aspectos impreteríveis para que se possa, de forma dirigida, entender a composição do sistema fuzzy do estimador de velocidade proposto neste trabalho. 


\subsection{Aspectos de Sintonização de Parâmetros em Sistemas de Inferência Fuzzy Paramétricos}

\subsubsection{Introdução}

Para que se componha a contento o sistema de inferência fuzzy, é necessário que sejam mapeadas as características da planta de modo que estas sejam representadas fielmente na modelagem. Isto consiste em modelar as regras do sistema fuzzy e especificar adequadamente as funções de pertinência das entradas deste sistema, de modo a se cumprir este compromisso.

Nos sistemas de inferência paramétricos, ao contrário dos não-paramétricos, conforme já comentado, como Mamdani, Zadeh e Larsen, ao invés de se usar regiões geométricas para definir conseqüentes das regras, são usados polinômios. Deste modo, para que isto seja feito, é necessário o ajuste adequado dos coeficientes destes polinômios (Seção 3.2) de modo que se cumpra o compromisso do sistema estimador fuzzy representar a planta adequadamente.

Elucidando objetivamente o exposto, para uma determinada regra, dada por:

$$
\text { R: SE ( } x \text { é "GRANDE") E (y é "MÉDIO"), então } z_{r}=f\left(x_{1}, x_{2}\right)
$$

será feita a regressão linear, usando o seguinte polinômio:

$$
z_{r}=a \cdot x_{1}+b \cdot x_{2}+c
$$


sendo que a partir das entradas $x$ e $y$, das funções de pertinência ativadas, resulte então em uma resposta de acordo com um valor $z$, conseqüente de $x$ e $y$. Desta forma, a grande questão agora se torna o ajuste dos coeficientes do polinômio $z_{r}$, que obviamente, por ser um trabalho repetitivo e sistemático, aplica-se algoritmos computacionais para tal.

Para isto, há métodos computacionais dedicados, com ênfase o Adaptive Neuro-Fuzzy Inference System (ANFIS), ou traduzindo-se, sistema de inferência neuro-fuzzy adaptativo, o qual é uma ferramenta extremamente otimizada para esta finalidade.

A partir dos vetores de entrada, do tipo e do número das funções de pertinência das entradas e do vetor de saída, o ANFIS consegue, através de algoritmos backpropagation e regressão linear, ajustar os coeficientes dos polinômios e as funções de pertinência das entradas, otimizando ao máximo a fidelidade da inferência fuzzy sobre a planta representada. A inferência adotada é a de Takagi-Sugeno.

O poder do ANFIS, por suas características notáveis, é amplamente explorado. Aqui, explicitam-se alguns exemplos, no intuito de se confirmar esta afirmação.

Em Silva (2007), o ANFIS é utilizado em um sistema estimador de identificação de torque de carga, com ótimos resultados, inclusive comparados com outra técnica inteligente para a mesma finalidade, as redes neurais; porém, com a utilização do algoritmo backpropagation (GOEDTEL, 2003). O ANFIS já foi empregado na estimação de parâmetros de um MI (VASUDEVAN et al., 2003) e para o controle do MI (VASUDEVAN et al., 2004). 
O ANFIS pode ser encontrado no MatLab ${ }^{\circledR}$, onde possui uma interface gráfica com o usuário (GUI) extremamente amigável. O Apêndice B trata do ANFIS no ambiente MatLab ${ }^{\circledR}$.

\subsubsection{Funcionamento do ANFIS}

Em virtude do fato de que o funcionamento do ANFIS é um assunto bastante vasto e no intuito de estar justificando o uso deste método para a sintonização dos parâmetros do estimador fuzzy, faz-se então uma descrição sucinta do mesmo. Além do ANFIS, mencionam-se como exemplos outros sistemas neuro-fuzzy com focos diversos, tais como o NEFCLASS (Neuro-Fuzzy Classification), que é usado para determinar a classe correta ou categoria de um determinado padrão de entrada, e o NEFCON (Neuro-Fuzzy Control), dedicado à aplicações em controle, utilizando o modelo de inferência de Mamdani, dentre outros.

O ANFIS é utilizado usualmente em aplicações de previsão e aproximação de funções, utilizando para isto o sistema de inferência TS. Tanto para o caso de um sistema de inferência de ordem 0 (constante) como para um de ordem 1 (linear), é demonstrado que são sistemas aproximadores universais, sendo que o de ordem 1 tem maior robustez, quando comparado com o de ordem 0.

Devido ao seu poder e flexibilidade de aplicações, popularizou-se e isto o levou a ser implementado no ambiente $M A T L A B^{\circledR}$, como um toolbox do mesmo. Foi criado e desenvolvido inicialmente por Roger Jang (JANG, 1997).

A seguir, é exemplificada, com o intuito de elucidação, a estrutura de uma arquitetura ANFIS para a situação de três entradas $\left\{x_{1}, x_{2}, x_{3}\right\}$, sendo que cada uma está particionada em dois conjuntos fuzzy, $A$ e $B$. Por meio da Figura 3.5, nota-se 
que esta arquitetura é composta em camadas, cada uma com uma finalidade específica.

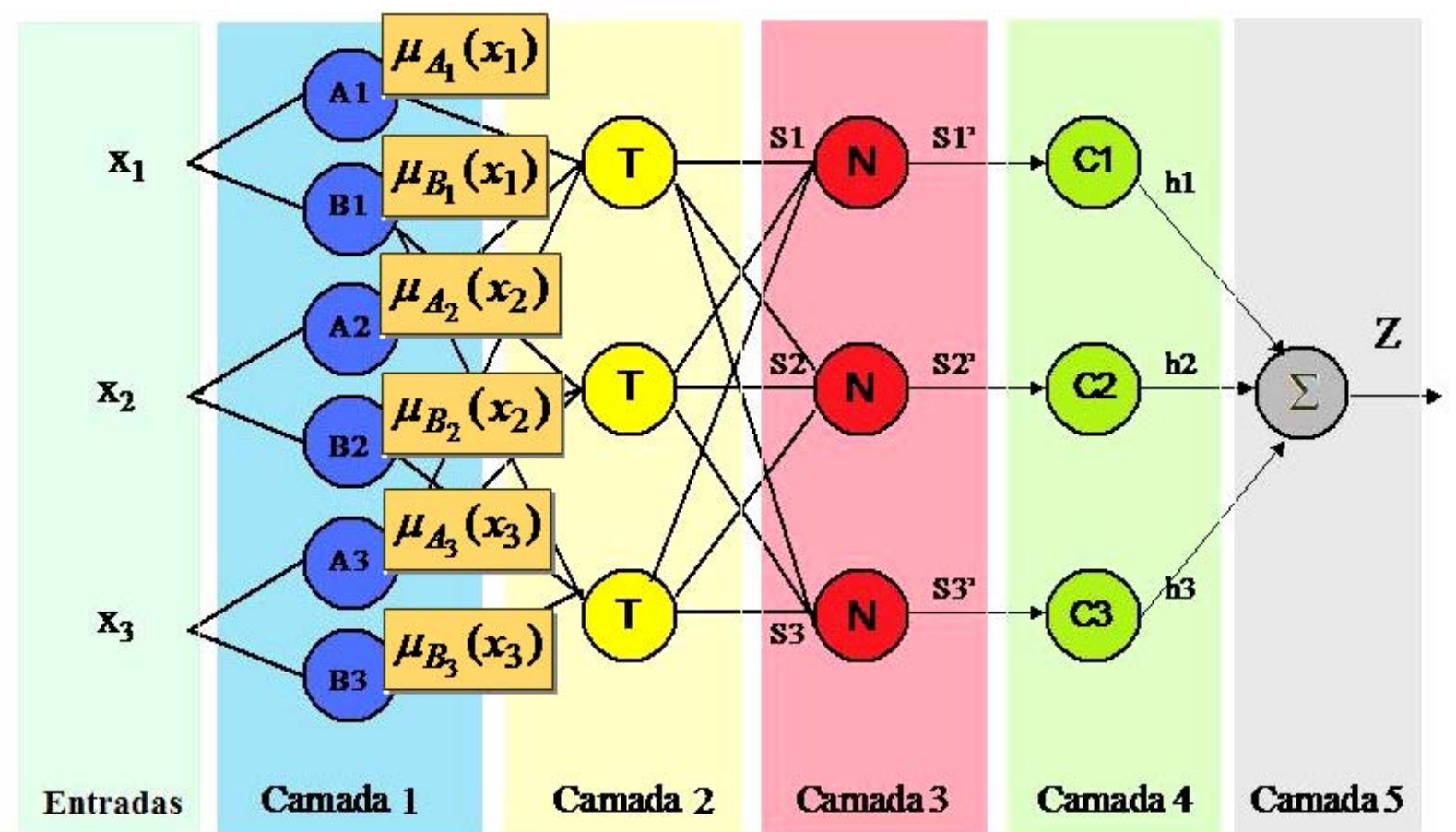

Figura 3.5 - Exemplo de estrutura em camadas da arquitetura ANFIS com três entradas.

A seguir, as camadas têm a sua função descrita na arquitetura ANFIS.

- Camada 1: Calcula o grau de pertinência com que as entradas precisas ("crisp") $\mathrm{x}_{1}, \mathrm{x}_{2}$, e $\mathrm{x}_{3}$ satisfazem os termos lingüísticos $\left(A_{i}=\right.$ ALTO e $B_{i}=$ BAIXO $)$ associados a estes nós. Nesta camada, os parâmetros ajustáveis são os perfis de cada conjunto fuzzy (termo lingüístico de cada variável de entrada).

- Camada 2: Cada nó desta camada corresponde a uma regra e calcula o nível de disparo (firing strength) da regra, ou seja, com que grau o conseqüente da regra está sendo atendido. Nesta camada, os neurônios executam a operação de Tnorm (geralmente produto). 
Para o exemplo da Figura 3.5, as saídas dos neurônios da camada 2 são equacionadas da seguinte forma:

$$
\begin{aligned}
& S_{1}=\mu_{A_{1}}\left(x_{1}\right) \cdot \mu_{A_{2}}\left(x_{2}\right) \cdot \mu_{A_{3}}\left(x_{3}\right) \\
& S_{2}=\mu_{B_{1}}\left(x_{1}\right) \cdot \mu_{B_{2}}\left(x_{2}\right) \cdot \mu_{A_{3}}\left(x_{3}\right) \\
& S_{3}=\mu_{B_{1}}\left(x_{1}\right) \cdot \mu_{B_{2}}\left(x_{2}\right) \cdot \mu_{B_{3}}\left(x_{3}\right)
\end{aligned}
$$

- Camada 3: Esta camada realiza uma normalização (nem sempre existente em outras arquiteturas) nos níveis de disparo das regras. Deste modo, cada nó está rotulado com a letra " $N$ ".

Cada nó $i$ calcula a razão entre o nível de disparo da regra $i$ pela soma dos níveis de disparo de todas as regras.

A normalização é utilizada como um pré-processamento para a defuzzificação. As saídas dos nós desta camada, referentes à Figura 3.5, são dadas por:

$$
\begin{aligned}
& S_{1}^{\prime}=\frac{S_{1}}{S_{1}+S_{2}+S_{3}} \\
& S_{2}^{\prime}=\frac{S_{2}}{S_{1}+S_{2}+S_{3}} \\
& S_{3}^{\prime}=\frac{S_{3}}{S_{1}+S_{2}+S_{3}}
\end{aligned}
$$

- Camada 4: Nesta camada, as saídas dos neurônios são calculadas pelo produto entre os níveis de disparo normalizados $\left(S_{i}, i=1,2\right.$ e 3$)$ e o valor do 
conseqüente da regra em $S_{i}$. Os valores de saída de cada nó desta camada são dados por:

$$
\begin{aligned}
& h_{1}=S_{1}^{\prime}{ }^{*} C_{1} \\
& h_{2}=S_{2}^{\prime}{ }^{*} C_{2} \\
& h_{3}=S_{3}^{\prime}{ }^{*} C_{3}
\end{aligned}
$$

sendo que os valores de $C_{i}$ correspondem aos conseqüentes 'singletons' ou aos conseqüentes de Takagi-Sugeno de primeira ordem (combinações lineares das entradas). Como exemplo de parâmetros do conseqüente, tem-se:

$$
h_{1}=S_{1}^{\prime} \cdot\left(p_{1} \cdot x+q_{1} \cdot y+r_{1}\right)=S_{1}^{\prime} \cdot f_{1}
$$

- Camada 5: O nó desta última camada da arquitetura calcula a saída precisa do sistema e, juntamente com os nós das camadas 3 e 4, promove a defuzzificação. Sua saída é dada por:

$$
Z=h_{1}+h_{2}+h_{3}=S_{1}^{\prime} \cdot C_{1}+S_{2}^{\prime} \cdot C_{2}+S_{3}^{\prime} \cdot C_{3}
$$

ou

$$
Z=\frac{S_{1} \cdot C_{1}+S_{2} \cdot C_{2}+S_{3} \cdot C_{3}}{S_{1}+S_{2}+S_{3}}=\frac{\sum_{i} S_{i} \cdot f_{i}}{\sum_{i} S_{i}}=\sum_{i} S_{i} \cdot f_{i}
$$

sendo que $S_{1}^{\prime}, S_{2}^{\prime}$ e $S_{3}^{\prime}$ são dados pelas Equações (3.15), (3.16) e (3.17), respectivamente. 


\section{Metodologia Proposta Para Estimação de}

\section{Velocidade Usando Sistemas Fuzzy}

\subsection{Introdução}

Este capítulo tem a finalidade de explicitar a composição do estimador fuzzy sensorless para o MIT, visando que este cumpra sua tarefa com simplicidade e confiabilidade.

O desenvolvimento do estimador foi elaborado e desenvolvido completamente no MatLab ${ }^{\circledR}$, no ambiente gráfico Simulink ${ }^{\circledR}$ (Dynamic System of Simulation for Matlab $^{\circledR}$ ) (ONG, 1997), onde que, através da flexibilidade deste, foi composto e simulado em toda a faixa de aplicação que se espera de um dispositivo concebido para operar em âmbito industrial, de acordo com a norma NBR 7094.

A escolha do Matlab ${ }^{\circledR} /$ Simulink $^{\circledR}$ recai em se poder compor o aparato de motor/estimador graficamente, com blocos previamente dispostos para fazê-los, confiáveis e estáveis, fazendo com que o foco de pesquisa esteja no sistema estimador e não em contornar problemas como estabilidade, confiabilidade e falta de recursos de um ambiente computacional. Um exemplo disto está no bloco de conversões de tensões em valores eficazes (RMS - Root Mean Square), onde que, a partir das tensões das fontes, dadas em valor de pico, convertem-se as mesmas em valores RMS. Maiores detalhes podem ser verificados no Apêndice A.

Neste mesmo ambiente, com a fundamentação teórica descrita no Capítulo 2 e demais prerrogativas correlatas (ONG, 1997 e BARBI, 1985), foi modelado o 
60

MIT, aplicando-se ao mesmo as cargas de interesse encontradas em ambiente industrial (DIAS \& LOBOSCO, 1988).

\subsubsection{Características do estimador fuzzy}

O estimador fuzzy deste trabalho tem as seguintes características, a saber:

- Uma entrada de tensão;

- Uma entrada de corrente;

- Inicialmente composto para um MIT de $1 \mathrm{cv}$.

Estas características são provenientes da pressuposição de que o MIT é equilibrado, ou seja, a impedância é a mesma nas três fases; assim a tensão também é suposta igual nas três fases, logo, a corrente também deve ser igual nas três fases.

\subsection{Descrição da Estratégia de Obtenção das Curvas de Velocidade}

Descrever-se-á, nesta seção, o procedimento para a obtenção das curvas de velocidade estimadas, bem como parâmetros do MIT utilizado para esta tarefa.

Para melhor compreensão, na Figura 4.1, há um pequeno diagrama esquemático, onde se visualiza globalmente o fluxo de informações no estimador fuzzy proposto. 


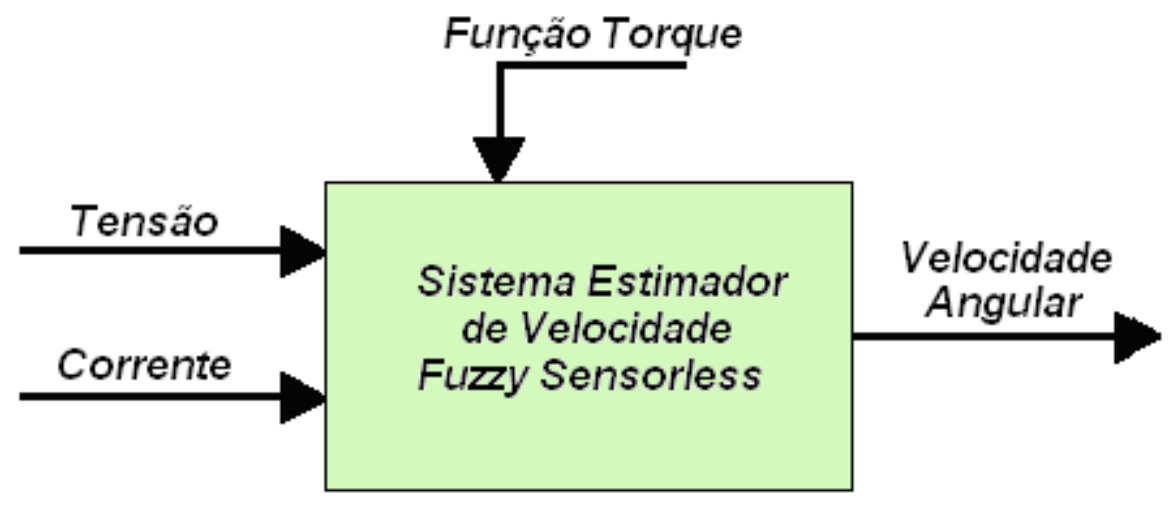

Figura 4.1 - Visão geral do sistema estimador de velocidade fuzzy.

As entradas são somente os dados de tensão e corrente. A "Função Torque" é alusivo ao torque imposto ao MIT em funcionamento, não sendo uma entrada de sinal, mas um parâmetro do sistema, ou seja, informa como o valor do torque varia com o tempo. Para simulações, é de suma importância, pois é de acordo com esta função é que o sistema estimador saberá como se comporta a carga. Num sistema real, esta função é a imposição de carga no eixo do motor. Assim, este dado não é propriamente uma entrada, pois quando implementado na prática, o sistema estimador de velocidade adquirirá somente tensões e correntes e conforme a dificuldade de movimentar a carga, então, com as variações, sobretudo da corrente.

Finalmente, após o processamento dos sinais de entrada e do torque imposto ao MIT, tem-se a saída de velocidade estimada disponibilizada.

\subsubsection{Parâmetros de referência de simulação do MIT}

Os parâmetros descritos na Tabela 4.1 têm importância para que se explicite qual foi o MIT escolhido para a finalidade de concepção do estimador. 
A escolha paira sobre o fato de que este motor está disponível no Laboratório de Controle Inteligente de Máquinas Elétricas - LACIME / EESC-USP, onde as futuras pesquisas sobre o estimador serão feitas e então terão a comparação do presente trabalho. Outro fator a considerar é de que este é um MIT de uso trivial em aplicações de controle industriais, pelas suas características de uso geral. Os dados são referentes ao motor do fabricante WEG, linha Standart, 4 pólos, $60 \mathrm{~Hz}, 220 / 380 \mathrm{~V}$, de $1 \mathrm{cv}$ de potência $(745,7 \mathrm{~W})$.

Tabela 4.1 - Parâmetros do MIT usado para simulações.

\begin{tabular}{|l|l|}
\hline Potência Nominal & $P_{n}=1 \mathrm{cv}(745,7 \mathrm{~W})$ \\
\hline Tensão Nominal de Linha & $V_{L}=220 \mathrm{~V}$ \\
\hline Número de Pares de Pólos & $Z_{p}=2$ \\
\hline Resistência de Estator & $R_{S}=7,32 \Omega$ \\
\hline Resistência de Rotor & $R_{R}=2,78 \Omega$ \\
\hline Indutância de Estator & $L_{S}=8,95 \cdot 10^{-3} \mathrm{H}$ \\
\hline Indutância de Rotor & $L_{R}=5,44.10^{-3} \mathrm{H}$ \\
\hline Indutância Mútua & $M_{S}=0,2034 \mathrm{H}$ \\
\hline Torque Nominal & $T=4,1 \mathrm{~N} \cdot \mathrm{m}$ \\
\hline Momento de Inércia do Rotor & $J=2,71.10^{-3} \mathrm{~kg} \cdot \mathrm{m}^{2}$ \\
\hline Coeficiente de Atrito Viscoso & $B=2,75 \cdot 10^{-4} \mathrm{Kg} \cdot \mathrm{m}^{2} / \mathrm{s}$ \\
\hline Velocidade Síncrona & $n_{S}=188,49 \mathrm{rad} / \mathrm{s}$ \\
\hline Escorregamento Nominal & $s=3,8 \%$ \\
\hline
\end{tabular}

Para se gerar os dados de treinamento, teste e validação, obviamente, é necessário que este MIT esteja acionando uma determinada carga e então a atuação do sistema estimador possa realizar seu trabalho de, a partir dos sinais de tensão e corrente, estimar a rotação do eixo deste MIT. Assim, foram aplicadas, nas simulações, as cargas comumente encontradas no ambiente industrial, descritas na Seção 2.4 , com suas respectivas funções matemáticas.

A título de conveniência, repetir-se-á aqui as funções matemáticas, a saber: 
Tabela 4.2 - Equacionamento das cargas presentes no ambiente industrial.

\begin{tabular}{|l|l|}
\hline Constante & $T(\omega)=K$ \\
\hline Linear & $T(\omega)=a \cdot \omega+K$ \\
\hline Quadrática & $T(\omega)=a \cdot \omega^{2}+K$ \\
\hline Inversa & $T(\omega)=a \cdot e^{-b . \omega}+K$ \\
\hline
\end{tabular}

Assim, de posse destes elementos, procedeu-se à estratégia de obtenção das curvas de velocidade.

\subsection{Estrutura do Sistema Fuzzy Para Estimação de Velocidade no}

MIT

No intuito de se conceber o sistema fuzzy que apresentasse o melhor custo/benefício, a pesquisa do estimador foi concentrada em encontrar o conjunto de elementos que melhor cumprisse esta prerrogativa. Assim sendo, nesta seção, será tratada a forma com que isto foi conseguido. Para cada elemento do sistema, será tratada a justificativa de sua obtenção e aplicação.

\section{- $\quad$ Funções de pertinência das entradas}

As entradas do sistema, conforme já explicitado, são a tensão e corrente do MIT a ter a velocidade de seu eixo estimada. Ao longo da pesquisa, foi verificado que os melhores resultados obtidos, em termos de minimização de erro e diminuição coerente do número de funções de pertinência destas entradas, foram obtidos com as funções de pertinência gaussiana, que melhor se encaixou neste compromisso.

Apesar de necessitar de um maior esforço computacional para ser processada, pois sua definição matemática está fundamentada em uma 
exponencial, funções como as triangulares ou trapezoidais, que têm suas fundamentações matemáticas baseadas em equações lineares, necessitaram de um número muito maior do que as 7 gaussianas eleitas, em torno de 11 a 13 .

Assim, justifica-se a predileção na adoção da função gaussiana. Além disso, salienta-se novamente que não há consenso sobre um método genérico para estimação de velocidade visando atender às diversas necessidades para sistemas a laço aberto ou controle realimentado (GOEDTEL, 2007).

Em seguida, são apresentadas as funções de pertinência utilizadas para o estimador de velocidade sensorless fuzzy. Para tensão e corrente, as funções de pertinência destas variáveis possuem os seguintes acrônimos, a saber:

- EB: Extra Baixa;

- MB: Muito Baixa;

- PB: Pouco Baixa;

- M: Média;

- PA: Pouco Alta;

- MA: Muito Alta;

- EA: Extra Alta.

Na Figura 4.2 estão ilustradas as funções de pertinência para a tensão, sendo o seu universo de discurso compreendido entre 0 a 242V RMS, para todos os tipos de carga abordados pelo trabalho. 


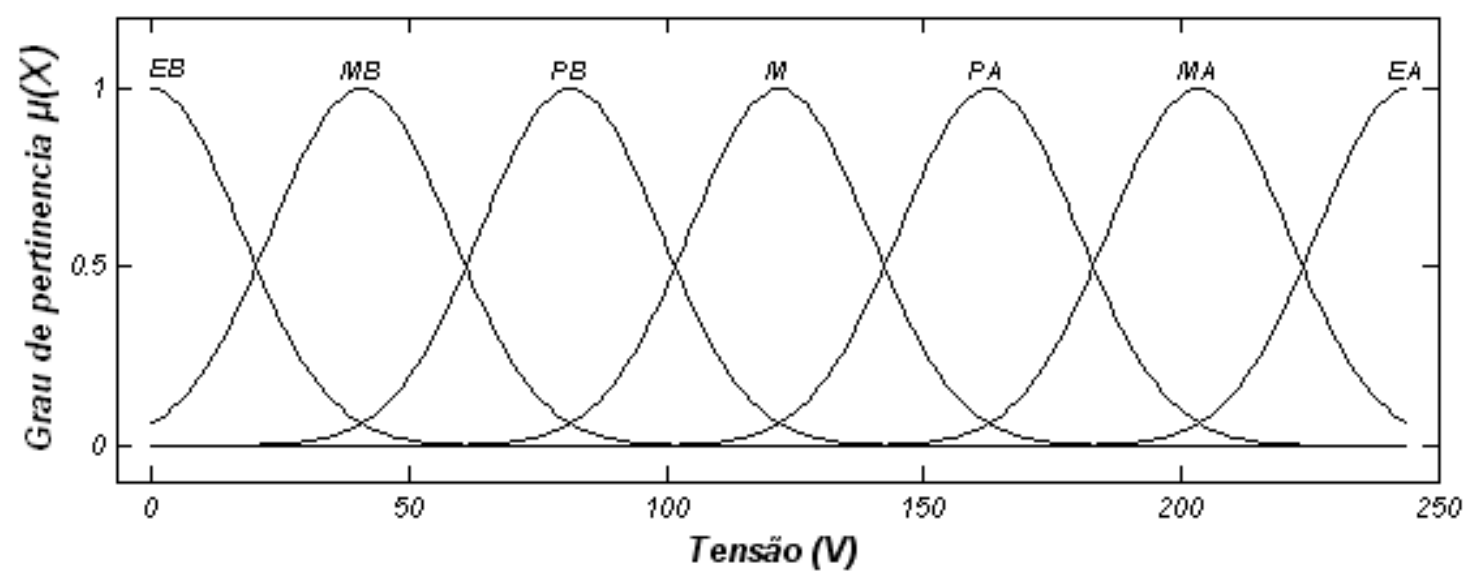

Figura 4.2 - Funções de pertinência para a variável tensão (V).

Na Figura 4.3 estão ilustradas as funções de pertinência para a corrente, sendo o seu universo de discurso compreendido entre 0 a 24.3A RMS, englobando neste intervalo o pico de partida do motor. Estão dimensionadas para todos os tipos de carga abordados pelo trabalho.

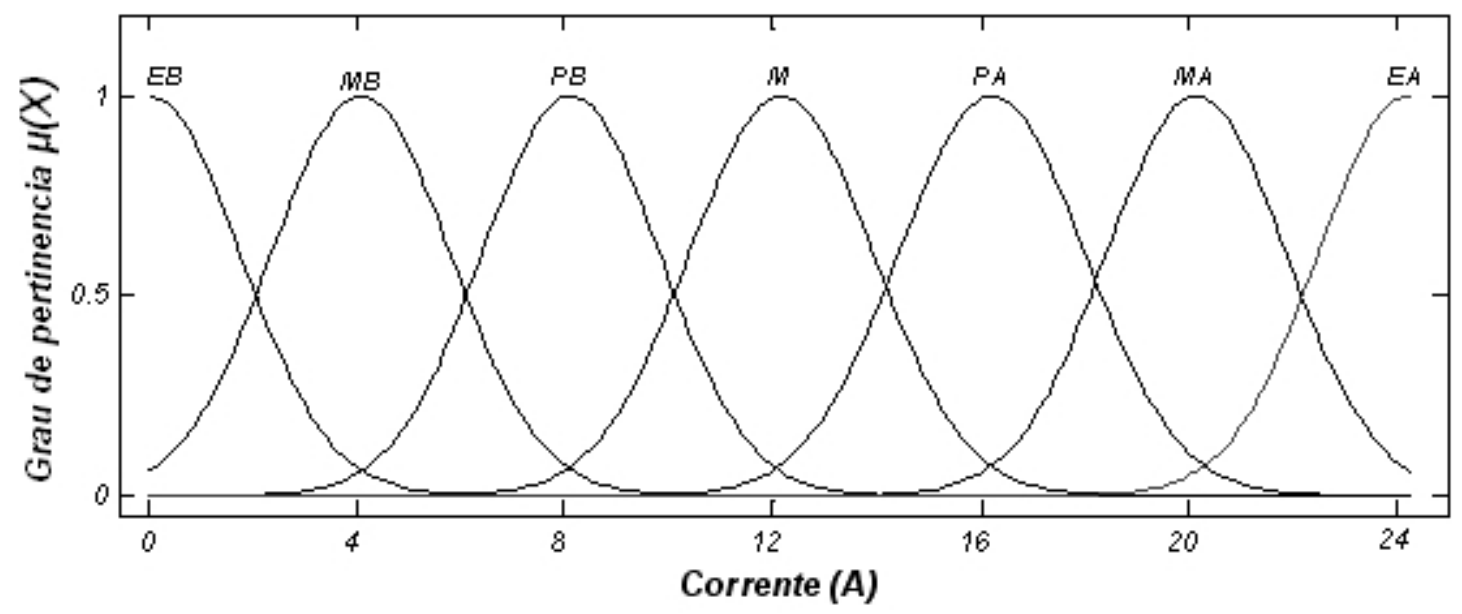

Figura 4.3 - Funções de pertinência para a variável corrente $(A)$.

Com a devida associação das funções da entrada, são então formadas 49 regras para o estimador fuzzy. Nesta assertiva, cabe a observação de que, sendo o número de regras total o produto do número de funções das entradas, a minimização 
racional do número destas é extremamente bem-vindo em termos de esforço computacional do sistema. Se adotadas as triangulares, em número de 13 , conforme uma das possibilidades comentadas anteriormente, ter-se-ia 169 regras, ou seja, mais do que o triplo obtido com esta configuração. Tendo em vista que cada regra gera um polinômio, conforme exposto no Capítulo 3, o incremento de esforço seria significativo.

\section{- $\quad$ Erro pré-determinado de estimação}

Na GUI do ANFIS no ambiente MatLab ${ }^{\circledR}$, é possível que se pré-defina o erro mínimo desejável para o sistema, conforme pode-se verificar no Apêndice $B$. Obviamente, o erro almejado é sempre de valor nulo. Assim, para que isto se concretize, foi estudado, de modo a alcançar este objetivo, a utilização do valor zero de erro, sendo que alcançar este valor na prática ficou limitado por fatores como número de épocas de treinamento e o tempo deste.

\section{- $\quad$ Número de épocas utilizadas no treinamento}

O número de épocas utilizado no treinamento foi variado numa ampla faixa, no intuito de se obter a melhor relação deste em relação ao erro. Com 10 épocas, em pouco mais de 90 segundos, já estava treinado o sistema, com erros em torno de $3 \%$ de estimação. Por outro lado, a tentativa de se deixar o ANFIS configurado com 10.000 épocas (com mais de 10 horas de processamento) alterou muito pouco o erro de estimação, caindo para 1,5\%. Em diversas tentativas, conclui-se que com um máximo de 100 épocas já são suficientes para que se obtenha em torno de $2 \%$ de 
erro em poucos minutos de treinamento. Neste caso, a ocorrência de overfitting (saturação da estrutura neural do sistema ANFIS) pode ser detectada por meio da validação cruzada.

\section{- $\quad$ Tipo de função de saída adotado}

O ANFIS permite a seleção dos tipos de função de pertinência na saída, sendo linear (TS de ordem 1) ou então constante (TS de ordem 0 ou de Tsukamoto). Apesar de maior esforço, o uso de função constante dobrou o erro, motivo pelo qual se justifica a predileção pela linear.

\section{- $\quad$ Tipo de treinamento utilizado}

Com a disponibilização pelo ANFIS dos métodos backpropagation e híbrido para esta finalidade, ambos foram estudados no intuito de se obter melhores resultados com menor esforço. Indiscutivelmente, o híbrido produziu o melhor resultado.

Deve-se salientar que o sistema estimador fuzzy de velocidade, após treinado, é dispensada esta etapa, pois ela tem a finalidade apenas de ajustar os parâmetros das funções de pertinência da entrada e os coeficientes do polinômio do modelo de inferência TS. Para a estimação de velocidade, já com os coeficientes ajustados previamente, basta então aplicar os valores de entrada, de tensão e corrente, para que se obtenha, com as regras apropriadas devidamente ativadas e ajustadas, o valor de velocidade estimada. 
4.3.1 Esquematização do processo de estimação de velocidade utilizando lógica fuzzy

De posse de todas as informações transcritas até aqui, é possível esquematizá-las graficamente, no intuito de melhor compreensão de como foram arranjados estes elementos para obter a estimação de velocidade com lógica fuzzy.

A Figura 4.4 cumpre esta finalidade, mostrando os passos realizados.

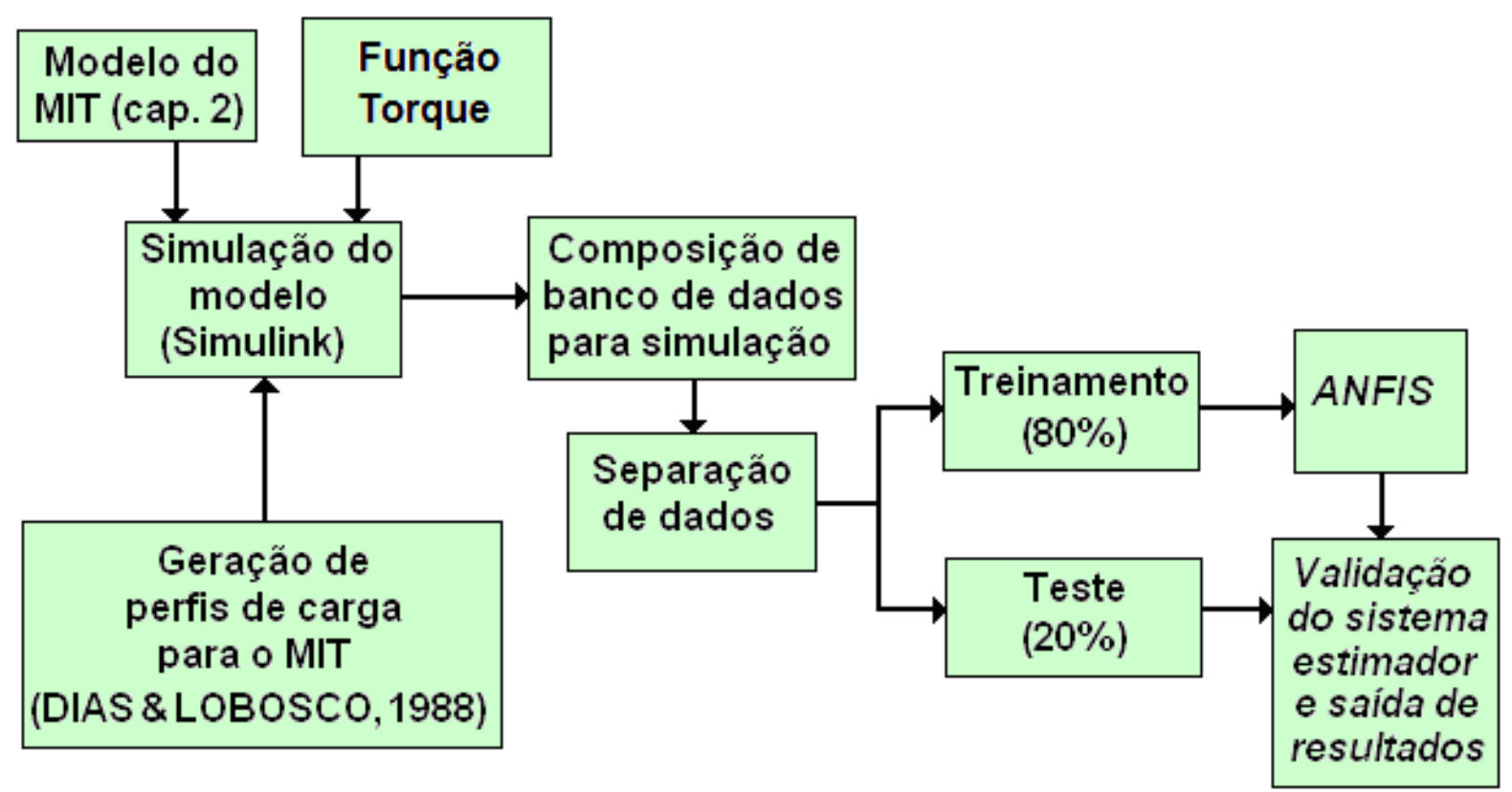

Figura 4.4 - Esquematização gráfica da estratégia de obtenção de estimação de velocidade com uso de lógica fuzzy.

Após treinado através do ANFIS, o estimador está em condições de exercer sua função, bastando as entradas de tensão e corrente para que se obtenha a estimação de velocidade. 


\section{Resultados da Aplicação do Sistema Fuzzy}

\section{para Estimação de Velocidade do MIT}

\subsection{Introdução}

Neste item serão apresentados os resultados de simulação computacional do comportamento do estimador fuzzy de velocidade realizado no ambiente Matlab $^{\circledR} /$ Simulink $^{\circledR}$.

Todas as simulações foram feitas em um intervalo de tempo de $1 \mathrm{~s}$, de modo que se pudesse avaliar o desempenho do sistema tanto em regime transitório quanto em regime permanente.

Os valores de torque a serem aplicados foram sorteados aleatoriamente por intermédio da função random do MATLAB ${ }^{\circledR}$, normalizados entre 0 N.m (a vazio) e 8,0 N.m, quase o dobro do torque nominal do motor, que é 4,1 N.m. Assim, estão distribuídos aleatoriamente ao longo dos valores aplicados, para valores de tensão obtidos da mesma forma no intervalo de $198 \mathrm{~V}$ a $242 \mathrm{~V}$ RMS, de acordo com a norma NBR 7094 (2003), permitindo uma variação de $\pm 10 \%$ da tensão de alimentação do motor, tendo como referência a tensão de 220V RMS nominal. De um sortimento de resultados, os mais críticos e expressivos estão expostos, no intuito de revelar o comportamento do dispositivo estimador de velocidade fuzzy.

Foram aplicados, para efeito de avaliação nos vetores componentes de cada curva (estimada e real), a função erro relativo médio percentual e desvio padrão. 
Salienta-se que os dados de treinamento não foram usados para teste, de modo a se avaliar com fidelidade a capacidade do sistema de cumprir sua função.

Além disso, dependendo da situação, a amplitude de variação de torque foi maior, de modo a ser mais um item de avaliação deste estimador.

Primeiramente, os resultados serão ilustrados em forma gráfica e, em seguida, em forma tabular, sintetizados, para comparação de desempenho. Estão ordenados por ordem crescente de tensão de alimentação para cada tipo de carga considerada (sub-alimentação, nominal e sobre-alimentação).

\subsection{Resultados em Formato Gráfico}

Neste item, serão analisados graficamente cada caso das cargas mencionadas na Seção 2.4 (DIAS \& LOBOSCO, 1988). Para isto, escolheram-se combinações de torques e tensões de alimentação que permitem avaliar o comportamento do estimador.

\subsubsection{Estimação de velocidade considerando carga quadrática}

\section{- Sub-alimentação de tensão}

Para o caso de uma carga quadrática que varia num intervalo de 3,50 a 5,50 N.m, o seguinte resultado gráfico é mostrado na Figura 5.1, obtido pelo estimador fuzzy, com tensão de alimentação abaixo da nominal, em 203V RMS. A estimação não acompanha oscilações rápidas do MIT, conforme é possível notar, especialmente na faixa de 0 a $50 \mathrm{rad} / \mathrm{s}$ (próximo à partida). Nota-se também a 
significativa queda de velocidade do motor, pelo fato de estar subalimentado e estar submetido a um torque final acima de sua capacidade nominal.

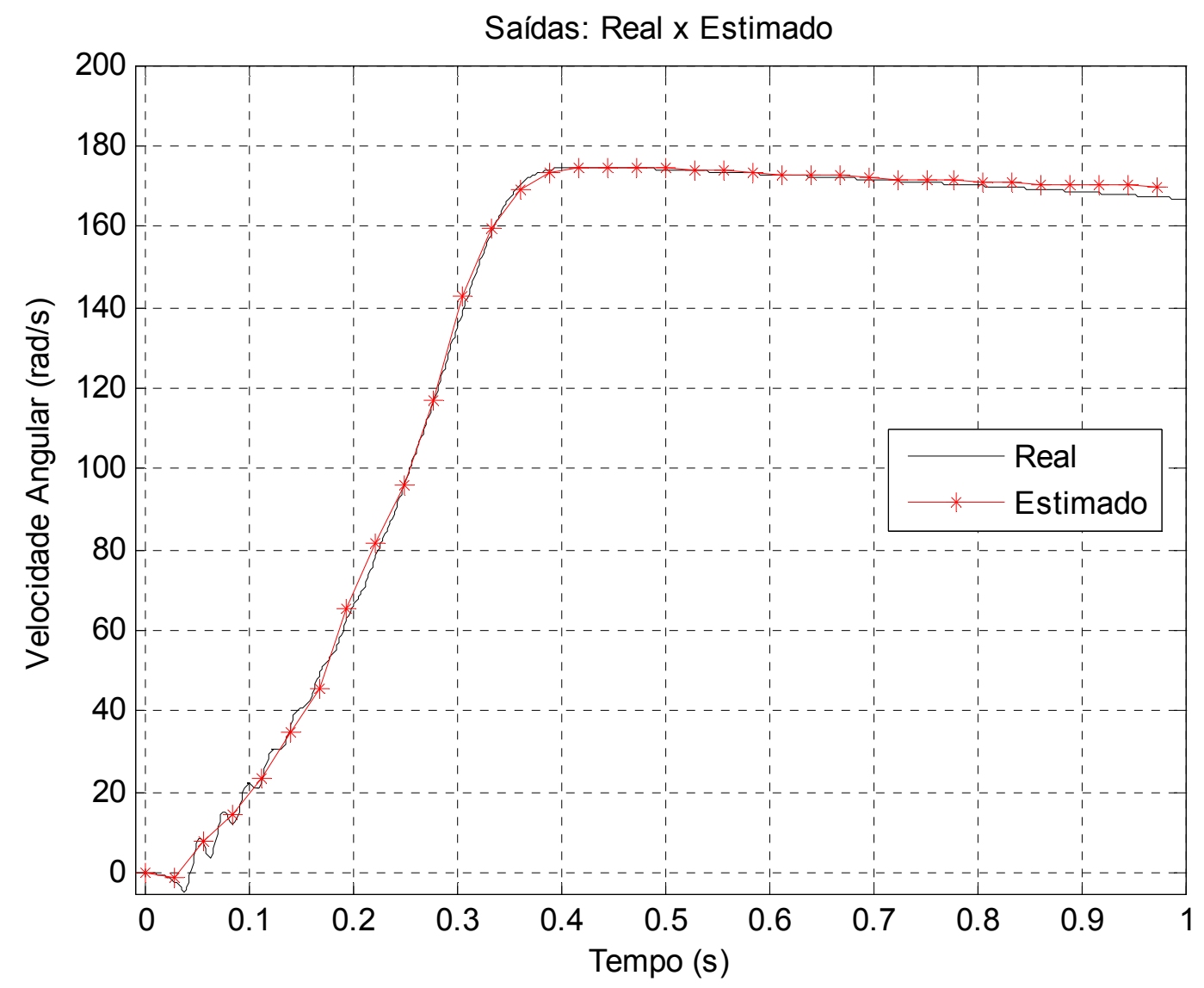

Figura 5.1 - Resposta do estimador de velocidade fuzzy diante de uma situação de carga quadrática, com alimentação de 203V.

Para a situação de carga quadrática com aplicação de subalimentação e valores de torque supra-mencionados, o erro relativo médio entre os valores reais e aqueles obtidos pelo estimador fuzzy foi de $1,64 \%$ e o desvio padrão de $3,85 \%$.

\section{- Tensão de alimentação nominal}

No caso de uma carga quadrática que varia num intervalo de 2,19 a 3,30 N.m, o seguinte resultado gráfico é mostrado na Figura 5.2, obtido pelo estimador fuzzy, com tensão de alimentação nominal de 220V RMS. 
Nesta situação, logo que o motor entra em regime, nota-se que na saída do regime transitório, na linha real, é marcada com um overshoot e o estimador ignora a oscilação proveniente deste fenômeno. Esta observação poderá ser constatada ao longo de outras situações.

Verifica-se o desempenho do estimador fuzzy nestas circunstâncias na Figura 5.2.

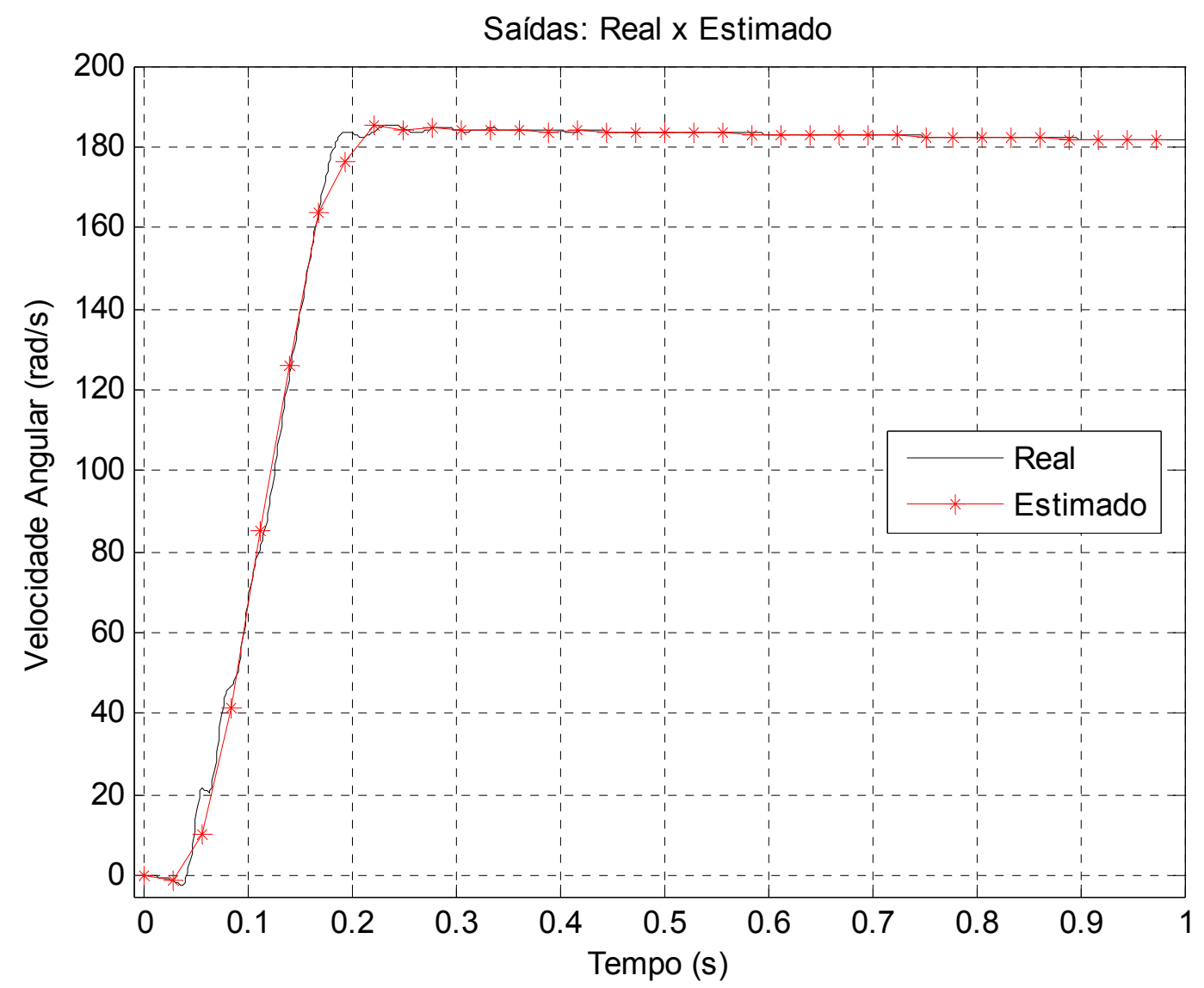

Figura 5.2 - Resposta do estimador de velocidade fuzzy diante de uma situação de carga quadrática, com alimentação de $220 \mathrm{~V}$.

Para a situação de carga quadrática com alimentação nominal e valores de torque já referidos, o erro relativo médio entre os valores reais e aqueles obtidos pelo estimador fuzzy foi de $0,93 \%$ e o desvio padrão de $2,65 \%$. 


\section{- Sobre-alimentação de tensão}

Aplicando-se uma carga quadrática que varia num intervalo de 0,55 a 1,45 N.m, o seguinte resultado gráfico é mostrado na Figura 5.3, obtido pelo estimador fuzzy, com tensão de alimentação nominal de 242V RMS.

Nesta situação, pelo fato de que se aplicaram faixas de torques muito abaixo do nominal, ao entrar nas proximidades da região de regime, a oscilação de velocidade foi bastante acentuada e o estimador tende a acompanhar com certo retardo esta característica.

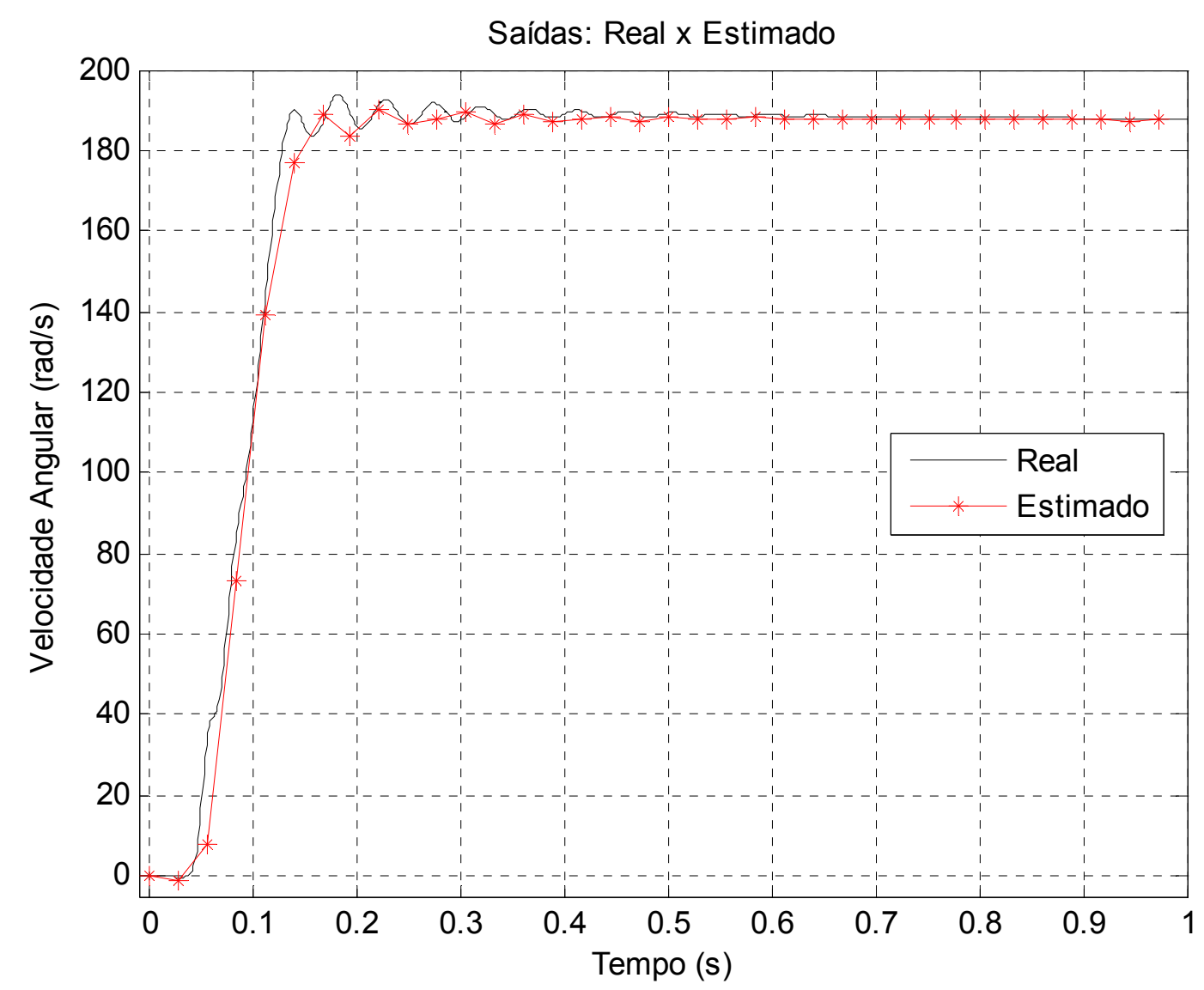

Figura 5.3 - Resposta do estimador de velocidade fuzzy diante de uma situação de carga quadrática, com alimentação de $242 \mathrm{~V}$. 
Para a situação de carga quadrática com aplicação de sobre-alimentação e valores de torque descritos, o erro relativo médio entre os valores reais e aqueles obtidos pelo estimador fuzzy foi de $1,41 \%$ e o desvio padrão de $3,25 \%$.

\subsubsection{Estimação de velocidade considerando carga linear}

\section{- Sub-alimentação de tensão}

Para o caso de torque resistente que varia linearmente entre 0,05 N.m e 2,70 N.m (inicialmente, quase a vazio), com o incremento de velocidade, o comportamento do estimador fuzzy é mostrado na Figura 5.4, com tensão de alimentação abaixo da nominal, em 200V RMS. Novamente, a estimação não acompanha oscilações próximas à partida, mas numa faixa agora compreendida entre 0 a $25 \mathrm{rad} / \mathrm{s}$. Há significativa queda de velocidade do motor, pelo fato de estar subalimentado, mesmo tendo um torque final de carga aplicado abaixo de seu nominal. 


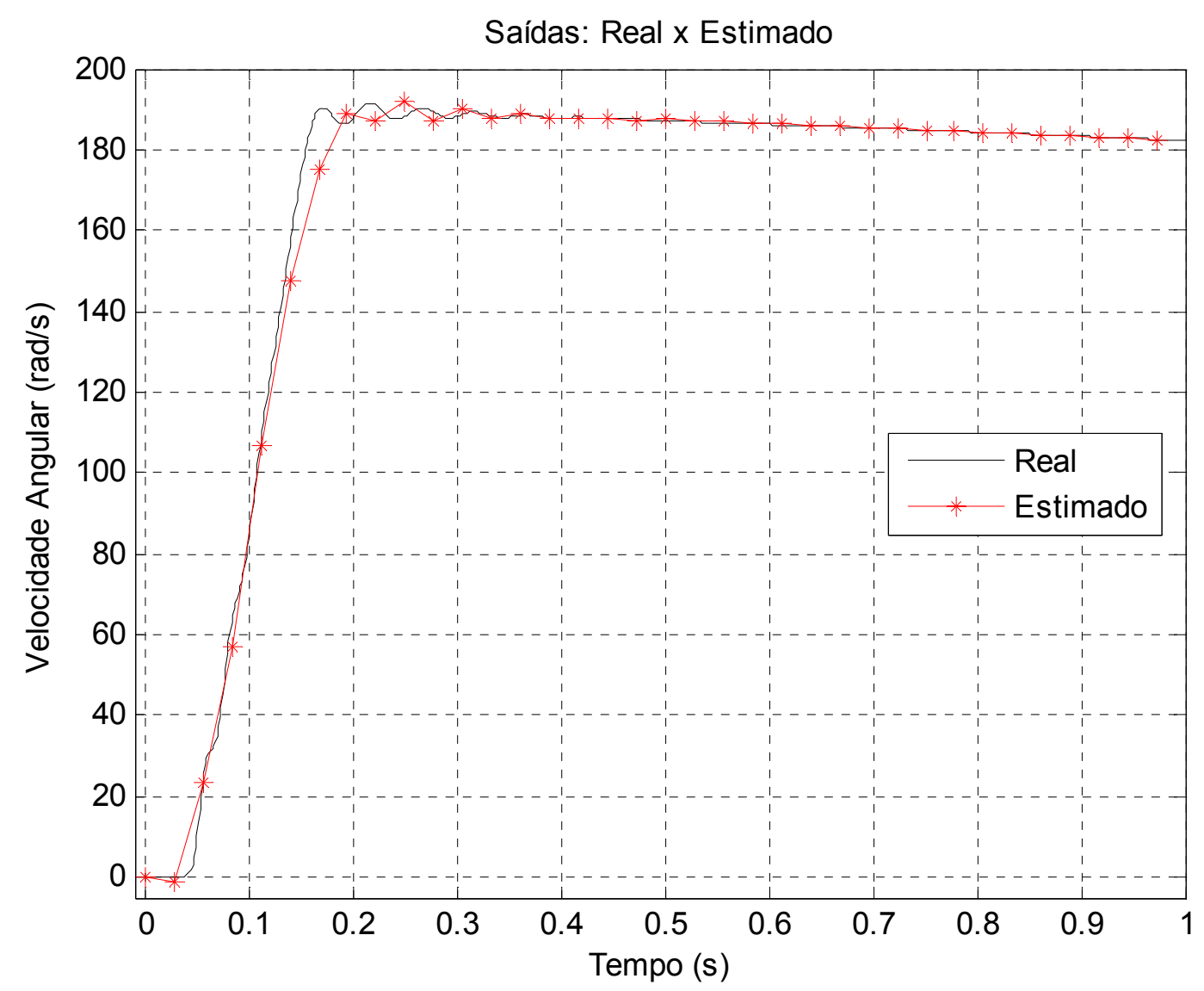

Figura 5.4 - Resposta do estimador de velocidade fuzzy diante de uma situação de carga linear, com alimentação de $200 \mathrm{~V}$.

Para a situação de carga linear com aplicação de sub-alimentação e valores de torque referidos, o erro relativo médio entre os valores reais e aqueles obtidos pelo estimador fuzzy foi de $1,74 \%$ e o desvio padrão de $4,84 \%$.

\section{- Tensão de alimentação nominal}

No caso de uma carga linear variando numa faixa de torques de carga entre 3,50 a 5,50 N.m, o seguinte resultado gráfico é mostrado na Figura 5.5, obtido pelo estimador fuzzy, com tensão de alimentação nominal de 220V RMS. Pelo fato da carga inciar próximo ao torque nominal e então passar para um valor acima deste, nota-se então a queda de velocidade do motor. 


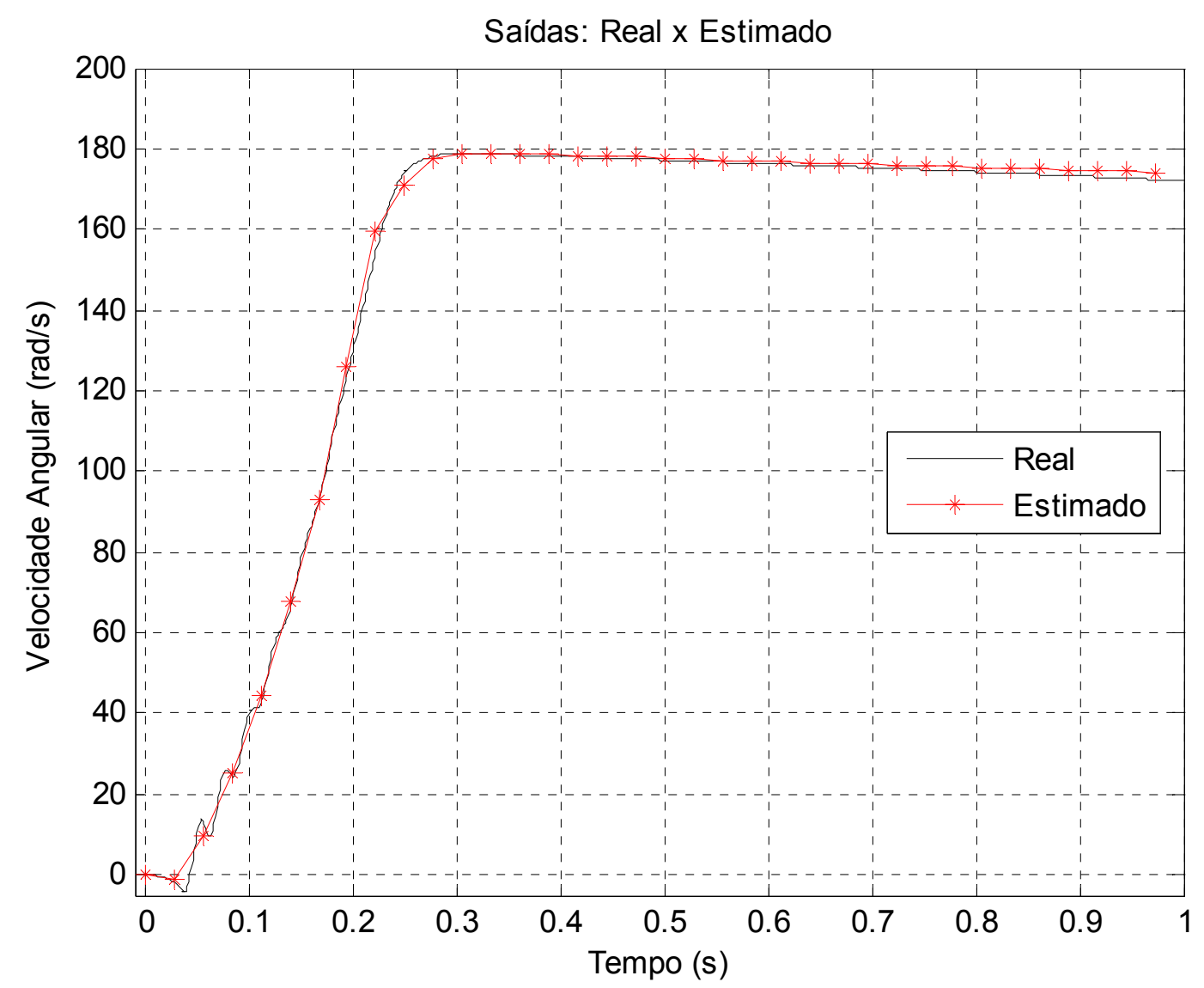

Figura 5.5 - Resposta do estimador de velocidade fuzzy diante de situação de carga linear, com alimentação de $220 \mathrm{~V}$.

Para a situação de carga linear, o erro relativo médio entre os valores reais e aqueles obtidos pelo estimador fuzzy foi de $1,16 \%$ e o desvio padrão de $2,32 \%$.

\section{- $\quad$ Sobre-alimentação de tensão}

Numa situação de torque resistente variando linearmente entre 2,00 N.m e 4,80 N.m, uma faixa mais ampla que as anteriores, é possível então se verificar o comportamento do estimador fuzzy na Figura 5.6, com sobre-alimentação de 240V RMS. Verifica-se que a queda de velocidade do motor é menos significativa aqui em virtude da sobre-alimentação. 


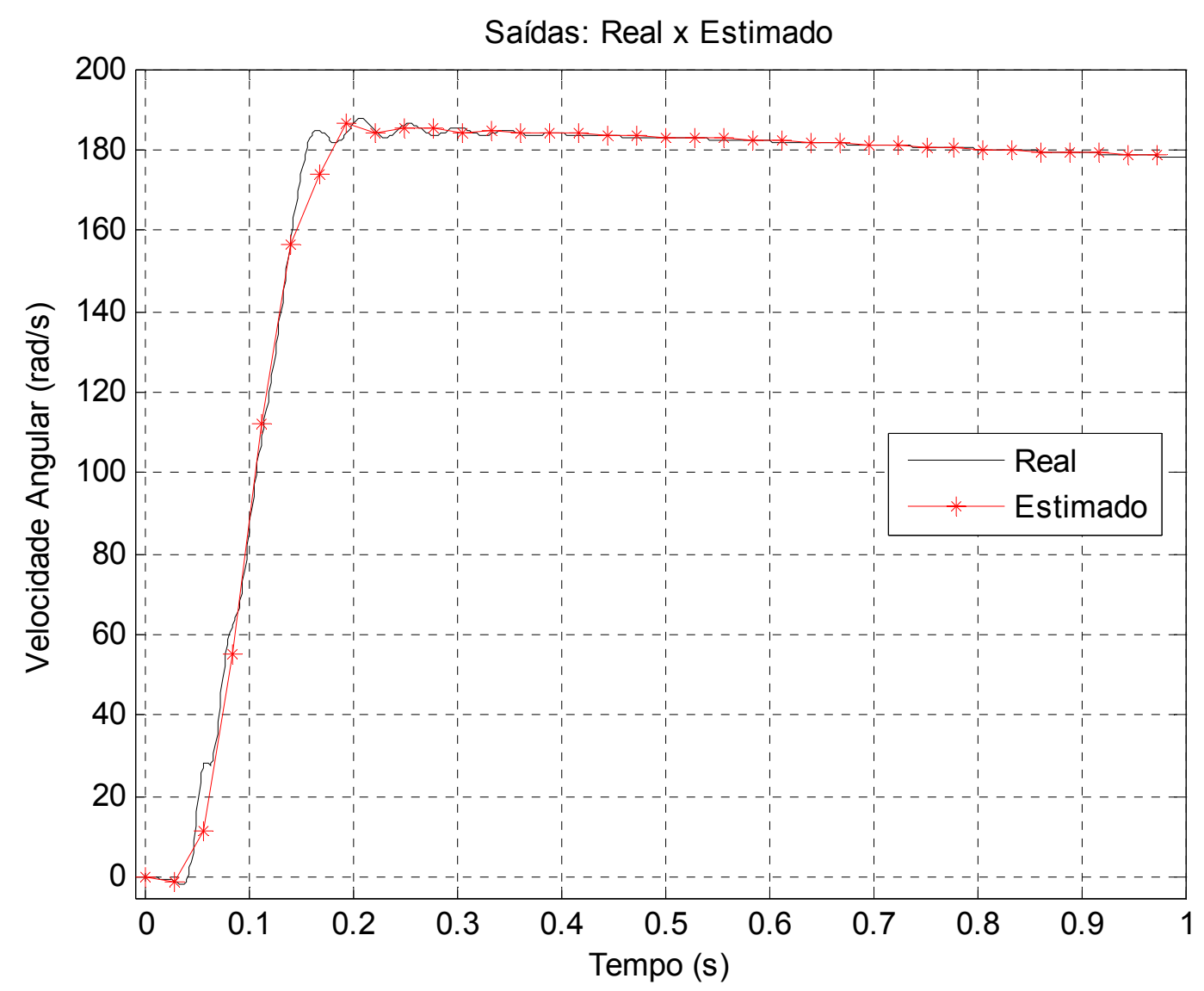

Figura 5.6 - Resposta do estimador de velocidade fuzzy diante de uma situação de carga linear, com alimentação de $240 \mathrm{~V}$.

Para a situação de carga linear, aplicando-se sobre-alimentação e valores de torque referidos, o erro relativo médio entre os valores reais e aqueles obtidos pelo estimador fuzzy foi de $0,87 \%$ e o desvio padrão de $2,42 \%$.

\subsubsection{Estimação de velocidade considerando carga inversa}

As situações seguintes ilustram uma conjuntura contrária às anteriores, onde o motor parte com torque elevado e então este se reduz proporcionalmente, conforme relação verificada na Seção 2.4. 


\section{- Sub-alimentação}

Mesmo sendo um cenário desfavorável (queda do torque de carga com o tempo), pode-se notar por intermédio da Figura 5.7 um comportamento satisfatório do estimador, sendo adotada para esta análise a faixa de variação de 4,50 N.m a 3,50 N.m.

Especialmente, para o caso de sub-alimentação do motor, em 203V RMS, aqui é configurada a situação mais severa em que o estimador foi submetida, pois trata-se de um cenário completamente desfavorável. Observa-se o tempo para a partida, maior que nas outras situações já apresentadas.

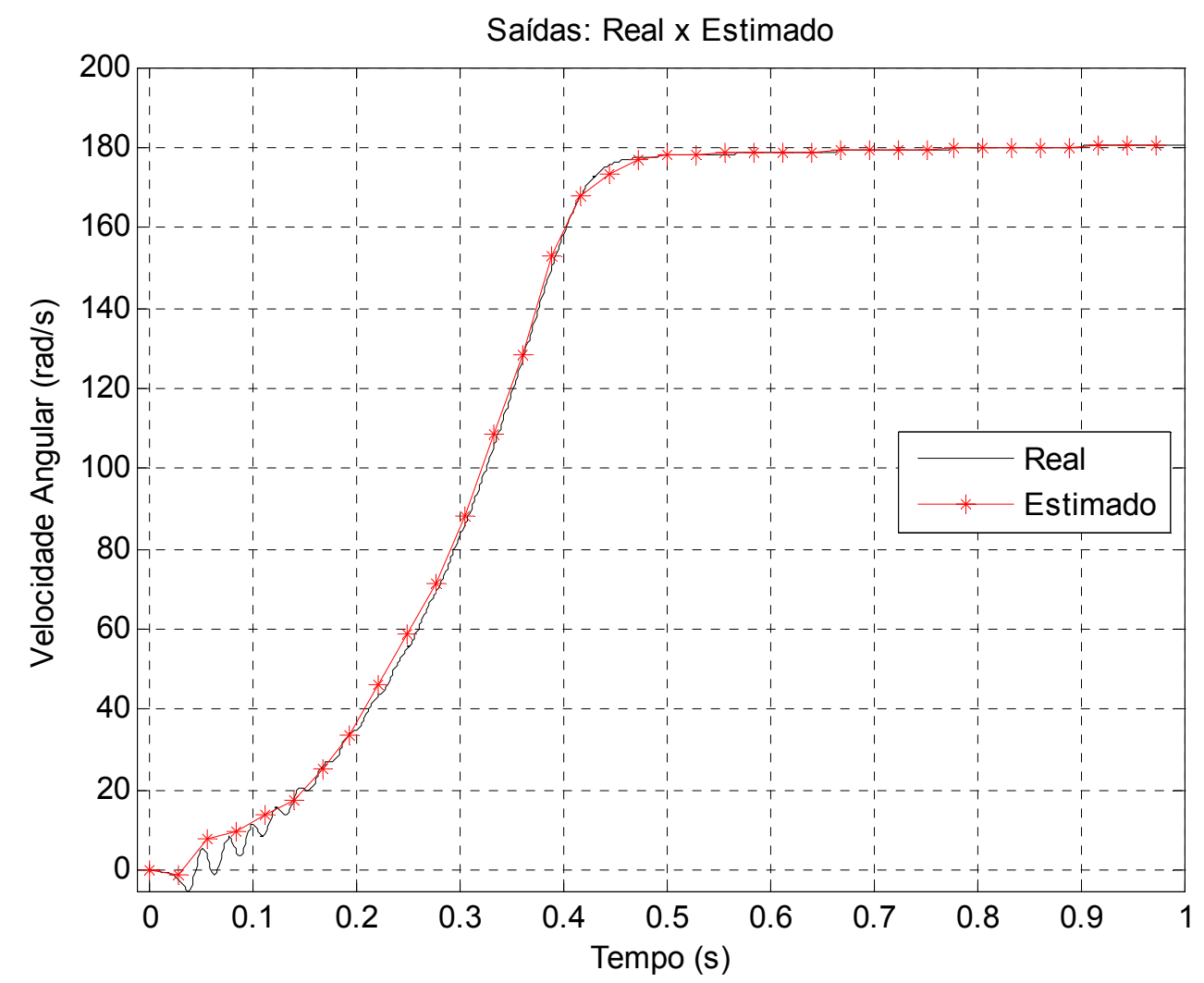

Figura 5.7 - Resposta do estimador de velocidade fuzzy diante de uma situação de carga inversa, com alimentação de $203 \mathrm{~V}$. 
Para a situação de carga inversa com o motor sub-alimentado, o erro relativo médio entre os valores reais e aqueles obtidos pelo estimador fuzzy foi de $5,30 \%$ e o desvio padrão de $28,87 \%$. Pelos motivos mencionados, está nesta situação o maior erro de estimação para as cargas previstas.

\section{- $\quad$ Tensão de alimentação nominal}

Partindo-se das considerações tecidas no item anterior, analisa-se a situação de estimação de velocidade em carga inversa com tensão de alimentação nominal. Verifica-se menor dificuldade na partida do motor e, assim, para uma faixa de torques ligeiramente superiores à da situação anterior, variando de 4,80 N.m a 3,83 N.m, uma maior estabilidade de estimação de velocidade. Porém, para baixas rotações, até $40 \mathrm{rad} / \mathrm{s}$, há um afastamento das curvas real e estimada. 


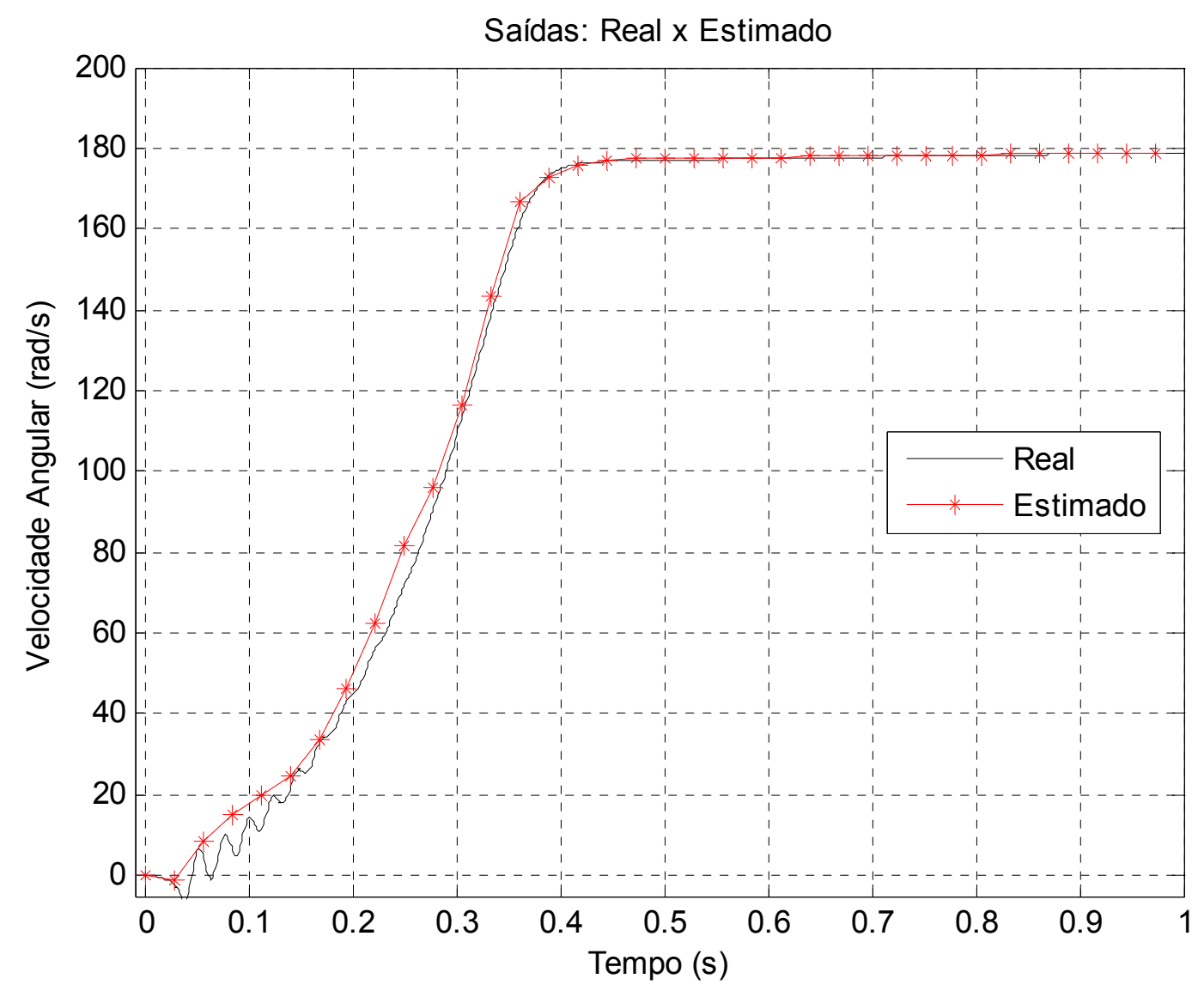

Figura 5.8 - Resposta do estimador de velocidade fuzzy diante de uma situação de carga inversa, com alimentação de $220 \mathrm{~V}$.

Para a situação de carga inversa com alimentação nominal de tensão, o erro relativo médio entre os valores reais e aqueles obtidos pelo estimador fuzzy foi de $2,08 \%$ e o desvio padrão de $3,88 \%$, desempenho superior ao item anterior.

\section{- Sobre-alimentação}

Verifica-se agora a estimação de velocidade de carga inversa com sobretensão de alimentação de 242V RMS. Esta conjuntura incrementa o torque do motor, conferindo-Ihe maior facilidade para suportar partidas em cenários desfavoráveis. Nota-se uma situação mais comportada, com de torques entre 4,20 N.m e 1,78 N.m. 


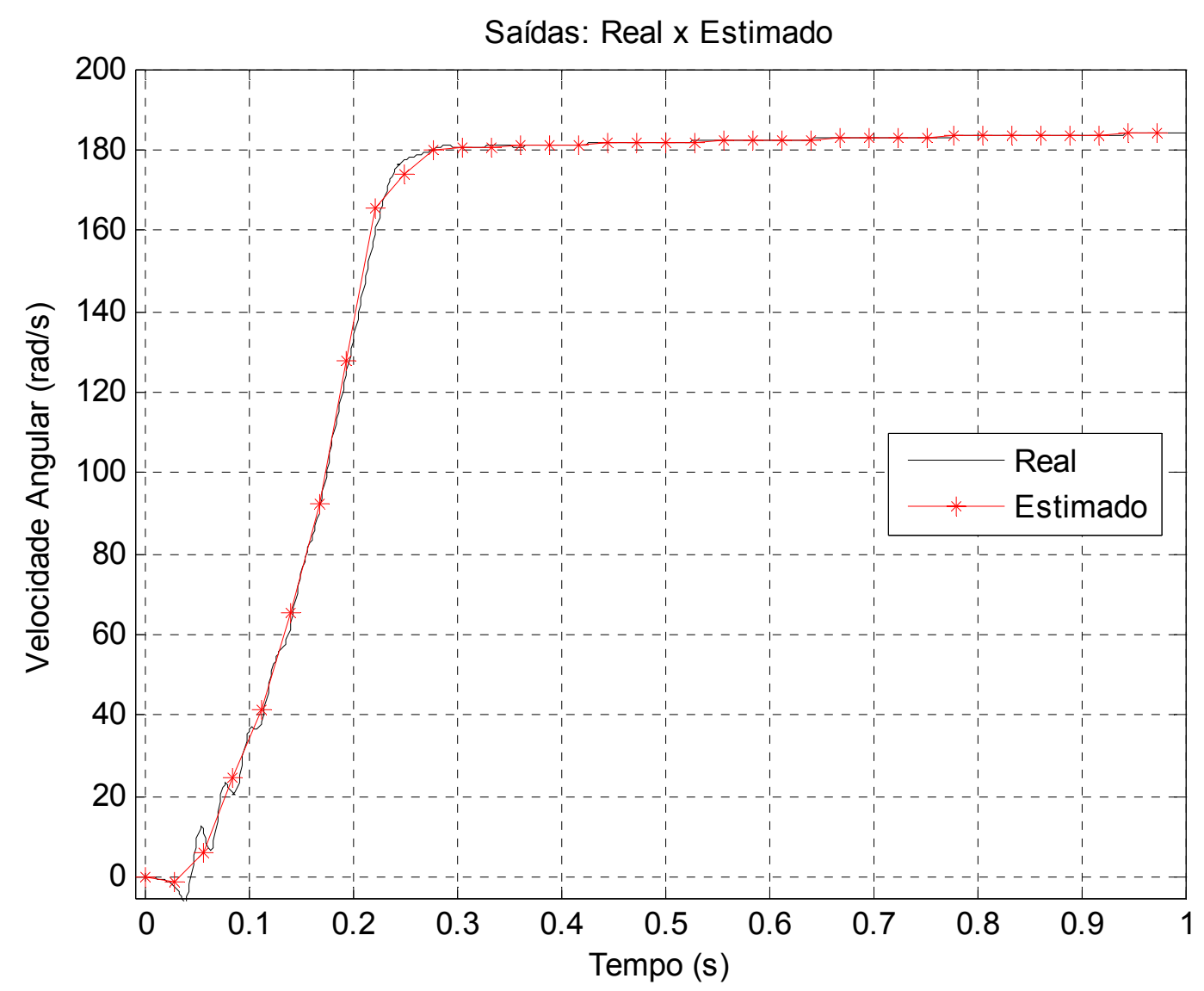

Figura 5.9 - Resposta do estimador de velocidade fuzzy diante de uma situação de carga inversa, com alimentação de $242 \mathrm{~V}$.

Para a situação de carga inversa com alimentação nominal de tensão, o erro relativo médio entre os valores reais e aqueles obtidos pelo estimador fuzzy foi de $1,20 \%$ e o desvio padrão de $4,10 \%$.

\subsubsection{Estimação de velocidade considerando carga constante}

Esta é a situação de carga que menos apresenta transitoriedades em sua composição como um todo. Porém, conforme poderá ser constatado, não por este fato, obtiveram-se os menores erros de estimação. 


\section{- Sub-alimentação}

Para uma situação de alimentação com tensão e solicitação de torque de carga abaixo dos nominais, com 207V RMS (subtensão) e torque de carga de 1,83 N.m (abaixo do nominal), na Figura 5.4 pode-se verificar o comportamento do estimador fuzzy nestas condições.

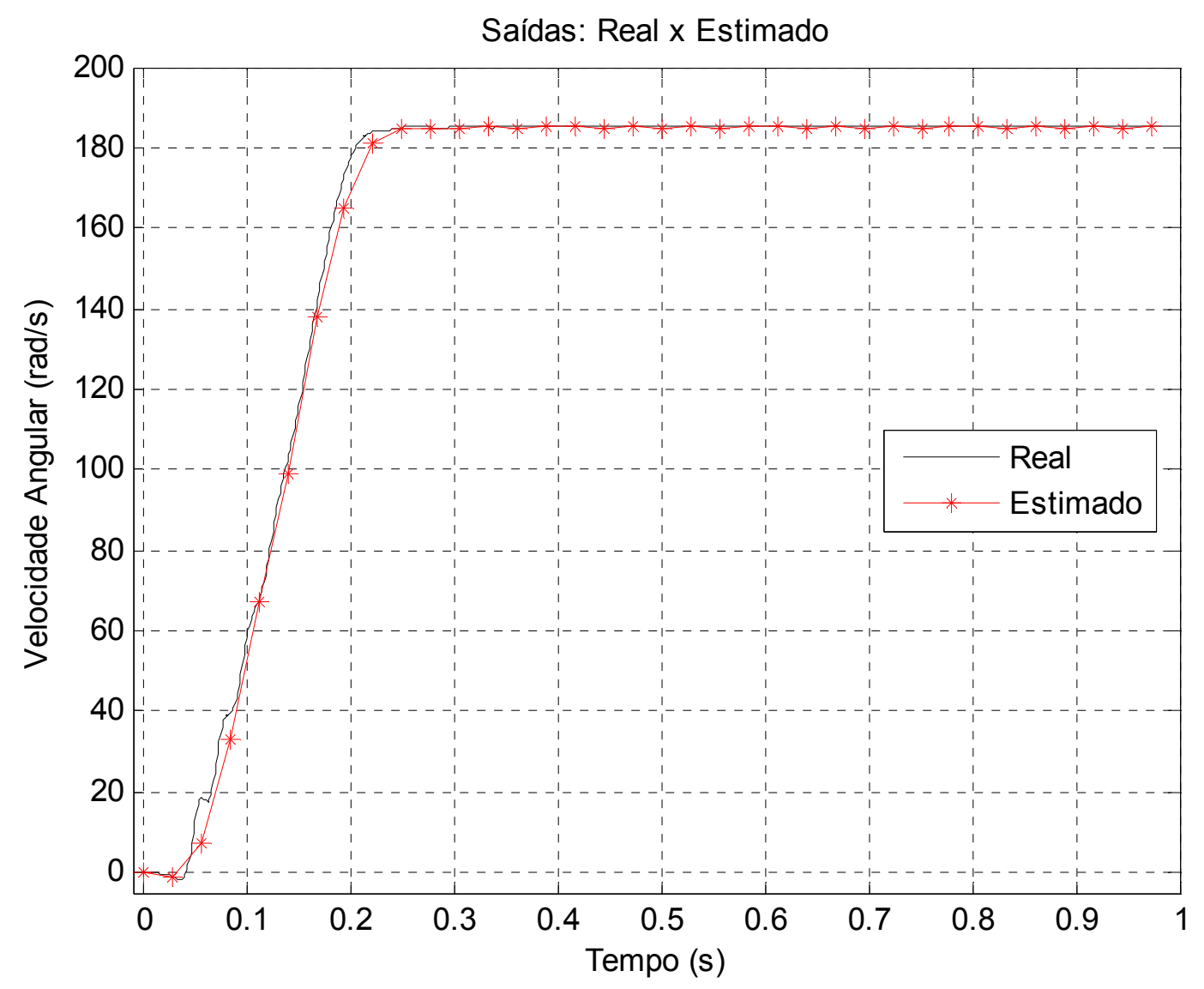

Figura 5.10 - Resposta do estimador de velocidade fuzzy diante de uma situação de carga constante com alimentação de $207 \mathrm{~V}$ e torque de carga abaixo do nominal.

Para a situação de carga constante supra-citada, com sub-alimentação de tensão, o erro relativo médio entre os valores reais e aqueles obtidos pelo estimador fuzzy foi de $1,32 \%$ e o desvio padrão de $3,83 \%$. 


\section{- $\quad$ Tensão de alimentação nominal}

Para efeito de verificação de precisão do sistema, adotou-se valor de torque de carga nominal, de 4,10 N.m para tensão de alimentação nominal, de modo a estar aferindo este aspecto. A Figura 5.11 ilustra a resposta do estimador fuzzy diante de uma situação de carga constante. Obviamente, é o cenário mais favorável que o estimador pode estar exposto, conforme os elementos descritos.

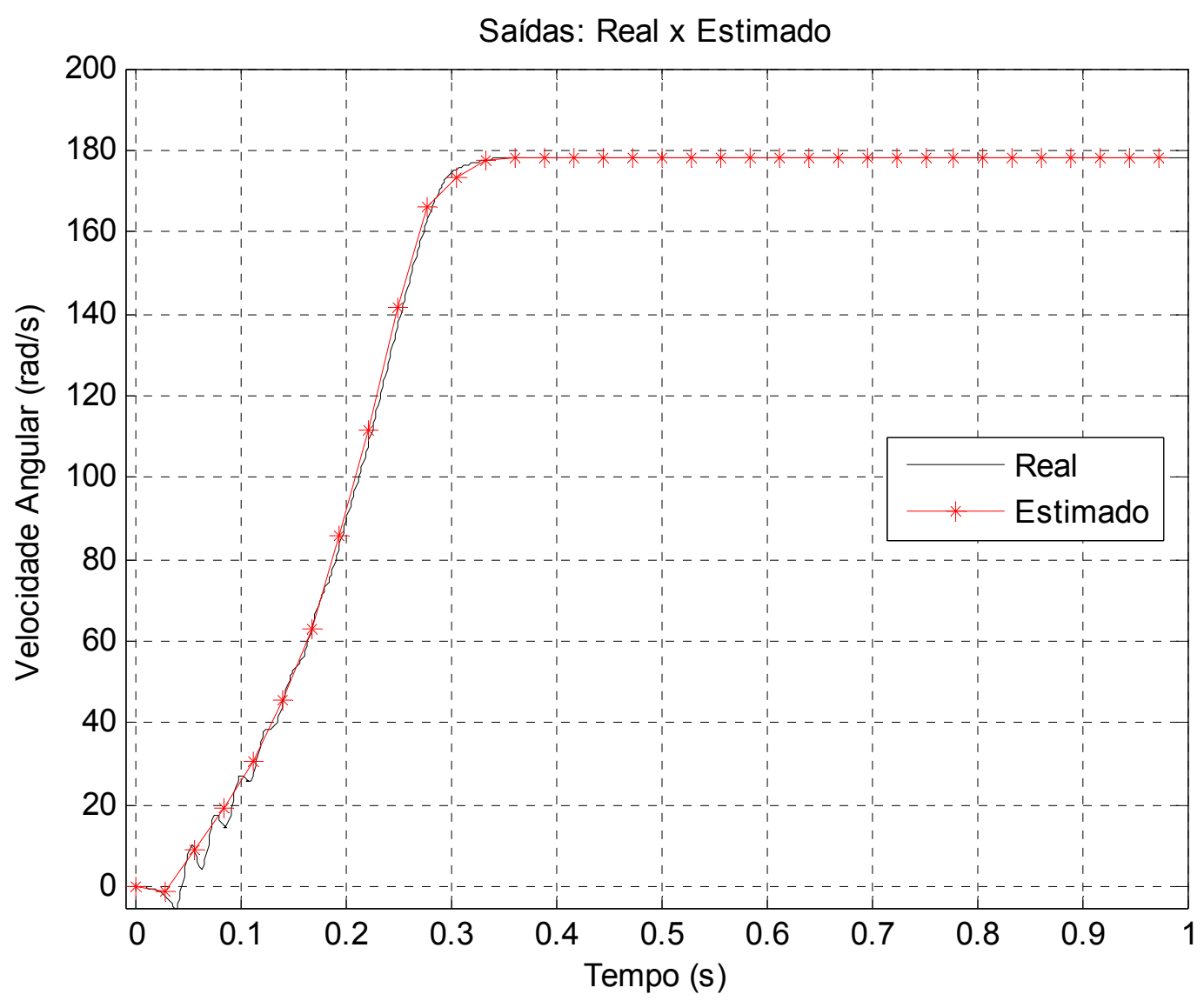

Figura 5.11 - Resposta do estimador de velocidade fuzzy diante de uma situação de carga constante com alimentação de $220 \mathrm{~V}$ e torque nominal.

Para a situação de carga constante sob tensão de alimentação nominal, o erro relativo médio entre os valores reais e aqueles obtidos pelo estimador fuzzy foi de $1,84 \%$ e o desvio padrão de $6,29 \%$. 


\section{- Sobre-alimentação}

Analisa-se agora a situação em que o estimador está exposto à situação de sobre-alimentação do motor, operando com 239 V RMS, para uma carga constante; porém com o motor sobre-dimensionado para a carga, que está abaixo do nominal, em 1,16 N.m. Na Figura 5.12, pode-se conferir o comportamento do estimador.

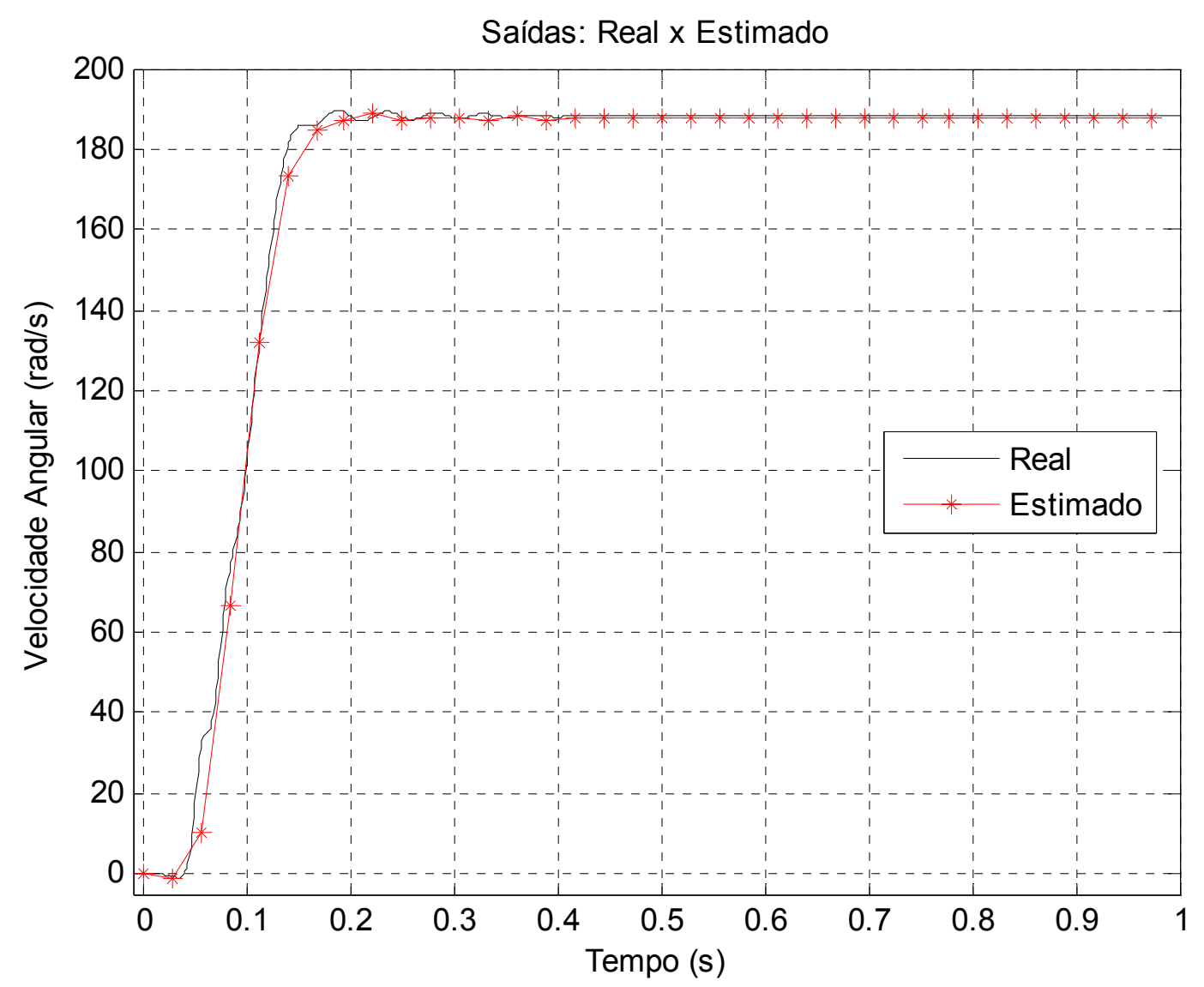

Figura 5.12 - Resposta do estimador de velocidade fuzzy diante de uma situação de carga constante com alimentação de $239 \mathrm{~V}$ e torque de carga abaixo do nominal.

Para a situação de carga constante com sobre-alimentação do motor e torque de carga abaixo do nominal, o erro relativo médio entre os valores reais e estimados foi de $1,10 \%$ e o desvio padrão de $2,93 \%$. 


\subsubsection{Estimação de velocidade para um degrau de carga}

Finalizando a seqüência de simulações para verificação do comportamento do estimador de velocidade fuzzy, aplicou-se então um degrau de carga no motor e foi feita em seguida a análise do comportamento do mesmo. Importante ressaltar que o estimador não foi treinado para responder a esta situação, ao contrário das anteriores, porém, em situações práticas, é uma circunstância de muito provável ocorrência. Diante disto, é relevante considerá-la.

Para isso, inicializou-se o motor com uma carga constante e em tensão nominal de trabalho de 220V RMS, em seu torque nominal de 4,1 N.m e, após a entrada total em regime permanente, no instante $0.55 \mathrm{~s}$, foi aplicado abruptamente um novo torque de 6 N.m, que é um valor acima do nominal para o motor de $1 \mathrm{cv}$. Mesmo nestas condições, o estimador mostrou sua capacidade, conforme se pode verificar por meio da Figura 5.13, acompanhando o degrau e mostrando apenas a variação efetiva de velocidade do motor, acrescida do erro de estimação. 


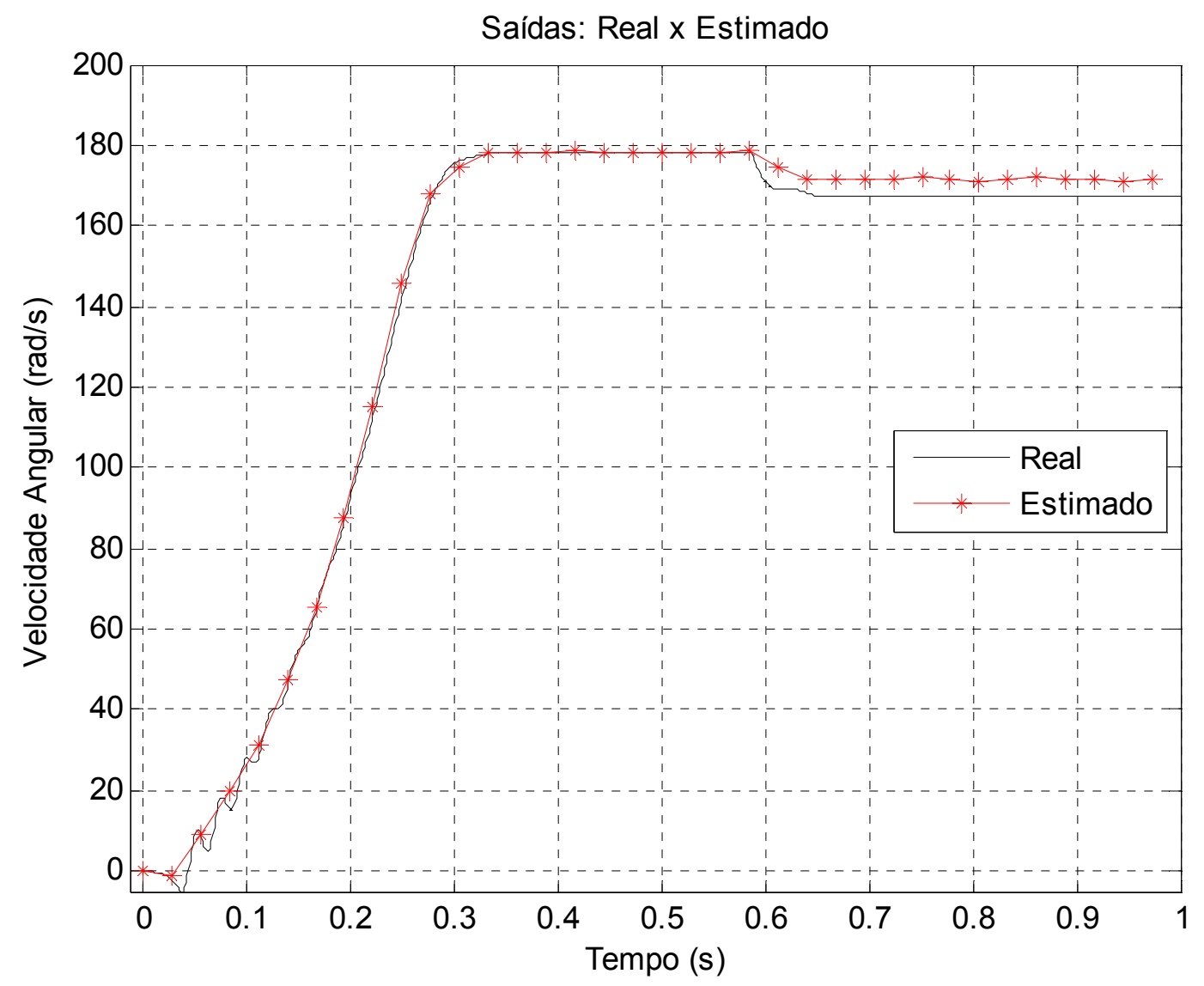

Figura 5.13 - Resposta do estimador de velocidade fuzzy diante da imposição de um degrau de torque de carga.

Para a situação de degrau de carga, o erro relativo médio entre os valores reais e aqueles obtidos pelo estimador fuzzy foi de $2,75 \%$ e o desvio padrão de $5,64 \%$.

\subsection{Resultados em Formato Tabular}

Em seguida, na Tabela 5.1, estão expressos os resultados do desempenho do estimador para as situações apresentadas. Escolheram-se, conforme já verificado, situações de torque de carga abaixo, próximo e acima do nominal, de modo que se verifiquem as capacidades do sistema apresentado. 
Tabela 5.1 - Resultados do estimador fuzzy em forma tabular, englobando todas as cargas abordadas.

\begin{tabular}{|c|c|c|c|c|c|}
\hline $\begin{array}{c}\text { Tipo de } \\
\text { Carga }\end{array}$ & $\begin{array}{c}\text { Tensão de } \\
\text { Alimentação } \\
\text { RMS (V) }\end{array}$ & $\begin{array}{c}\text { Torque } \\
\text { Inicial } \\
\text { (N.m) }\end{array}$ & $\begin{array}{c}\text { Torque } \\
\text { Final } \\
\text { (N.m) }\end{array}$ & $\begin{array}{c}\text { Erro } \\
\text { Relativo } \\
\text { Médio (\%) }\end{array}$ & $\begin{array}{c}\text { Desvio } \\
\text { Padrão } \\
\text { (\%) }\end{array}$ \\
\hline \multirow{3}{*}{ Quadrática } & 203 & 3,50 & 5,50 & 1,64 & 3,85 \\
\cline { 2 - 6 } & 220 & 2,19 & 3,30 & 0,93 & 2,65 \\
\cline { 2 - 6 } & 242 & 0,55 & 1,45 & 1,41 & 3,25 \\
\hline \multirow{3}{*}{ Linear } & 200 & 0,05 & 2,70 & 1,74 & 4,84 \\
\cline { 2 - 6 } & 220 & 3,50 & 5,50 & 1,16 & 2,32 \\
\cline { 2 - 6 } & 240 & 2,00 & 4,80 & 0,87 & 2,42 \\
\hline \multirow{3}{*}{ Inversa } & 203 & 4,50 & 3,50 & 5,30 & 28,87 \\
\cline { 2 - 6 } & 220 & 4,80 & 3,83 & 2,08 & 3,88 \\
\cline { 2 - 6 } & 242 & 4,20 & 1,78 & 1,20 & 4,10 \\
\hline \multirow{2}{*}{ Constante } & 207 & \multicolumn{2}{|c|}{1,83} & 1,32 & 3,83 \\
\cline { 2 - 6 } & 220 & 4,10 & 1,84 & 6,29 \\
\cline { 2 - 6 } & 239 & \multicolumn{2}{|c|}{1,16} & 1,10 & 2,93 \\
\hline Degrau & 220 & 4,10 & 6,00 & 2,75 & 5,64 \\
\hline
\end{tabular}

Salienta-se o fato que em carga constante não existirem diferenças entre início e fim de torque, então se verifica apenas um valor para o mesmo na tabela. 


\section{Conclusões Gerais e Trabalhos Futuros}

\subsection{Conclusões Gerais}

O presente trabalho apresentou uma estratégia baseada em sistemas fuzzy para a estimação de velocidade em motores de indução trifásicos sem o uso de sensores (sensorless), usando apenas sinais de tensão e corrente do motor.

Com a análise dos resultados, tanto quanto pelos gráficos como pelos erros de estimação, verifica-se a viabilidade do estimador fuzzy para aplicações industriais que necessitem de um dispositivo simplificado e de baixo custo, no intervalo de trabalho considerado, dispensando o uso de algoritmos complexos com esforço computacional elevado. Tendo como entradas apenas sinais de alimentação, tornouse possível obter uma estimação de velocidade confiável e estável, obviamente considerando-se as faixas de erros expostos. Assim, o estimador está apto, conforme foi verificado nos resultados, a trabalhar em ambiente industrial, no que tange à variação de tensão de alimentação imposta na norma NBR 7094 (2003).

Sintetizando, o estimador proposto tem como vantagens: simplicidade, baixo custo computacional, não exige intervenções mecânicas, pode ser implementado em uma pastilha dedicada para lógica fuzzy ou então em um microcontrolador. Como ressalva, tem-se precisão menor nas baixíssimas velocidades e em transitórios de partida, conforme verificado nos resultados, sendo menos indicado se esta informação for crítica. 
Verificado que para validação do modelo já foram consideradas as principais situações do ambiente industrial, pode-se notar que o erro médio esteve em torno de $2,4 \%$. Este desempenho foi bastante satisfatório, sendo que tais valores validam a estratégia proposta neste trabalho.

O teste para a situação inesperada do degrau de carga exprime o comportamento oportuno do dispositivo, contribuindo para a validação do mesmo.

\subsection{Trabalhos Futuros}

Estão previstas, como trabalhos futuros, as seguintes realizações:

- Avaliação em laboratório, com dados experimentais reais;

- Extensão do domínio de trabalho do estimador fuzzy para alimentação com inversores de freqüência, de modo que, a partir de uma alimentação não-senoidal, o dispositivo tenha a capacidade de realizar a mesma função neste novo cenário;

- Estratégia de detecção da potência do motor que terá estimada a velocidade, de modo a flexibilizar o uso do dispositivo com diversos tipos de Ml e não somente para aquele que foi desenvolvido;

- Implementação em hardware do estimador, tendo já em vista, conforme premissa de desenvolvimento do trabalho, um hardware simplificado, constituído de um microcontrolador, sensores de tensão e corrente e um display, constatando em campo o aqui exposto.

- Verificação da imunidade à ruídos na indústria, já que o foco de desenvolvimento do estimador é sua aplicação neste ambiente. 


\subsection{Publicações Relativas ao Trabalho}

Apresentam-se nesta seção os trabalhos relativos à publicação em congressos nacionais dos resultados da pesquisa sobre o estimador de velocidade fuzzy no período do mestrado.

1) Cristiano Minotti, Ivan Nunes da Silva, Marcelo Suetake, Alessandro Goedtel, "Estimador de Velocidade Sensorless Para Máquinas de Indução Trifásicas Usando Lógica Fuzzy", Proceedings of the 6th Congresso Temático de Dinâmica, Controle e Aplicações (DINCON'2007), pp. 1417-1425, São José do Rio Preto/SP, 2007.

2) Cristiano Minotti, Ivan Nunes da Silva, Sérgio Ferreira da Silva, Alessandro Goedtel, "Estimador de Velocidade Sensorless Para Motores de Indução Trifásicos Usando Lógica Fuzzy", VIII Simpósio Brasileiro de Automação Inteligente (SBAI 2007), Florianópolis/SC, 2007. 


\section{Referências Bibliográficas}

BARBI, I. (1985). Teoria Fundamental do Motor de Indução. Editora da UFSC, 1985.

BOSE, B. K. (1987). Power Electronics and AC Drives. Prentice Hall, USA.

CAD, M. M. (2000). Estratégias de Modelagem Dinâmica e Simulação Computacional do Motor de Indução Trifásico. Dissertação (Mestrado) - Escola de Engenharia de São Carlos (EESC), Universidade de São Paulo (USP).

CREPPE, R. C. (1999). Máquinas Elétricas Especiais. Curso de Extensão Universitária - Faculdade de Engenharia de Bauru (FEB), Universidade Estadual Paulista (UNESP).

DIAS, L. P. C.; LOBOSCO, O. S. (1998). Motores Elétricos: Seleção e Aplicação, vol. I. McGraw-Hill Inc..

Empresa de Pesquisa Energética (2007). Disponível em <http://www.epe.gov.br/default.aspx>. Acessado em: 28/05/2008.

FITZGERALD, A., E.; KINGSLEY JR.; KUSKO, A.C. (1975). Electric Machinery. Mc Graw Hill, USA.

GOEDTEL, A. (2003). Estimativa de Conjugado de Carga Aplicado em Eixos de Motores de Indução Trifásicos Através de Redes Neurais Artificiais. Dissertação (Mestrado) - Faculdade de Engenharia de Bauru (FEB), Universidade Estadual Paulista (UNESP).

GOEDTEL, A. (2006). Recurrent Neural Network for Induction Motor Speed Estimation in Industry Applications, IEEE Melecon, pp. 1134-1137. 
GOEDTEL, A. (2007). Estimador Neural de Velocidade Para Motores de Indução Trifásicos. Tese (Doutorado) - Escola de Engenharia de São Carlos (EESC), Universidade de São Paulo (USP).

GOMIDE, F. A. C. (2007). Computação com Regras. Departamento de Engenharia de Computação e Automação Industrial (DCA) - Universidade de Campinas (UNICAMP). Disponível em <http://www.dca.fee.unicamp.br/ gomide/courses/ IA861/transp/Notas_IA_861_Computacao_com_Regras.pdf>. Acessado em: $16 / 03 / 2007$.

GONZAGA, D. P.; AMÊNDOLA, C. A. M. (2003). Motor de Indução Trifásico: Modelagem e Simulação. Escola de Engenharia de São Carlos (EESC), Universidade de São Carlos (USP).

JANG, J. S. R., Sun, C.-T., Mizutani, E. (1997). Neuro-Fuzzy and Soft Computing. Prentice-Hall, USA.

KLIR, G. J.; YUAN, B. (1995). Fuzzy Sets and Fuzzy Logic - Theory and Applications. Prentice Hall, USA.

KOSOV, I. L. (1998). Máquinas Elétricas e Transformadores. Editora Globo, São Paulo.

LÓPEZ, J. C.; ROMERAL, L. ARIAS, A.; CHEKKOURI, M. R. (2002). Speed Fuzzy Estimator for a Motion System. IEEE 7th International Workshop on Advanced Motion Control, 2002, pp. 335-340.

LÓPEZ, J. C.; ROMERAL, L. ARIAS, A.; ALDABAS, E. (2006). Novel Fuzzy Adaptive Sensorless Induction Motor Drive. IEEE Transactions on Industrial Electronics, vol. 53, no. 4, pp. 1170-1178. 
LU, B.; HABETLER, T. G.; HARLEY, R. G. (2006). A Survey of Efficiency-Estimation Methods for In-Service Induction Motors. IEEE Transactions on Industry Applications, vol. 42, no. 4, pp. 924-933.

NBR 7094 (2003). Máquinas Elétricas Girantes - Motores de Indução Especificação. Associação Brasileira de Normas Técnicas, Rio de Janeiro.

OHMAE, T., et al. (1982). A microprocessor-controlled high-accuracy widerange speed regulator for motor drives. IEEE Transactions on Industrial Electronics, Vol. IE-29, n.3, pp. 207-211.

ONG, C. M. (1997). Dynamic Simulation of Electric Machinery Using Matlab ${ }^{\circledR} /$ Simulink. Prentice Hall, USA.

PEDRICZ, W. (1993). Fuzzy Control and Fuzzy Systems. John Wiley and Sons, New York, USA.

SEN, P.C. (1989). Principles of Electric Machines and Power Electronics. John Wiley and Sons, USA.

SILVA, S. F.(2007). Identificação de Torque de Carga em Motores de Indução Usando Abordagem Baseada em Sistemas Fuzzy. Dissertação (Mestrado) Escola de Engenharia de São Carlos (EESC), Universidade de São Paulo (USP).

SOARES, G. A., FILHO, O. A. K., TABOA, R. P. (2000). Eficiência Energética em Motores Impactos no Setor e Análise de Mercado. Revista Eletricidade Moderna, pp.112-124.

TSOUKALAS, L. H., UHRIG, R. E. (1997). Fuzzy and Neural Approaches in Engineering. John Wiley \& Sons, NY.

VAS, P. (1998). Sensorless Vector and Direct Torque Control. Oxford University Press. 
VAS, P. (1999). Artificial Intelligence Based Electrical Machines and Drives. Oxford University Press.

VASUDEVAN, M.; ARUMUGAM, R.; PARAMASIVAM, S. (2003). Adaptive neurofuzzy inference system modeling of an induction motor. The Fifth International Conference on Power Electronics and Drive Systems, vol. 1, pp. 427-432.

VASUDEVAN, M.; ARUMUGAM, R. (2004). A robust torque control of induction motor for electric vehicle applications using ANFIS. TENCON IEEE Region 10 Conference, vol. 4, pp. 17-20.

YUSIVAR, F.; HAMADA, D.; UCHIDA, K.; WAKAO, S.; ONUKI, T. (1999). A New Method of Motor Speed Estimation Using Fuzzy Logic Algorithm. International Conference in Electric Machines and Drives, pp.278 - 280

ZADEH, L. A. (1965). Fuzzy sets. Information and Control, v. 8, pp. 29-44.

ZADEH, L. A. (1973). Outline of new approach to the analysis of complex systems and decision. IEEE Transactions on Systems, Man and Cybernetics, v. 3, pp. 2844. 


\section{Apêndice A - Modelo em Simulink ${ }^{\circledR}$}

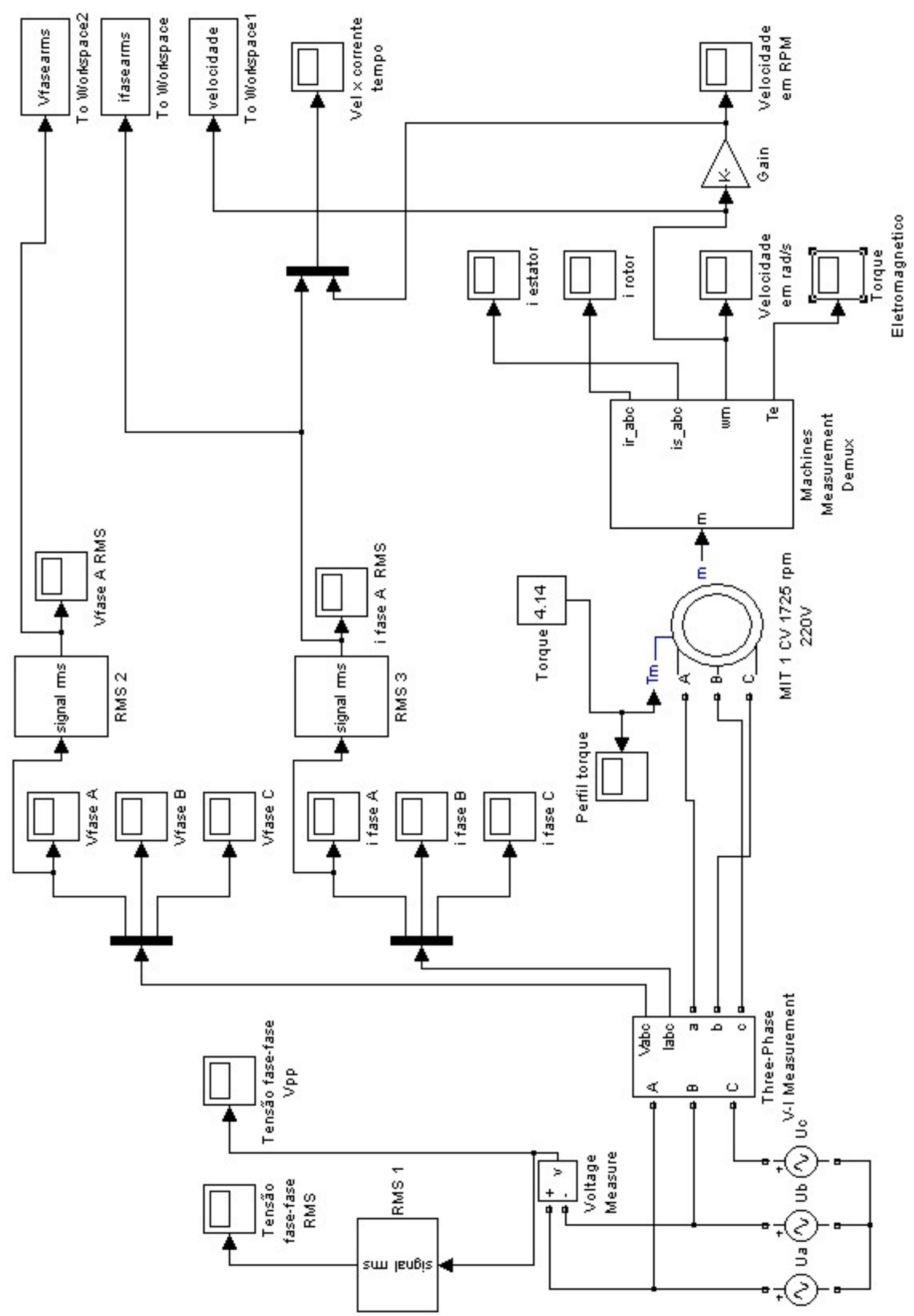




\section{Apêndice B - O ANFIS no MatLab ${ }^{\circledR}$}

Ao se solicitar o uso do ANFIS no MatLab ${ }^{\circledR}$, a seguinte janela (GUI) mostrada na Figura B.1 será aberta.

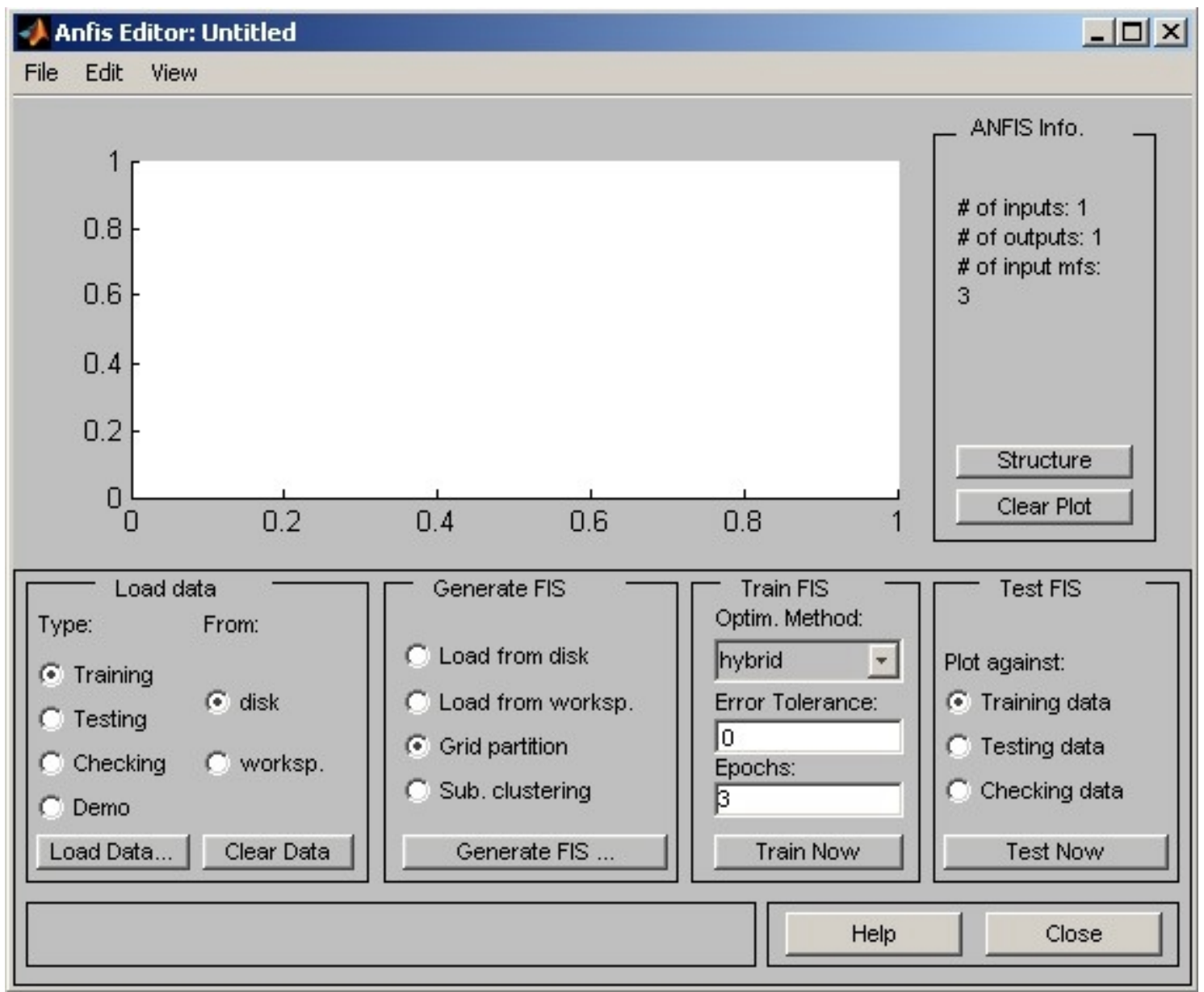

Figura B.1 - GUI do ANFIS no ambiente MatLab ${ }^{\circledR}$.

Depois de estarem carregados os dados de treinamento no ANFIS, é então disponibilizada a tela de configuração de parâmetros, onde se pode escolher o tipo de função de pertinência a utilizar, o número de funções de pertinência a usar para cada uma das entradas e para a saída, e se o polinômio a se adotar será do $1^{\circ} \mathrm{grau}$ ou se será uma constante arbitrária. O ANFIS também já disponibiliza a topologia 
que foi otimizada (Figura B.2), onde estão relacionadas, graficamente, as interrelações antecedentes-conseqüentes das regras. (este parágrafo mudou de posição)

Após este passo, já com os vetores de entrada-saída definidos e os parâmetros ajustados, escolhe-se então a quantidade de épocas (ou seja, quantas vezes o algoritmo de treinamento será executado) e o valor do erro. Assim que for atingido um destes valores, o treinamento é finalizado.

Assim, o ANFIS estará apto a começar seu trabalho. Após o processamento, o mesmo retornará as funções de pertinência ajustadas e otimizadas e as regras, as quais estarão em função do produto do número de funções de pertinência da entrada, excetuando a situação de particionamento (ou clustering).

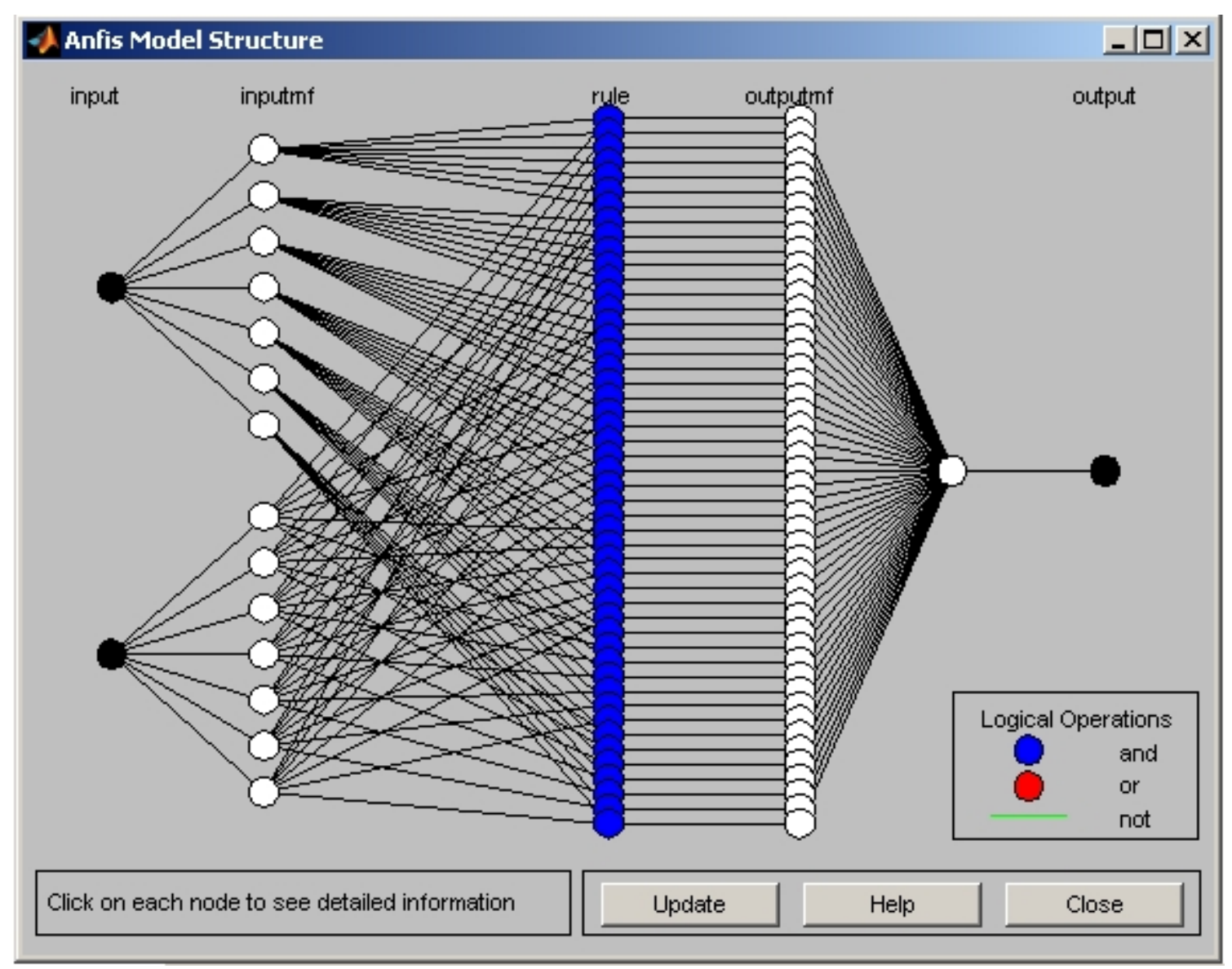

Figura B.2 - Estrutura da arquitetura do ANFIS para o estimador de velocidade fuzzy 
Para que o ANFIS ajuste o polinômio referente ao modelo de inferência de Takagi-Sugeno, há dois métodos disponíveis, a saber:

- Backpropagation;

- Hybrid.

No método backpropagation, os coeficientes são ajustados através de retropropagação, tal como em uma RNA perceptron multicamadas; no método hybrid, são utilizados os métodos dos mínimos quadrados (regressão linear) e o método backpropagation. Neste trabalho, salienta-se o uso do método hybrid (híbrido), por ter fornecido os melhores resultados.

A seguir, é apresentada na Figura B.3, a tela referente a uma das simulações, onde é possível conferir os parâmetros citados, tais como número de funções de pertinência adotadas, erro, número de épocas, entradas, saída, erro médio, entre outros. 


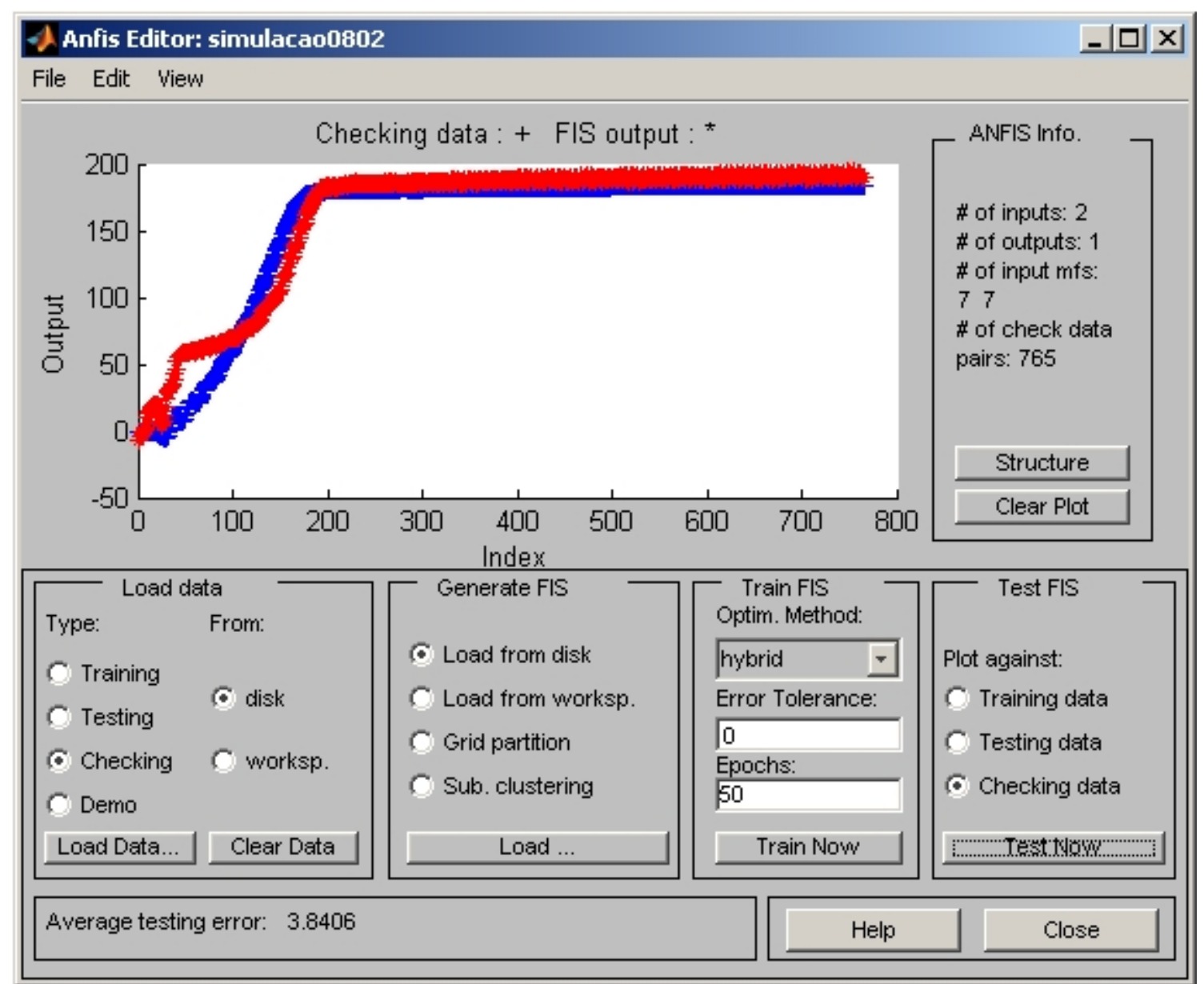

Figura B.3 - Tela do ANFIS durante uma simulação de carga inversa.

Salienta-se que para a obtenção dos gráficos do Capítulo 5, após a execução do ANFIS, com os dados obtidos, através do comando evalfis, no ambiente do MatLab ${ }^{\circledR}$, obtém-se então, com o devido tratamento, as curvas de comparação entre simulado e estimado. Para validar o modelo, além da adoção da validação cruzada (cross validation), foram testados diversos valores de número de épocas, de modo a se chegar em um valor ótimo que concilie eficiência e rapidez no treinamento.

Finalmente, comentam-se aqui algumas restrições do uso do ANFIS:

- Permite apenas uma variável de saída; 
- As funções de pertinência da saída são de um único tipo por vez, ou seja, constante ou linear. 